University of Louisville

ThinkIR: The University of Louisville's Institutional Repository

Electronic Theses and Dissertations

8-2011

\title{
Effects of children's literature on students' on-task behavior during mathematics instruction.
}

Jeremy Todd Whitney

University of Louisville

Follow this and additional works at: https://ir.library.louisville.edu/etd

\section{Recommended Citation}

Whitney, Jeremy Todd, "Effects of children's literature on students' on-task behavior during mathematics instruction." (2011). Electronic Theses and Dissertations. Paper 1563.

https://doi.org/10.18297/etd/1563

This Doctoral Dissertation is brought to you for free and open access by ThinkIR: The University of Louisville's Institutional Repository. It has been accepted for inclusion in Electronic Theses and Dissertations by an authorized administrator of ThinkIR: The University of Louisville's Institutional Repository. This title appears here courtesy of the author, who has retained all other copyrights. For more information, please contact thinkir@louisville.edu. 
EFFECTS OF CHILDREN'S LITERATURE ON STUDENTS' ON-TASK BEHAVIOR DURING MATHEMATICS INSTRUCTION

\author{
By \\ Jeremy Todd Whitney \\ B.A., University of Louisville, 2005 \\ M.Ed., University of Louisville, 2007

\begin{abstract}
A Dissertation
Submitted to the Faculty of the

College of Education and Human Development of the University of Louisville

In Partial Fulfillment of the Requirements

For the Degree of
\end{abstract} \\ Doctor of Philosophy \\ Department of Curriculum and Instruction \\ University of Louisville \\ Louisville, Kentucky
}

August 2011 
Copyright 2011 by Jeremy Todd Whitney

All rights reserved 


\title{
EFFECTS OF CHILDREN'S LITERATURE ON STUDENTS' ON-TASK BEHAVIOR DURING MATHEMATICS INSTRUCTION
}

\author{
By \\ Jeremy Todd Whitney \\ B.A., University of Louisville, 2005 \\ M.Ed., University of Louisville, 2007 \\ A Dissertation Approved on
}

July 13,2011

by the following Dissertation Committee:

Dissertation Director (Amy Shearer Lingo)

Nicole Fenty

Terry Scott

Karen Karp

Justin Cooper 


\section{DEDICATION}

This dissertation is dedicated to my mother, Pat Whitney. You were and will always be the most influential and important person in my life. 


\section{ACKNOWLEDGMENTS}

Although only my name appears on the cover of this dissertation, a great many people have contributed to its production. I owe my gratitude to all those people who have made this dissertation possible. First, I would like to thank the members of my dissertation committee. I would like to thank Terry Scott for providing me with valuable feedback, resources, and moral support. Thanks goes to Nicole Fenty for her guidance and support during the pilot study for this dissertation. I appreciate the moral support and feedback Justin Cooper provided me throughout this process. I valued the commitment, dedication, expertise, and support Karen Karp has given me. And last, but certainly not least, gratitude goes to my advisor and chair, Amy Lingo. Words cannot sufficiently describe all of the things she has done for me. I have grown both personally and professionally because of her commitment, dedication, and support. She has not only been a great mentor, but also a great friend.

I would also like to thank Regina Hirn for her assistance with running the data reports and providing me with guidance throughout the doctoral program. I am appreciative of Nellie Mae Summerfield and Elizabeth Wine for helping me with data collection as well as Janice Donan for proofreading the drafts of my dissertation. And finally, I would like to thank Lisa Donan for her patience, understanding, and moral support throughout my doctoral program. I will fondly remember my experience as a doctoral student at the University of Louisville. 


\section{ABSTRACT \\ EFFECTS OF CHILDREN'S LITERATURE ON STUDENTS' ON-TASK BEHAVIOR DURING MATHEMATICS INSTRUCTION \\ Jeremy Todd Whitney \\ July 13,2011}

Nationally, there are increasing numbers of students who are at-risk for academic and/or social failure (U.S. Department of Education, 2009). In an attempt to address this trend, the 2004 reauthorization of the Individuals with Disabilities Education Act (PL 108-446) encouraged educators to provide early and appropriate interventions not only to identify and help children with disabilities, but to also provide additional supports for students with academic difficulties and challenging behaviors. Although there have been evidenced-based academic interventions pertaining to students with challenging behaviors, most of the literature has been focused on reading interventions rather than mathematics interventions (Bos \& Vaughn, 2005).

This study examined the effects of integrating children's literature in mathematics instruction on the academic and behavioral outcomes of students with academic difficulty and challenging behaviors. A single subject, multiple baseline design across participants was implemented to examine the effects of this curricular approach on increasing student engagement, reducing disruptive behaviors, and increasing the teacher's rate of providing opportunities to respond for four elementary students identified as exhibiting academic difficulty and challenging behaviors during Tier II 
mathematics instruction. In addition, two pretest/posttest designs were used to assess the academic achievement of the student participants.

Results of this study suggest that integrating children's literature in mathematics instruction is an effective curricular approach for increasing engagement for students with academic difficulties and challenging behaviors. Furthermore, results suggest that this curricular approach was effective in increasing the teacher's rate of providing opportunities for students to respond. However, results were not definitive regarding the effectiveness of integrating children's literature in mathematics instruction on decreasing disruptive behavior and there were no results of significance on student mathematics achievement. Directions for future research and educational implications are discussed. 
TABLE OF CONTENTS

PAGE

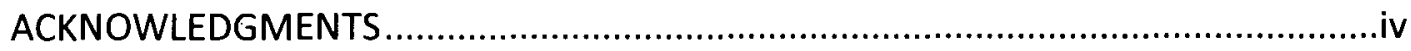

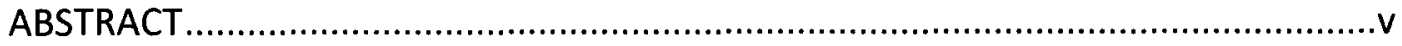

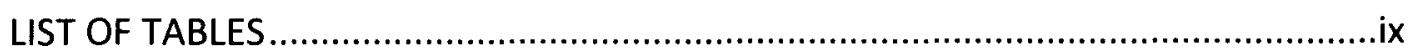

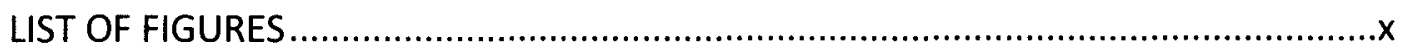

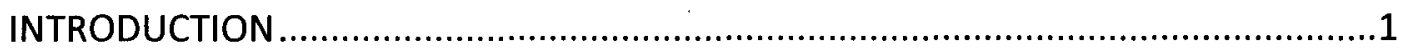

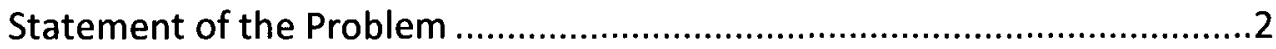

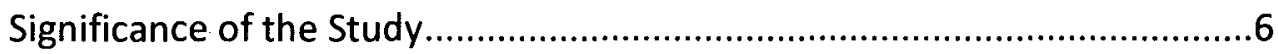

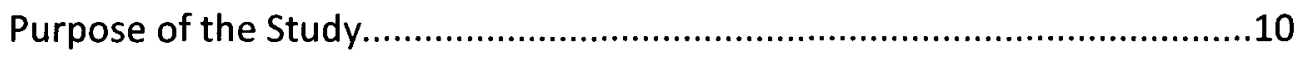

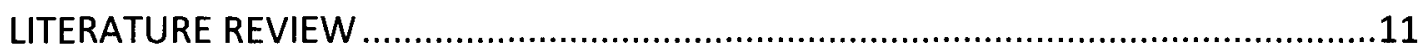

Theoretical Framework......................................................................12

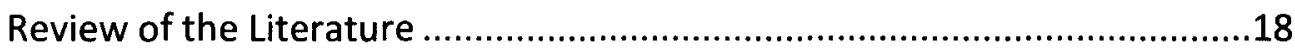

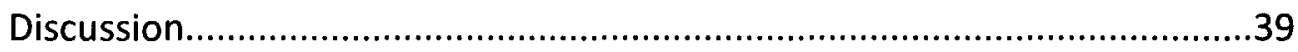

METHODS

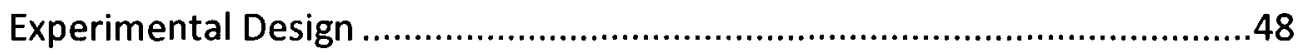

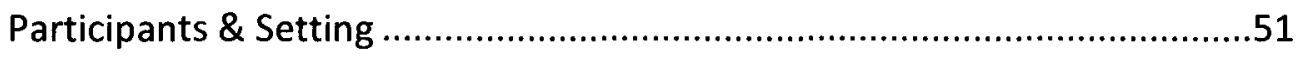

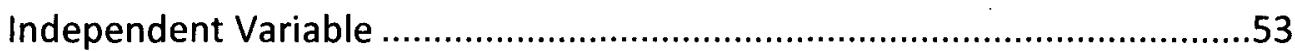

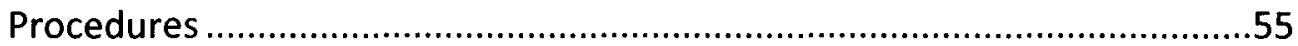

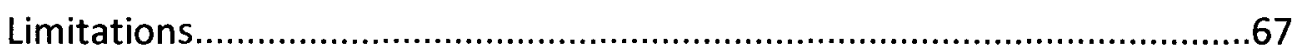

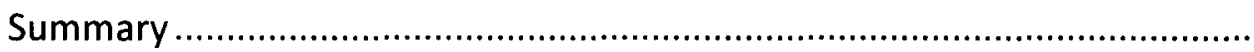




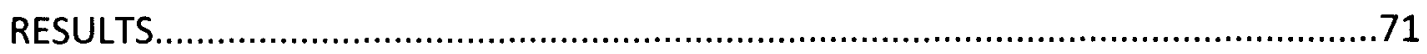

Intervention Results....................................................................

Social Validity Results ................................................................91

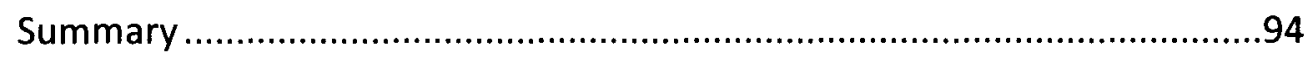

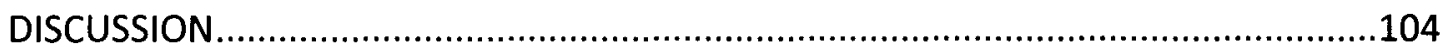

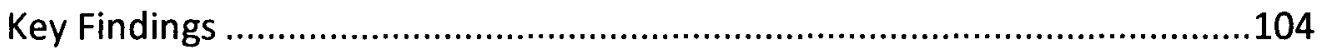

Limitations and Future Research ................................................113

Educational Implications ............................................................116

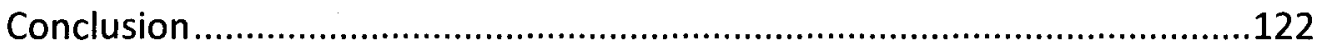

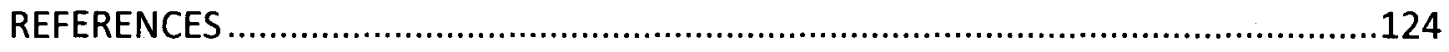

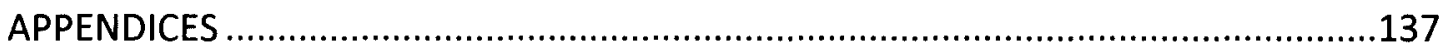

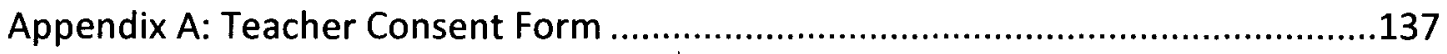

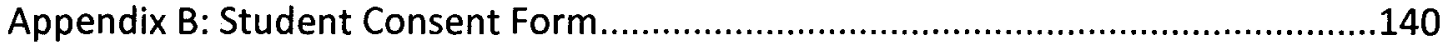

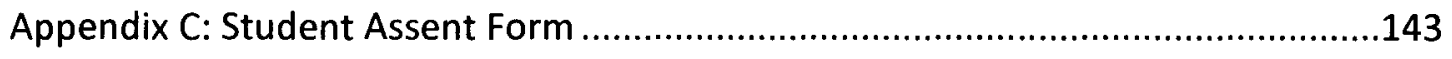

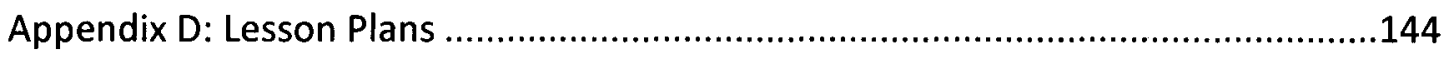

Appendix E: Observation Coding Variables .................................................178

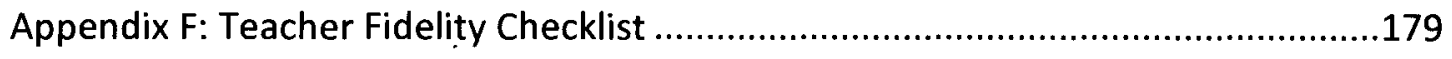

Appendix G: Social Validity Questionnaire: Student .....................................180

Appendix H: Social Validity Questionnaire: Teacher ..........................................181

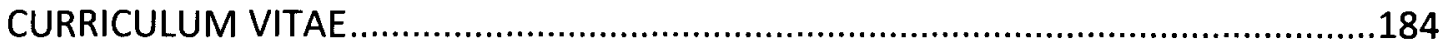




\section{LIST OF TABLES}

TABLE

PAGE

2-1. Children's Literature and Mathematics Studies

3-1. Description of Participants

3-2. Books Included in Study

3-3. Interobserver Agreement Data.

4-1. Mean Percentages of Student Engagement and Rate of Student Disruptive Behavior

4-2. Mean Rate of Teacher Providing Opportunities for Students to Respond ........80

4-3. Individual Content Area/Total Standard Scores

4-4. Individual Subtest Standard Scores .88

4-5. Paired Samples t-test Summary Table.

4-6. Single-Group Repeated-Measures ANOVA Summary Table .90

4-7. Pairwise Comparison of Mean Scores Based on Estimated Marginal Means ....90 


\section{LIST OF FIGURES}

$\begin{array}{ll}\text { FIGURE PAGE } & \text { PAT }\end{array}$

2-1. Conceptual Model for Integrating Children's Literature In Mathematics..........15

4-1. Multiple Baseline Across Participants Graph - Percentage of Total Student Engagement ....................................................................................97

4-2. Multiple Baseline Across Participants Graph - Percentage of Student Passive

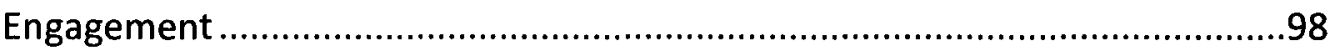

4-3. Multiple Baseline Across Participants Graph - Percentage of Student Active

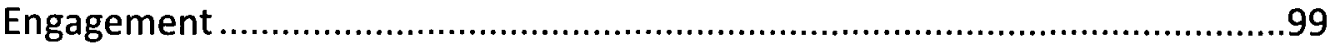

4-4. Multiple Baseline Across Participants Graph - Number of Student Disruptions

4-5. Multiple Baseline Across Participants Graph - Rate of Total Teacher OTR.

4-6. Multiple Baseline Across Participants Graph - Rate of Teacher OTR Group 102

4-7. Multiple Baseline Across Participants Graph - Rate of Teacher OTR Individual 


\section{CHAPTER 1 \\ INTRODUCTION}

The purpose of this chapter is to provide a brief overview of the literature and rationale for using children's literature to teach mathematics. Specifically, this review will discuss the importance of integrating children's literature in mathematics instruction and the potential effect on the academic and behavioral outcomes for students with academic difficulties and challenging behaviors. Students with academic difficulties can include those who are one or more grade levels below their peers in mathematics and/or receiving special education services for a learning disability (e.g., mathematics disability, reading disability, or mild mental disability). Students with challenging behaviors can include those who regularly exhibit inappropriate and/or disruptive behavior in the classroom (e.g., receiving three or more office referrals in the current school year), and/or receiving special education services for behavior problems (e.g., Emotional Behavior Disorder or Attention-Deficit Hyperactivity Disorder). This chapter will begin with the current issues regarding this topic. It will conclude with a discussion of how this study will support and extend the existing research on integrating children's literature in mathematics as well as the study's research questions. 


\section{Statement of the Problem}

\section{Prevalence and Issues of Students with Learning \& Behavior Disorders}

Nationally, there are increasing numbers of students who are at-risk for academic and/or social failure. According to the 28th Annual Report to Congress on the Implementation of the Individuals with Disabilities Education Act, 2006 (U.S. Department of Education, 2009), there was a 9.5\% increase in the number of students (ages $6-21$ ) with high-incidence disabilities between 1995 and 2004, including those identified as having learning and behavioral disorders. Because the Individuals with Disabilities Education Improvement Act of 2004 (IDEA, 2004) requires students with disabilities to be placed in the least restrictive environment appropriate to facilitate success, more students with disabilities are being served in the general education classroom. Data from the U.S. Department of Education indicated in $2008,80 \%$ of all students with disabilities (ages $6-21$ ) spent at least some portion of their day in a regular education classroom, and $58 \%$ spent $80 \%$ or more of their day in a regular education classroom (Data Accountability Center, 2010). These trends impact both special education and general education teachers and stress the need to provide teachers with effective, empirically validated teaching practices designed to improve the academic and behavioral outcomes for students with academic difficulties and challenging behaviors in general education classrooms.

Researchers have suggested there is a relationship between inappropriate classroom behaviors and academic achievement (Nelson, Benner, Lane, \& Smith, 2004; Sutherland \& Wehby, 2001). For example, the reported rates of prevalence of academic 
difficulties for students with emotional behavior disorder (EBD) have ranged from $25 \%$ to $97 \%$ (Nelson, et al., 2004). In addition, students with Attention-Deficit Hyperactivity Disorder (ADHD) often experience behavior difficulties that affect their academic success (Barry, Lyman, \& Klingler, 2002; Zentall, 2007). Although it is not clear which causes the other, there appears to be a reciprocal relationship between behavior and academic achievement (Sutherland \& Wehby, 2001). It becomes essential that both special education teachers and general education teachers implement evidence-based practices in an effort to make sure all students are successful academically as well as socially.

\section{Prevalence and Issues of Students with Mathematics Difficulties}

Between $5 \%$ and $8 \%$ of school-aged children have some form of memory or cognitive deficit that affects their learning of mathematics (Geary, 2004). According to Fuchs, Fuchs, \& Hollenbeck (2007), this number has been steadily increasing since it first became recognized as a disability in 1975 . Additionally, many students with mathematics disabilities have comorbid disorders that include reading disabilities and attention-deficit disorder (Geary, 2004). For example, Zentall (2007) reports that students with ADHD have higher rates of mathematics disabilities (31\%) than that of general education students $(6 \%$ to $7 \%)$ and a quarter of students with mathematics disabilities have ADHD. In addition, Landerl and Moll (2010) state comorbidity rates across studies range from $17 \%$ to $70 \%$ for students with mathematics disabilities showing reading problems and $11 \%$ to $56 \%$ for students with reading disabilities showing problems in mathematics. Comorbidity rates range from $47 \%$ to $70 \%$ of 
students with mathematics disabilities showing problems in spelling and $36 \%$ to $42 \%$ of students with spelling problems showing deficits in mathematics. These statistics suggest that mathematical disabilities may be overlooked in students who experience difficulties in other academic areas.

Adding to the problem, the complexity associated with the learning of mathematics makes it difficult to differentiate between mathematics learning disabilities and mathematics difficulties unrelated to a disability. Geary (2004) states:

In theory, a learning disability can result from deficits in the ability to represent or process information in one or all of the mathematical domains (e.g., geometry) or in one or a set of individual competencies with each domain. The goal is further complicated by the task of distinguishing poor achievement due to inadequate instruction from poor achievement due to an actual cognitive disability (p. 4).

Thus, there is much variation in which struggling students are identified as having a mathematics learning disability since there is no standard definition or standard assessment tool for diagnosis (Louie, Brodesky, Brett, Yang, \& Tan, 2008). This suggests that a student who is diagnosed with a mathematics disability in one state or district, may not be identified in another. These findings stress the importance that teachers should incorporate evidence-based practices into instruction that will not only help students labeled with a specific learning disability in mathematics be successful but other struggling learners as well.

\section{Trends in Student Mathematical Performance}

One of the expectations of the No Child Left Behind Act (2001) is that all students, including students with disabilities, will reach proficiency in mathematics by the year 2014. Recent reports of student performance suggest that although students 
are making progress in the area of mathematics, the goal of every student reaching proficiency will not be met if current rates of progress continue. Results from the 2009 National Assessment of Educational Progress (NAEP) indicated $6 \%$ of fourth grade students were at advanced, $41 \%$ were at or above proficient, and $84 \%$ were at or above basic in mathematics while $16 \%$ were below the basic level of performance (i.e., below grade level). When looking only at students with disabilities, only $2 \%$ of fourth grade students were at advanced, $19 \%$ were at or above proficiency, and $59 \%$ were at or above basic while $41 \%$ were below basic. Results from eighth grade show only $8 \%$ of regular education students and $1 \%$ of students with disabilities were at advanced, $35 \%$ of regular education students and $9 \%$ of students with disabilities were at or above proficient in mathematics, and $76 \%$ of regular education students and $36 \%$ of students with disabilities were at or above basic while $24 \%$ of regular education students and $64 \%$ of students with disabilities were below basic level. When compared to the results of 2007, although there were no gains in the average mathematics scores in fourth grade students, there were statistically significant gains in eighth grade (National Center for Education Statistics, 2009). This is a sign of significant progress; however, with a quarter of regular education students and over half of students with disabilities being below grade level expectations in mathematics, this is an alarming statistic. Furthermore, it is disturbing that the gap is becoming wider for students with disabilities. These data indicate that there is still much work to be done to ensure that all students performing below grade level are making adequate progress. 
In regards to U.S. student performance in mathematics compared to other countries, there are conflicting results. Results from the 2007 Trends in International Mathematics and Science Study (TIMSS) report showed that U.S. students' average mathematics score was 529 for fourth grade students and 508 for eighth grade students. Both scores were above the TIMSS scale average and were an increase from 1995 scores. Fourth graders in eight of the other 35 participating countries and eighth graders in five of the other $\mathbf{4 7}$ participating countries scored above the U.S. students (Gonzales, Williams, Jocelyn, Roey, Kastberg, \& Brenwald, 2008). On the other hand, results from the 2006 Program for International Student Assessment (PISA) showed that U.S. 15-year-old students' average mathematics literacy score of 474 was lower than the Organization for Economic Cooperation and Development (OECD) average of 498. This placed U.S. 15-year-olds in the bottom quarter of participating OECD nations, a position relatively unchanged from 2003 (Baldi, Jin, Skemer, Green, \& Herget, 2007). From these results, it is apparent that educators need to identify new strategies and practices that can lead to improved mathematics performance for all students.

\section{Significance of the Study}

Over the past several years, curriculum integration has gained acceptance by educators and encouraged by many national reform movements (Czerniak, Weber, Sandmann, \& Ahern, 1999). The National Council of Teachers of English (NCTE) Standards for the English Language Arts (1996) states:

English language arts are important not only as subjects in and of themselves, but also as supporting skills for students' learning in all other subjects. The English language arts help students gather and convey information about mathematics, history, science, the arts, and an array of other subjects, and in all 
of these subjects students use language to solve problems, theorize, and synthesize. (p. 6)

Furthermore, The National Council of Teachers of Mathematics (NCTM), in its

curriculum standards, stresses the need for:

a truly integrated çurricular organization in all grades to permit students to develop mathematical power more readily and to allow the necessary flexibility over time to incorporate the content of these standards. Teaching practice should move toward connecting mathematics, its ideas, and its application away from treating mathematics as a body of isolated concepts and procedures. (National Council of Teachers of Mathematics, 1991, p. 3)

Focusing specifically on integrating the content areas reading and mathematics, Wallace and Clark (2005) conducted a literature review and concluded that there were three categories, or "reading stances", in the mathematics classroom: (1) reading problems (2) reading mathematics, and (3) reading life (p. 69). Reading problems is described as "the student extracting necessary information to solve a problem" and the texts used are primarily textbooks, worksheets, and workbooks (p. 69). The purpose of learning in the reading problems stance is "simply to memorize rote procedures and apply them to similar problems" (p. 71). Reading mathematics can be described as "the construction of knowledge about the world of mathematics. This type of reading draws on multiple texts as a way to supplement the textbook so that the textbook is not the authoritative source of mathematics in the classroom" (p. 71). Reading life builds upon the reading mathematics stance and "moves further to see mathematics as a language of power necessary to take part in a democratic society...the primary 'texts' to be read should be life texts, including written texts such as newspapers and magazines, and also 
verbal texts such as speeches and weather reports, and numerical texts such as on labels and advertisement" (pp. 69, 76).

Integrating children's literature in mathematics instruction is most aligned with the reading mathematics stance. It is a curricular approach that both special education teachers and general education teachers can implement in an effort to increase student engagement in mathematics which can potentially increase mathematics achievement. Integrating children's literature in mathematics promotes communication and provides real-world connections, which are recommended as effective teaching practices by the National Council for Teaching Mathematics (NCTM) Principles and Standards for School Mathematics (2000). More specifically, the NCTM Curriculum and Evaluation Standards for School Mathematics (1989) state “Many children's books present interesting problems and illustrate how other children solve them. Through these books students see mathematics in a different context while they use reading as a form of communication" (p. 27). Columba, Kim, \& Moe (2009) state "when mathematical concepts are taught in isolation, children often have difficulty learning them...Stories, both narrative and expository in structure, provide contexts in which mathematics concepts can be presented together with opportunities to think critically, solve problems, and make connections to students' knowledge about the world" (p. 19). Integrating children's literature in mathematics instruction "provides a context through which mathematical concepts, patterns, problem solving, and real-world contexts may be explored (Moyer, 2000, p. 246). 
Seven studies examining the effects of children's literature in mathematics instruction were included in the review for the current study. These studies can be separated into two broad categories; student mathematics achievement and student engagement. Results suggested that integrating children's literature in mathematics instruction has positive effects on mathematics achievement (Capraro \& Capraro, 2006; Casey, Erkut, Ceder, \& Young, 2008; Hong, 1996; Jennings, Jennings, Richey, \& DixonKrauss, 1992; Keat \& Wilburne, 2009; Young-Loveridge, 2004) along with other factors such as increasing student interest in mathematics (Jennings, et al., 1992), increasing student disposition towards mathematics (Hong, 1996), increasing student mathematical communication (Capraro \& Capraro, 2006), raising student confidence in mathematics (Keat \& Wilburne, 2009), and increasing positive student attitude (Mink \& Fraser, 2002).

This study extends the literature on integrating children's literature in mathematics instruction in several ways. First, this study examined the effects of integrating children's literature in mathematics instruction on students with academic difficulties and challenging behaviors, which has not been addressed in previous research studies. Secondly, this study investigated if integrating children's literature in mathematics instruction can be effective in increasing on-task behavior while decreasing inappropriate and/or disruptive classroom behaviors for this population. Finally, this study examined the effects of integrating children's literature in mathematics instruction on teacher behaviors such as increasing students' opportunities to respond. 


\section{Purpose of the Study}

The purpose of this study was to support and extend the existing research by investigating the following primary research questions listed in order of importance: (1) Will integrating children's literature in mathematics instruction increase student engagement while reducing disruptive behaviors during mathematics instruction for students with academic difficulties and challenging behaviors?; (2) Does integrating children's literature in mathematics instruction increase the teacher's rate of providing opportunities for students to respond during mathematics instruction?. In addition, this study included a secondary research question: Will integrating children's literature in mathematics instruction increase mathematics achievement for students with academic difficulties and challenging behaviors?

This chapter was a brief overview of the literature and rationale for using children's literature to teach mathematics. Chapter 2 presents a critical analysis of the effects of using children's literature to teach mathematics on the academic and behavioral outcomes for students with academic difficulties and challenging behaviors. Chapter 3 delineates the research design and methodology of the study. The instruments used to gather the data, the procedures followed, and sample selection is described. A detailed analysis of the data is presented in Chapter 4. Chapter 5 interprets and explains the results of the study. This includes how the findings contribute to existing literature as well as educational implications. The study concludes with references and appendices. 


\section{CHAPTER 2 \\ LITERATURE REVIEW}

Students with academic difficulties and challenging behaviors present a multitude of challenges for teachers. This includes providing differentiated instruction to ensure that every student has the opportunity for academic success and managing classroom disruptions. It is suggested that using effective instructional practices can increase student academic achievement while decreasing inappropriate and/or disruptive classroom behaviors (Deno, 1998; Wehby, Symons, Canale, \& Go, 1998). Although it is not clear which causes the other, there appears to be a reciprocal relationship between behavior and academic achievement (Sutherland \& Wehby, 2001). Effective instructional practices such as promoting communication of mathematical thoughts and ideas and providing relevant, real-world connections are needed in mathematics instruction (NCTM, 2000) and may lead to an increase of mathematical achievement. One way to accomplish this is to integrate children's literature in mathematics instruction. Integrating children's literature in mathematics instruction has the potential to motivate children to think and reason mathematically when teaching important mathematics concepts and skills by promoting communication through interaction and discussion (Columba, et al., 2009). The purpose of this literature review is to provide a critical analysis of the effects of using children's literature to teach mathematics on the academic and behavioral outcomes for students with academic 
difficulties or challenging behaviors. Before analysis of the literature, this review will present the theoretical framework for integrating children's literature in mathematics instruction.

\section{Theoretical Framework}

It has been common practice for teachers to read aloud children's books to young children. Read alouds have been used to introduce reading as a fun and engaging experience in an attempt to improve reading skills. A read aloud, or modeled reading, is when a teacher orally reads a selection to students. The benefits of reading aloud to students to improve reading have been known for years. In 1985, the U.S. Department of Education's Commission on reading published Becoming A Nation of Readers. The commission stated that "the single most important activity for building the knowledge required for eventual success in reading is reading aloud to children" (Anderson, 1985, p. 33). Specific benefits of reading aloud to students include increasing their vocabulary, improving listening comprehension skills, and increasing their ability to recognize words (Layne \& Wright, 2007). These benefits are not exclusive to literacy instruction and could carry over into mathematics instruction. Increasing a student's mathematics vocabulary, improving listening comprehension skills, and recognizing words related to mathematics would be beneficial in the learning of mathematics. This is supported by The National Council of Teachers of Mathematics (NCTM) when they state "students who have opportunities, encouragement, and support for speaking, writing, reading, and listening in mathematics classes reap dual benefits: they communicate to learn mathematics, and they learn to communicate mathematically" (NCTM, 2000, p. 60). 
The U.S. Department of Education's Commission on reading also found that the benefits of reading aloud were greater when the student is an active participant and engaged in the discussion (Anderson, 1985). The read aloud must be interactive and foster communication to accomplish this. An interactive read aloud differs from a straight-through storybook reading that relegates the student to be a passive listener (Barrentine, 1996). It encourages teachers to pose questions throughout the reading "that enhance meaning construction and also show how one makes sense of the text" (Barrentine, 1996, p. 36). An interactive read aloud to teach mathematics concepts can play an important role in mathematics instruction because "many children's books present interesting problems and illustrate how other children solve them. Through these books students see mathematics in a different context while they use reading as a form of communication" (National Council of Teachers of Mathematics, 1989, p. 27). Incorporating an interactive storybook reading in mathematics can establish a different context as well as provide a real-world connection to mathematical problems. Interactive read alouds incorporate aspects of Cambourne's conditions of learning (Cambourne, 1988, 1995). After spending three years observing the oral language development of young children, Brian Cambourne identified a set of conditions that are present in the natural environment when language is learned. Because he determined oral language development to be an example of successful complex learning, he concluded that these conditions can also be applied to enhance student development in literacy learning. Cambourne's theory declares that there are certain conditions that are the core of effective teaching and learning in natural settings. 
These conditions include immersion, demonstration, engagement, expectations, responsibility, employment, approximations, and response.

Although each condition could be associated with reading aloud storybooks, demonstration and engagement are the most supportive of interactive read alouds. Cambourne's condition of demonstration refers to "the ability to observe (see, hear, witness, experience, feel, study, explore) actions and artifacts" (Cambourne, 1995, p. 185). He states that all learning begins with demonstration and consistency and concluded that repeated demonstrations are necessary for learning. According to Cambourne, although demonstration is a necessary condition, it is not sufficient. Students must be engaged in the demonstration for successful learning to occur and engagement is dependent on active participation, not as a passive listener. As seen in Figure 2-1, during an interactive storybook reading in mathematics, engagement is fostered through providing students with sufficient opportunities to respond and modeling of mathematics concepts by both the teacher and peers. This is an important component of the interactive read aloud because "engaged students interact with each other and the teacher in response to the text. With repeated engagement in demonstrations children internalize the ability to use process and strategy information" (Barrentine, 1996, p. 38). Furthermore, increased engagement can potentially lead to an increase in mathematics performance and a decrease in inappropriate behavior. 
Figure2-1. Conceptual Model for Integrating Children's Literature in Mathematics

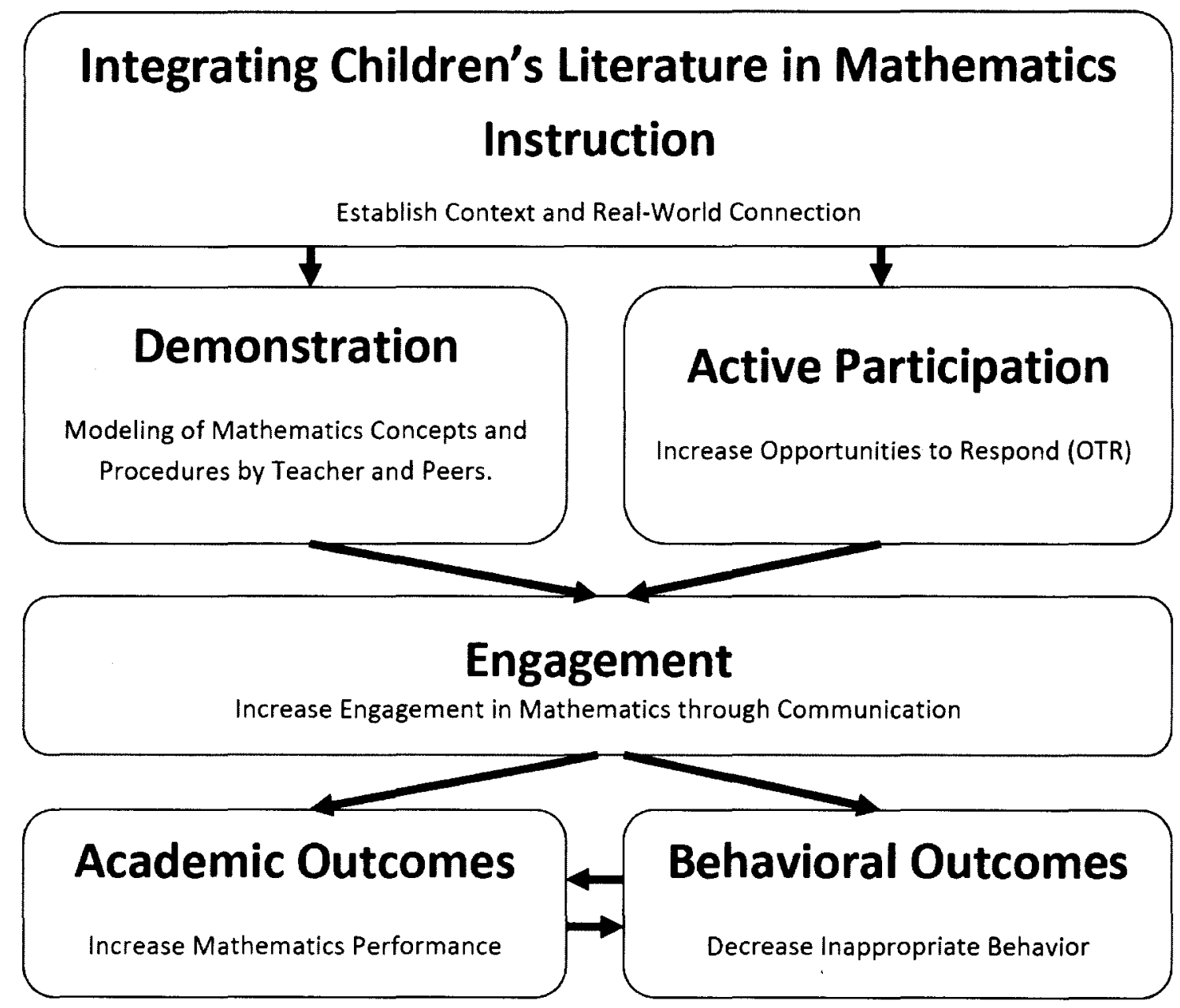

Active Student Engagement and Opportunities to Respond

According to Cambourne's conditions of learning, active student engagement must be present for successful learning to occur, but it can also play a crucial role in student behavioral outcomes as well. Students who are engaged in the learning process are less likely to exhibit inappropriate behaviors and more likely to achieve academic success (Conroy, Sutherland, Snyder, \& Marsh, 2008; Simonsen, Faribanks, Briesch, Myers, \& Sugai, 2008; Sutherland \& Wehby, 2001). In traditional practice, during instructional time the teacher presents or explains information while the students are 
expected to sit quietly and listen. This is often referred to as passive engagement. If the teacher gives students opportunities to respond, it usually involves individual responding where one student actively responds to the teacher's question while the rest of the students are only passively involved (Armendariz \& Umbreit, 1999).

Furthermore, it has been suggested that higher-achieving students are more likely to actively respond to the teacher's questions than lower-achieving students (Greenwood, Delquadri, \& Hall, 1984).

Active student engagement for all students is a desirable outcome for teachers, but how is it achieved? A potentially effective teaching practice is giving students frequent opportunities to respond (OTR). An OTR can be defined as the interaction between a teacher's academic prompt (i.e., verbal, visual, or written) and a student's response. According to Conroy, et al. (2008), although the delivery of OTR's can vary (e.g. choral responding and individual responding), OTR's generally include the following components:

Increasing rates of teacher instructional talk that include repeated verbal, visual, or verbal and visual types of prompts for responding; presenting information in a manner that increases students correct responding (e.g., 'This is an A. What letter is this?'); implementing individualized instructional modifications appropriate for the students' level of functioning, along with frequent checks for understanding and accuracy; using repeated instructional prompting that incorporates wait time to allow students to respond; and providing corrective feedback, error correction, and progress monitoring (Stichter, Lewis, Whittaker, Richter, Johnson, \& Trussell, 2006). (p. 26 - 27)

\section{Importance of Increasing Students' Opportunities to Respond}

Because of national legislation and high-stakes accountability, teachers have been challenged to teach mathematics in different ways than that of the past. The 
National Council for Teaching Mathematics (NCTM) Principles and Standards for School Mathematics (2000) has established guidelines for effective mathematics instruction. One of the standards emphasizes the importance of learning mathematics through communication. More specifically, the standard states that:

Instructional programs from prekindergarten through grade 12 should enable all students to organize and consolidate their mathematical thinking through communication; communicate their mathematical thinking coherently and clearly to peers, teachers, and others; analyze and evaluate the mathematical thinking and strategies of others; and use the language of mathematics to express mathematical ideas precisely. (p. 60-62)

Learning to communicate fosters the interaction and exploration of thoughts and ideas.

When students are asked to communicate their thinking, either to justify their reasoning or to formulate a question, "it requires reflective thinking and diminishes guesses or responses based on rote memorization" (Columba, et al., 2009, p. 25). Furthermore, promoting communication gives students the opportunity to see different perspectives and methods of others which will allow them to "learn to understand and evaluate the thinking of others and to build on those ideas" (NCTM, 2000, p. 62). Research has shown that students' being prompted to explain their thinking is positively related to achievement outcomes while giving only answers is not related or negatively related to achievement outcomes (Fuchs, Fuchs, Hamlett, Phillips, Karns, \& Dutka, 1997; Nattiv, 1994; Webb, 1991). In addition, fostering student communication gives the teacher an opportunity to formatively assess individual student learning (Franke, Fennema, \& Carpenter, 1997). Despite the importance of students communicating their thinking and instruction becoming more student focused, instructional practices have remained 
teacher-centered (Kennedy, 2004). Students ask questions infrequently (Graesser \&

Person, 1994) and teacher talk typically dominates the instruction (Cazden, 2001).

Providing sufficient opportunities for students to respond is an effective teaching strategy that can foster communication in the mathematics classroom. Increasing OTR can affect student academic and behavioral outcomes during mathematics instruction. Specifically, research has suggested increasing the rate of OTR improves students' mathematics performance (Christle \& Schuster, 2003; Lambert, Cartledge, Heward, \& Lo, 2006; Skinner, Belfiore, Mace, Williams-Wilson, and Johns, 1997; Skinner, Ford, \& Yunker, 1991; Sutherland, Alder, \& Gunter, 2003), increases student engagement during mathematics instruction (Carnine, 1976; Christle \& Schuster, 2003; Davis \& O'Neil, 2004; Haydon, Conroy, Scott, Sindelar, Barber, \& Orlando, 2010; Haydon, Mancil, \& Van Loan, 2009; McKenzie \& Henry, 1979; Sutherland, et al., 2003), and decreases disruptive behavior during mathematics instruction (Armendariz \& Umbreit, 1999; Haydon, et al., 2010; Haydon, et al., 2009; Lambert, et al., 2006; Sutherland, et al., 2003; West \& Sloan, 1986).

\section{Review of the Literature}

\section{Method Used to Select Reviewed Studies}

Inclusion Criteria. The purpose of this review is to provide a critical analysis of the effects of using children's literature to teach mathematics on the academic and behavioral outcomes of students. The studies included in the review were selected based on pre-determined criteria for relevancy. This criteria identifies studies that examined increasing the rates of student academic achievement, increasing student 
engagement, and/or decreasing inappropriate student behavior through children's literature.

The literature review consists of published studies that examined the effects of using children's literature to teach mathematics on academic (e.g., general mathematics, number skills, and geometry) and behavioral outcomes (e.g., interest, disposition, attitude, mathematical communication, and confidence) of students. Participants in the studies included students, grades kindergarten through six, in the regular education classroom setting. Studies varied in methodology, with some using quantitative methods only while others used mixed-methods (both qualitative and quantitative). It is important to note that there were no studies that explicitly involved students with academic difficulties (e.g., mathematics disability, reading disability) or students exhibiting challenging behaviors (i.e., off-task, disruptive, or aggressive behavior).

\section{Literature Search}

To locate articles for inclusion in this review, several research strategies were used. The first strategy involved an exhaustive search of the following computerized databases: ERIC, Academic Search Premiere, ScienceDirect, ProQuest, JSTOR, and Wilson Educational. An additional search was conducted on Google Scholar. Keywords used for the search included: mathematics and children's literature, mathematics and storybooks, mathematics and picture books, mathematics instruction and children's literature, teaching methods and children's literature. Once articles were found, using Google Scholar, the author searched all articles that cited the specific article found using 
the first strategy. Next, the references of all relevant articles were searched to find other relevant studies that met the criteria. Articles that were not accessible through the computerized databases or Google Scholar were obtained through the University of Louisville library.

Seven studies met the inclusion criteria and are included in this review. Four studies examined the effects of integrating children's literature in mathematics instruction on mathematics achievement along with other factors such as student interest (Jennings, Jennings, Richey, \& Dixon-Krauss, 1992), student disposition (Hong, 1996), student mathematical communication (Capraro \& Capraro, 2006), and student confidence in mathematics (Keat \& Wilburne, 2009). One study examined the effects of integrating children's literature in mathematics instruction solely on mathematical achievement (Casey, Erkut, Ceder, \& Young, 2008). One study examined the effects of integrating children's literature in mathematics instruction on student attitude and classroom environment (Mink \& Fraser, 2002). The final study examined the effects of integrating children's literature and games in mathematics instruction on mathematical achievement (Young-Loveridge, 2004). Table 1, at the end of this review, gives a brief summary of the studies. A more detailed analysis of the characteristics of the studies and results is provided next.

\section{Methods of Reviewed Studies}

Participants. A total of 737 students served as participants across the seven studies. Four studies reported gender of the participants with a total of 197 male and 182 female (Casey, et al., 2008; Hong, 1996; Jennings, et al., 1992; Young-Loveridge, 
2004). Three studies reported race of each participant although specificity varied with some reporting numbers and some reporting percentages (e.g., 60\% minority; 58 white, two African-American, and one Asian-American; 48\% European, 44\% Maori, 4\% Pacific Islanders, and 4\% other) (Casey, et al., 2008; Hong, 1996; Jennings, et al., 1992). Three studies reported information regarding parents in the household (e.g., 39 one parent households and 22 two parent households; $42 \%$ fathers absent or unemployed) (Jennings, et al., 1992; Young-Loveridge, 2004). Four studies reported socio-economic status of the participants with two being very general (e.g., average SES, from low socioeconomic schøols)(Capraro \& Capraro, 2006; Young-Loveridge, 2004) and two being more specific (e.g., $31 \%$ receiving free and reduced lunch, $82 \%$ fathers and $50 \%$ mothers graduated from a 4-year college)( Casey, et al., 2008; Hong, 1996).

Setting. Six of the studies were conducted in the general education classroom (Capraro \& Capraro, 2006; Casey, et al., 2008; Hong, 1996; Jennings, et al., 1992; Keat \& Wilburne, 2009; Mink \& Fraser, 2002) while one study was conducted by pulling out participants in pairs to a separate room (Young-Loveridge, 2004). The grade level examined by the researchers consisted of five in the kindergarten setting (Casey, et al., 2008; Hong, 1996; Jennings, et al., 1992; Keat \& Wilburne, 2009; Young-Loveridge, 2004), one fifth grade setting (Mink \& Fraser, 2002), and one sixth grade setting (Capraro \& Capraro, 2006).

Dependent Variables. Four studies examined the effects of integrating children's literature in mathematics instruction on mathematics achievement, along with other factors such as student interest (Jennings, et al., 1992), student disposition 
(Hong, 1996), student mathematical communication (Capraro \& Capraro, 2006), and student confidence in mathematics (Keat \& Wilburne, 2009) as the dependent variables. Two studies examined the effects of integrating children's literature in mathematics instruction with only mathematics achievement as the dependent variable (Casey, et al., 2008; Young-Loveridge, 2004 ). Finally, one study examined the effects of integrating children's literature in mathematics instruction with student attitude and classroom environment as the dependent variables (Mink \& Fraser, 2002).

Independent Variables. Integrating children's literature in mathematics instruction was the independent variable in six studies. Although these six studies used the same independent variable, integrating children's literature in mathematics instruction, their methods varied. Jennings, et al. (1992) used a total of 20 books and designed mathematics lessons that included mathematics concepts to be taught, materials needed, and suggested questions. In addition, the researchers connected the content of the books to the introduction of new mathematics concepts, reinforcement of concepts already learned, and the expansion of concepts being taught. The authors placed the books and supplemental manipulatives in the play center for the children to use during free play.

Instead of integrating children's literature during mathematics instruction, Hong (1996) used 28 mathematics-related children's books during storybook reading time. The author provided lesson plans for teachers from both experimental and control groups. The experimental group's lesson plans included reading mathematics-related books that related to the weekly theme and doing follow-up mathematics activities 
related to the story. The control group's lesson plans included books related only to the weekly theme (e.g, weekly theme of "family") and a general follow-up discussion of the book related only to the weekly theme. Both groups then had free play and could choose from several different corners, including a mathematics corner.

Mink and Fraser (2002) used a program called project SMILE (Science and Mathematics Integrated with Literacy Experiences) as the independent variable. Project SMILE was adapted from Project CRISIS (Creating Independence through Student-owned Strategies), a program designed to teach secondary students to learn content area subjects through reading, writing, speaking, and listening. The SMILE program adapted the CRISIS strategies for elementary students through the incorporation of popular children's literature. Each unit in the SMILE mathematics manual was designed to be aligned with one or more of the NCTM Principles and Standards for School Mathematics (2000).

Capraro and Capraro (2006) supplemented mathematics instruction with mathematics-related children's literature as the independent variable. Both the experimental and control group were similar in instruction throughout the 90 minute class period with the exception of the last 20 minutes. The experimental group incorporated children's literature during this time while the control group had unstructured time devoted to independent mathematics seat work.

Casey, et al. (2008) involved two studies that used the integration of children's literature to teach mathematics as the independent variable. The intervention in both studies involved supplementing the regular mathematics curriculum with activities 
based on the book Tan and the Shape Changer, which were extended over eight class settings. The intervention students worked in cooperative groups to help the characters solve mathematics problems. The control group in both studies only followed the regular mathematics curriculum. Keat and Wilburne (2009) did something similar. The researchers supplemented the regular mathematics curriculum with storybooks related to money. Activities were developed to create problem-solving scenarios in which the children helped the characters in the story solve mathematical problems.

One study used the combination of children's literature and games in mathematics instruction as the independent variable (Young-Loveridge, 2004). At the beginning of each session, a number rhyme followed by a number story was read to the students. This was followed by number games such as commercial games (e.g., Snakes and Ladders) and various dice games using dice with dot patterns, dice with numerals up to three, and/or traditional dice. The session concluded with another number rhyme.

Implementers. Classroom teachers were used to implement the intervention in four studies (Capraro \& Capraro, 2006; Keat \& Wilburne, 2009; Hong, 1996; Mink \& Fraser, 2002). Two studies used classroom teachers and the principal investigators to implement the intervention (Casey, et al., 2008; Jennings, et al., 1992) and one study made no mention of the person implementing the intervention (Young-Loveridge, 2004). Three studies provided information regarding teacher experience. Casey, et al. (2008) described the teacher implementing the intervention as having 26 years experience, all at the same school. The teachers in the Capraro and Capraro (2006) 
study had received school-level teaching awards, more than ten years of teaching experience, and had been at their current school for at least five years. Hong (1996) stated that teachers in both control and experimental groups had an early childhood education certification from a two year college.

Research Method/Design. The studies varied in their research methods with four studies using a quantitative method design and three studies using a mixed methods design. Although these studies can be divided into two methodological categories, the studies varied within each category (i.e., participant selection and/or assignment, measures used). Therefore, a greater description of the design will be discussed.

Quantitative Methods. Jennings, et al. (1992) used a quasi-experimental pretest/post-test design by randomly selecting eight teachers to either the control or experimental group. The researcher used the Test of Early Mathematics Ability (TEMA) and the Metropolitan Readiness Test (MRT) to measure mathematics achievement and frequency of mathematics vocabulary used by students during free play to measure student interest in mathematics. Hong (1996) randomly selected students to either an experimental classroom or a control classroom. A pre-test/post-test, using The Learning Readiness Test (LRT) and The Early Mathematics Achievement Test (EMAT), was used to measure mathematics achievement while observation (i.e., frequency of students in mathematics corner and duration of time spent in mathematics corner) was used to measure student disposition. Young-Loveridge (2004) randomly assigned students that represented the lower two-thirds of scores on numeracy level. The researcher used a 
pre-test/post-test design of individual task-based interviews to measure the students' understanding of number skills.

The two studies conducted by Casey, et al. (2008) randomly assigned six teachers to either an experimental or control group in the first study and randomly assigned four teachers to either an experimental or control group in the second study. Both studies used the pre-test/post-test design that included the Triangles Subtest from the Kaufman-Assessment Battery for Children (K-ABC) to measure student near-transfer skills of geometry (i.e., specific mathematical content in lesson) and a tangram test, based on traditional tangram mathematical puzzles, to measure student far-transfer skills of geometry (i.e., wider range of geometry skills not specific to content in lesson).

Mixed Methods. Mink and Fraser (2002) used a mixed methods design that incorporated quantitative and qualitative methods. The researchers used a sample of $5^{\text {th }}$ grade students in two schools. A pre-test/post-test design was used to obtain quantitative data for analysis. The researchers used an adaptation of The National Assessment of Educational Progress (NAEP) attitude inventory to measure student attitudes regarding reading, writing, and mathematics and the My Class Inventory (MCl) to measure student perception of the classroom environment. Qualitative data were collected through classroom observations, student and teacher interviews, and student work samples.

Capraro and Capraro (2006) used a within-stage mixed-model design which incorporated both quantitative and qualitative methods. The researcher used a sample of $6^{\text {th }}$ grade students and three teachers. A pre-test/post-test design was used to 
measure student understanding and/or performance using three assessments (general reading, general mathematics, geometry-specific) designed by the researchers and teachers for quantitative data for analysis. Qualitative data were obtained through semi-structured interviews.

Keat and Wilburne (2009) used a mixed-methods design with a pre-test/posttest design for quantitative analysis and interviews for qualitative analysis. The pretest/post-test used an assessment created by the researcher to assess mathematical knowledge of money. The various qualitative measures included classroom observations, audio-tapes of story book readings, discussion with students, and pre and post study interviews with individual teachers.

\section{Results of Reviewed Studies}

According to the authors, the overall results of the studies suggest a positive relationship between integrating children's literature in mathematics instruction and student academic achievement. In addition, children's literature had a positive impact on factors related to student engagement in mathematics such as student interest (Jennings, et al., 1992), student disposition (Hong, 1996), student mathematical communication (Capraro \& Capraro, 2006), and student confidence in mathematics (Keat \& Wilburne, 2009). Although the authors suggest positive effects, not all statistical analysis produced significant results and some researchers did not provide sufficient information to allow the reader to fully understand the analysis conducted. Therefore, the results of the studies will be discussed in greater detail in relation to 
mathematics performance and student engagement including important statistical information excluded by the researchers.

Student Mathematics Performance. Results from Jennings, et al. (1992) indicated mixed results based on standardized mathematics scores. The authors indicated results from the pre-test for the Test of Early Mathematics Ability (TEMA) between the control and experimental groups were similar on scores with the experimental group having a mean test score of 7.94 and the control group having a mean test score of 8.41 , but no results from a statistical test were given. An independent samples t-test analysis of post-test scores suggested there was a reliable increase in the pre-test to post-test scores for the experimental group compared to the control group, $t(59)=5.57, p<.01$. In contrast, although the experimental group's scores from the Metropolitan Readiness Test (MRT) were higher than the control group's scores on both subtests, there was no statistically significant difference between the groups on the Operations subtest, $t(59)=1.56, p<.12$, or the Concepts subtest, $t(59)=.29, p<.77$.

Hong (1996) also measured student mathematics achievement through standardized mathematics scores. Analysis of pre-test scores showed that since there was no significant difference between the control and experimental group on the Learning Readiness Test (LRT), $t=1.47, p=.15$, the two groups had comparable mathematics knowledge. Post-test analysis of the Early Mathematics Achievement Test (EMAT) revealed there were no significant differences in achievement between the experimental and control group, $t=.37, p=.71$. These findings conflict with the positive 
results reported by Jennings, et al. (1992). Hong (1996) also examined the students' performance on mathematical tasks during free play. Students in the children's literature group had a statistically significant higher mean of correct responses on classification, $t=2.16, p=.04$; number combination, $t=4.34, p=.0001$; and shape tasks, $t=3.15, p=.004$.

Differing from the prior two studies, Young-Loveridge (2004) examined the effects of number books and games on students' numeracy scores through individual task-based interviews specific to the content being taught during the study, instead of using standardized mathematics tests. The results suggested that the intervention produced a significant effect, with the students in the number books and games group showing greater gains than the control group, $F(1,97)=45.91, p<.001$. Although the effect was initially large, analysis of a follow-up test taken six months after the intervention showed that the effect diminished over time yet still remained statistically significant at the .05 alpha level, $F(1,97)=6.95, p<.05$.

Capraro and Capraro (2006) extended and supported the findings of YoungLoveridge (2004) by creating an assessment, based on state curriculum objectives, measuring middle-school student scores on three categories: geometry skills, general mathematics, and reading. Results of the MANCOVA indicated there were statistically significant differences between the experimental group and the two control groups on geometry, $F=28.60,4 ; p=1.50 \times 10^{-15} ; R^{2}=.549 ;$ mathematics, $F=9.14,4 ; p=2.8 \times 10^{-6}$; $R^{2}=.280 ;$ but not on reading, $F=.35,4 ; p=.843 ; R^{2}=.015$. In addition, the Helmert contrast results indicated that the experimental group outperformed the two control 
groups when considering them together and individually on geometry, $p=1.38 \times 10^{-4}$, and general mathematics, $p=.035$, but not in reading.

Casey, et al. (2008) also examined the effects of children's literature on students' geometry skills. The study extended the results of Capraro and Capraro (2006) by assessing the students on two part-whole relation tasks (near and far transfer tasks). The near transfer task measured student performance on specific mathematical content taught during the study (i.e., the isosceles right triangle) while the far transfer task measured student learning on a wider range of part-whole relations (i.e., rectangles, triangles, parallelograms, etc.) . In the first study, a repeated measures ANOVA on student pre-test/post-test scores revealed that the intervention group had significantly greater improvement when compared to the control group on near transfer tasks, $F(1$, 151) $=8.84, p=.003$. In contrast, there was no statistically significant difference between student scores on the far transfer tasks. These results suggest that incorporating children's literature in geometry has positive results on near transfer knowledge, but it does not generalize to geometry skills not specific to the lesson.

In an attempt to replicate and extend the first study, Casey, et al. (2008) examined the effects of children's literature on students' geometry skills in an urban community rather than the suburban community from the first study. The second study also used the repeated measures ANOVA on student scores and it showed that the experimental group improved significantly more than the control group on the near transfer tasks, $F(1,59)=5.57, p=.022$. There was also a statistically significant difference between the experimental group and the control group on the far transfer 
tasks, $F(1,59)=7.79, p=.007$, which differs from the results from the first study. In addition, the findings from both studies had moderate effect sizes (Cohen, 1988) by condition (experimental v. control), accounting for 9 to $14 \%$ of the variance.

Although Keat and Wilburne (2009) reported positive results, these results cannot be included in the body of research supporting the effects of children's literature on students' mathematical performance. The researchers stated that a statistical analysis of pre-test and post-test scores measuring student mathematical knowledge of money "indicated significant development of knowledge in three weeks"(Keat \& Wilburne, 2009, p. 64), but the statistical test used was not given, nor was the obtained value of the test statistic or probability value. The only information given were mean scores with standard deviations (pre-test: $M=11, S D=1.5$; post-test: $M=21, S D=2.1$ ).

Student Engagement in Mathematics. The study by Jennings, et al. (1992) examined increasing interest in mathematics through children's literature. The researchers analyzed observational data collected during free play periods to determine group differences in the frequency of student mathematics vocabulary usage. Results of a chi-square analysis suggested that students in the experimental group used significantly more mathematics vocabulary words during free play than students in the control group, $x^{2}(6,61)=293.20, p<.01$.

Hong (1996) supported the findings of Jennings, et al. (1992) by examining the effects of children's literature on student dispositional outcomes (i.e., student interest in mathematics and their pursuit of mathematical activities). Analysis of student disposition towards mathematics showed the number of children choosing mathematics 
as their favorite learning corner were significantly greater than the control group, $x^{2}=$ $27.87, p=.0001$. Hong (1996) stated there was a tendency for more students in the experimental group to voluntarily choose the mathematics corner, $x^{2}=3.25, p<.10$, and spend more time in the mathematics corner, $t=1.32, p<.10$, than the control group. Although Hong reports a statistically significant difference, it is important to note the choice of alpha level, $p=.10$. Because Hong (1996) does not discuss his reasoning behind using a higher alpha level, it makes it difficult to have confidence in the obtained results.

Keat and Wilburne (2009) used qualitative analysis to assess how students' approaches to learning were influenced by integrating children's literature in mathematics instruction. Results from a thematic analysis from surveys, observations, and interviews revealed four themes. The first theme revealed the use of children's literature "prompted children to move through a sequence of mathematical problemsolving steps" (p. 64). The second theme revealed that as the study progressed, the children's books influenced the students' use of imagination that evolved into realistic mathematical problem solving. The third theme showed that "the children generated increasingly complex problems and made connections to other disciplines"(p. 65).

Finally, the fourth theme revealed "the children persisted in demonstrating each of the characteristics of enthusiasm (interest, pleasure, motivation) and engagement (attention, flexibility, persistence, self-regulation)" (p. 66).

Mink and Fraser (2002) evaluated the effects of a mathematics program which integrates children's literature on student attitudes toward reading, writing, and 
mathematics as well as creating a positive learning environment. The researchers analyzed an adapted version of the 1988 NAEP attitude survey and found there was a statistically significant difference in student attitudes towards writing, $t=5.34, p<.01$, and mathematics, $t=4.97, p<.01$, between pre-test and post-test ratings. In addition, the attitude toward mathematics changed from an average mean of 2.39 to 2.68 which is an effect size of .64. This is considered a medium effect according to Cohen (1988). A significant difference was also detected between actual and preferred learning environments with students preferring less friction and the actual classroom environment having higher friction, $t=-8.07, p<.01$; students preferring less competition while the actual classroom environment had higher competition, $t=-8.08$, $p<.01$; and students preferring more cohesiveness while the actual classroom environment had low cohesiveness, $t=-8.16, p<.01$. The effect sizes for the differences in scores ranged from .76 to .89 which indicates a medium to large effect (Cohen, 1988).

\section{Reliability and Validity of Reviewed Studies}

Reliability of Scores. According to Henson (2001), reliability is critical when interpreting the effects of studies and test results. He states "the more measurement error that exists in our scores, the less useful these scores may be for analysis, interpretation, and clinical purposes" (p. 179). Three of the seven studies provided reliability estimates on student scores. Mink and Fraser (2002) reported the Chronbach's alpha coefficient for both the Attitude Scale and the My Class Inventory scale (Fraser, Anderson, \& Walberg, 1991). The Chronbach's alpha coefficients ranged 
from .42 to .64 for the Attitude Scale which is considered undesirable to minimally acceptable (Henson, 2001). The Chronbach's alpha coefficients ranged from .64 to .89 for the My Class Inventory scale, which is considered minimally acceptable to very good (Henson, 2001). Capraro and Capraro (2006) reported Chronbach's alpha coefficients for the three measures used to assess student learning. The Chronbach's alpha coefficients for pre and post general reading scores $(\alpha=.78 ; \alpha=.89)$ and general mathematics scores $(\alpha=.82 ; \alpha=.95)$ are considered respectable to very good, while the pre and post general geometry scores are considered unacceptable $(\alpha=.45)$ to very good $(\alpha=.93)$ (Henson, 2001). Finally, Casey, et al. (2008) reported the Chronbach's alpha coefficients for the Kaufman - Assessment Battery for Children (K-ABC) on student scores $(\alpha=.86-.93)$, which are considered very good (Henson, 2001).

Procedural Reliability. According to Kennedy (2005), when collecting observational data, reliability is important because it can estimate how consistent data collectors are when collecting data during the study. It can also be used as an attempt to avoid observer drift. No studies reported interobserver agreement or teacher fidelity measures on observational data. The absence of procedural reliability poses threats to both internal and external validity, which limits the reliability of the results.

Threats to Internal Validity. Internal validity can be described as the degree to which a researcher can be confident that the independent variable is what changed the behavior, not the extraneous variables (Kennedy, 2005). Threats to internal validity are those other possible causes, or extraneous variables, that may have influenced the change in the behavior; and the extent to which you control these threats will 
determine the level of confidence in the findings (Gast, 2010). Three types of threats to internal validity were identified in the studies under review.

History. History effects are any events that occur during an experiment, and after the introduction of the independent variable, that have the potential to influence the outcome (Gast, 2010). Four studies mentioned the possibility of history effects. Jennings, et al. (1992) noted that realistic props and other manipulatives related to the children's story were placed in the centers, which provided opportunities for students in the experimental group to extend their learning. Since these materials were not provided for centers in the control group, it leads to the possibility that these materials may have contributed to the positive effects attained in the study. Similarly, YoungLoveridge (2004) admitted that incorporating mathematics games with children's literature makes it difficult to determine whether one approach was more effective than the other. When discussing the results of the standardized mathematics achievement test, Hong (1996) noted that the students' homework might have affected the results. He reported that $89.7 \%$ of the experimental group and $78.6 \%$ of the control group completed mathematics worksheets at home. Because the exercises on the homework worksheets were similar to the items on the test, it may have led to the insignificant results.

Instrumentation. Instrumentation threats refer to concerns regarding the measurement systems being used in the study (Gast, 2010). Two studies mentioned the possibility of instrumentation effects. Jennings, et al. (1992) considered factors that could have led to the discrepancy of results between the two standardized mathematics 
tests used; the Test of Early Mathematics Abilities (TEMA) and the Metropolitan Readiness Test (MRT). They stated the TEMA was administered individually and measured understanding at the concrete, semi-concrete, and abstract level. In contrast, the MRT was administered in a group setting and measured understanding at the semiconcrete and abstract level. The differences in obtained results leads to questions regarding which measurement instrument accurately assessed student learning through children's literature.

Capraro and Capraro (2006) posed questions regarding the possibility of one of their measurement instruments influencing results. The researchers reported that the statistically significant difference between scores on the general mathematics test should be viewed cautiously since 12 of the 63 items on the test were comprised of geometry concepts. They stated that it is reasonable that an increase in geometry performance on the 12 items could have accounted for the obtained statistically significant difference in scores.

Selection Bias. Selection refers to the differences in subject characteristics that could also cause the observed effect (Shadish, Cook, \& Campbell, 2002). Jennings, et al. (1992) reported that the four teachers in the study were selected from a pool of teachers identified as doing a good job of teaching number concepts and operations. By only selecting the highest quality teachers, the results (positive or negative) could be attributed, at least in part, to the quality of teaching and not the intervention alone. 


\section{External Validity and Generalization of Reviewed Studies}

External validity refers to whether the relationship between the independent variable(s) and dependent variable(s) hold across persons, settings, treatments, and outcomes that were in the experiment and across persons, settings, treatments, and outcomes not in the experiment (Shadish, et al., 2002). Five of the seven studies under review addressed generalization (Casey, et al., 2008; Hong, 1996; Jennings, et al., 1992; Keat \& Wilburne, 2009; Young-Loveridge, 2004). The authors suggested future research should be conducted across persons (e.g., different ages and/or grades, larger sample size, and different socioeconomic groups), settings (e.g., urban and/or suburban communities, and subject areas), and time (e.g., examine maintenance of effect over time and longitudinal studies) to improve the external validity and reliability of the findings.

\section{Social Validity of Reviewed Studies}

Kennedy (2005) describes social validity as "the estimation of the importance, effectiveness, appropriateness, and/or satisfaction various people experience in relation to a particular intervention" (p. 219). It is important when evaluating interventions in educational settings to determine if the intervention is not only effective for students, but also efficient and teacher-friendly in order to increase the likelihood that teachers will use the strategy in the future. Six studies (Capraro \& Capraro, 2006; Hong, 1996; Jennings, et al., 1992; Keat \& Wilburne, 2009; Mink \& Fraser, 2002; Young-Loveridge, 2004) assessed the social validity of the interventions on students and teachers. 
Students. Jennings, et al. (1992) collected observational data that included comments made by parents. Remarks from parents included, "I didn't know children this young could learn this much math" and "Shayla was so excited about measuring, she wanted to measure everything at home" (p. 271). Parents also reported their children asked to have the stories read to them at home. Keat and Wilburne (2009) interviewed teachers and indicated the teachers were surprised at the level of student interest when answering questions related to the children's book compared with questions posed in the mathematics book. One teacher noted the children "eagerly shouted out answers, explained their reasoning, and demonstrated continued interest in the subject even when their reasoning led them to inaccurate answers" (p. 64). Teachers in the Mink and Fraser (2002) study remarked they were impressed that the students worked well in groups and had fun learning. One teacher reported, "I think the most significant changes were in students' attitudes toward learning mathematics and changes in the classroom environment" (p. 20).

Teacher. The teacher implementing the intervention in the Hong (1996) study suggested that children's literature could easily be adapted to her existing mathematics program and can be taught with joy. This provides evidence that integrating children's literature into mathematics instruction can be practically implemented by the teacher. In contrast, Young-Loveridge (2004) did maintenance testing six months and fifteen months after the intervention and found that the classroom teachers were not continuing to use the number books and games program. Although no reason was 
given, the absence of continued implementation raises doubt that the program was viewed as important or practical to the teacher.

\section{Discussion}

The purpose of this literature review was to provide a critical analysis of the effects of using children's literature to teach mathematics on the academic and behavioral outcomes of students with academic difficulties and challenging behaviors. The overall results of the studies suggest a positive relationship between children's literature in mathematics instruction and mathematics achievement along with other factors related to student engagement in mathematics. Although the results were positive, analysis of the literature reveals specific areas in need of further examination that include: the need for generalization across persons and settings; and the effects of children's literature on student engagement, inappropriate student behavior, and teacher behavior. These areas will be discussed in greater detail next.

\section{Generalization}

The extensive search for published articles only revealed seven studies. The paucity of empirically-validated research on the effectiveness of incorporating children's literature in mathematics instruction is a major issue. Gast (2010) states that, "through the replication process the science of human behavior is advanced and our ability to design effective and efficient instructional and treatment programs enhanced" (p. 128). Future studies examining the effectiveness of integrating children's literature in mathematics instruction are needed across persons and settings to support and extend prior research. 
Across Persons. There is a specific need for research in this area for students with academic difficulties in mathematics or challenging behaviors since no studies were found that addressed this population. With $80 \%$ of all students with disabilities (ages 6 -21) spending at least some portion of their day in a regular education classroom and $58 \%$ spending $80 \%$ or more of their day in a regular education classroom (Data Accountability Center, 2010), it is essential that both special education and general education teachers are implementing evidence-based practices. More specifically, future studies should investigate if integrating children's literature in mathematics instruction can be effective in increasing academic achievement and on-task behavior, while decreasing inappropriate and/or disruptive classroom behaviors for students with academic difficulties in mathematics or challenging behaviors.

Across Settings. There is also a need for research on integrating children's literature in mathematics instruction across settings. Of the seven studies in this review, five were implemented in kindergarten settings, one in a fifth grade setting, and one in a sixth grade setting. Settings should not only include other grade levels in elementary, but also evaluate the effectiveness of this practice in middle and high school settings. Studies in this review were also conducted predominantly in the general education classroom while only one study was conducted by pulling out participants in pairs to a separate room. Future research should be conducted in smaller group settings that could include self-contained classrooms for students with learning disabilities (LD) or emotional behavior disorders (EBD) and intervention groups for students struggling in mathematics. 
In addition to different grade levels and classroom settings, future studies evaluating the effects of integrating children's literature in mathematics instruction should include different content areas in mathematics, especially those identified as a critical concern. An example of this can be found in The Final Report of the National Mathematics Advisory Panel (2008). The panel concluded that algebra is a central concern because it is a "demonstrable gateway to later achievement" (p. 3). The panel recommended that the "teaching of fractions must be acknowledged as critically important and improved before an increase in student algebra can be expected" (p. 18) and "proficiency with whole numbers, fractions, and particular aspects of geometry and measurement should be understood as the critical foundation of Algebra". (p. 18). Future studies revealing the positive effects of children's literature on academic achievement in algebra, or its foundational skills or concepts, could help provide research-based strategies to address these critical areas.

\section{Student and Teacher Behavior}

Student Behavior. The studies in this review examined the effects of integrating children's literature in mathematics instruction on student engagement through variables such as student interest, student disposition, student mathematical communication, and student confidence in mathematics. Furthermore, most of these were assessed through qualitative measures, and variables such as student on-task or inappropriate behaviors were not measured. As previously mentioned, researchers have suggested that there is a relationship between inappropriate classroom behaviors and low levels of academic achievement (Nelson, et al., 2004; Sutherland \& Wehby, 
2001). Although it is not clear which causes the other, there appears to be a reciprocal relationship between behavior and academic achievement (Sutherland \& Wehby, 2001). Future research studies which examine the effects of integrating children's literature in mathematics instruction on student behavioral outcomes could support and extend the prior research in this area.

Teacher Behavior. No studies in this review examined the effects of integrating children's literature in mathematics instruction on teacher behaviors. Teacher behaviors such as increasing students' opportunities to respond and increasing rates of praise could be beneficial for positive student-teacher interaction, which is especially crucial for students with behavioral problems. For example, a study conducted by Hamre and Pianta (2001) which followed students from Kindergarten to eighth grade, suggested that negative relationships between teachers and students with behavior problems in Kindergarten are associated with academic and behavioral problems through eighth grade. In addition, instructional interactions between teachers and students with behavior problems consist of less than $30 \%$ of all teacher-student interactions and, of these interactions, students at-risk for aggressive behaviors received low rates of praise while receiving high rates of reprimands (Van Acker, Grant, \& Henry, 1996; Wehby, et al., 1998). Sutherland, Wehby, and Yoder (2002) investigated the relationship between teacher praise and OTR in classrooms and their findings suggest there is a significant positive relation between the two. Giving students with problem behaviors sufficient opportunities to respond can allow for positive reinforcement following the student response, which can lead to positive teacher-student interactions. 
In summary, the studies in this literature review suggest that integrating children's literature in mathematics instruction can have a positive impact on students' academic (e.g., general mathematics, number skills, and geometry) and behavioral outcomes (e.g., increasing student disposition towards mathematics, increasing student mathematical communication, raising student confidence in mathematics, and increasing positive student attitude), but there is a need for additional studies to empirically validate this practice. Although the results were positive, there are still questions about whether the effects of using children's literature to teach mathematics can increase academic and behavioral outcomes of students with academic difficulties or challenging behaviors. 
Table 2-1. Children's Literature and Mathematics Studies

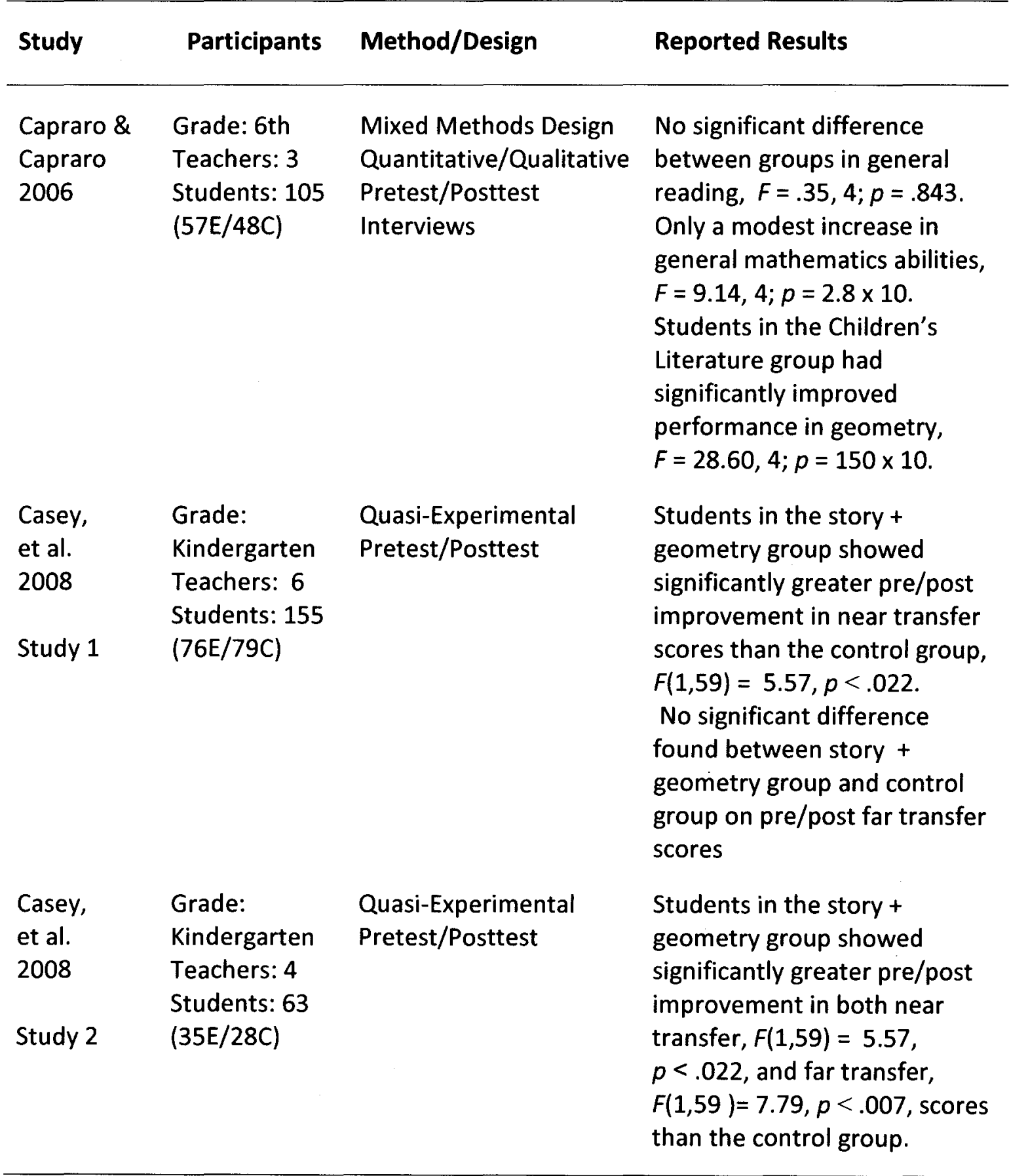

$E=$ Experimental Group; $C=$ Control Group

(Table continues on next page) 


\begin{tabular}{|c|c|c|c|}
\hline Study & Participants & Method/Design & Reported Results \\
\hline $\begin{array}{l}\text { Hong } \\
1996\end{array}$ & $\begin{array}{l}\text { Grade: } \\
\text { Kindergarten } \\
\text { Teachers: } 2 \\
\text { Students: } 57 \\
(29 \mathrm{E} / 28 \mathrm{C})\end{array}$ & $\begin{array}{l}\text { Quasi-Experimental } \\
\text { Pretest/Posttest } \\
\text { Observation }\end{array}$ & $\begin{array}{l}\text { No significant difference } \\
\text { between groups in general } \\
\text { mathematics achievement, } \\
t=.37, p<.71 \text {. } \\
\text { Students in the children's } \\
\text { literature group had a } \\
\text { statistically significant higher } \\
\text { mean of correct responses on } \\
\text { classification, } t=2.16, p=.04 \text {, } \\
\text { number combination, } \\
t=4.34, p=.0001, \text { and shape } \\
\text { tasks, } t=3.15, p=.004 \text {. }\end{array}$ \\
\hline $\begin{array}{l}\text { Jennings, } \\
\text { et al. } \\
1992\end{array}$ & $\begin{array}{l}\text { Grade: } \\
\text { Kindergarten } \\
\text { Teachers: } 4 \\
\text { Students: } 61 \\
(29 E / 32 C)\end{array}$ & $\begin{array}{l}\text { Quasi-Experimental } \\
\text { Pretest/Posttest } \\
\text { Observation }\end{array}$ & $\begin{array}{l}\text { Students in the children's } \\
\text { literature group showed } \\
\text { significantly greater pre/post } \\
\text { improvement in TEMA } \\
\text { mathematics achievement } \\
\text { scores, than the control group } \\
t(59)=5.57, p<.01 \text {. } \\
\text { No significant difference } \\
\text { between groups on the MRT } \\
\text { quantitative concepts scores, } \\
t(59)=1.56, p<.12, \text { and MRT } \\
\text { quantitative operations } \\
\text { scores, } t(59)=.29, p<.77 \text {. } \\
\text { Students in children's } \\
\text { literature group used } \\
\text { significantly more words in all } \\
7 \text { concept categories during } \\
\text { free play than the control } \\
\text { group, } x^{2}(6,61)=293, p<.01 \text {. }\end{array}$ \\
\hline $\begin{array}{l}\text { Keat \& } \\
\text { Wilburne } \\
2009\end{array}$ & $\begin{array}{l}\text { Grade: } \\
\text { Kindergarten } \\
\text { Teachers: } 3 \\
\text { Students: } 70\end{array}$ & $\begin{array}{l}\text { Mixed Methods Design } \\
\text { Quantitative/Qualitative } \\
\text { Pretest/Posttest } \\
\text { Interviews }\end{array}$ & $\begin{array}{l}\text { Comparison of pre/post test } \\
\text { scores showed improvement } \\
\text { in performance on coin } \\
\text { recognition and coin value. }\end{array}$ \\
\hline$E=$ Experime & roup; $C=$ Con & roup & (Table continues on next page) \\
\hline
\end{tabular}




\begin{tabular}{|c|c|c|c|}
\hline Study & Participants & Method/Design & Reported Results \\
\hline $\begin{array}{l}\text { Mink \& } \\
\text { Fraser } \\
2002\end{array}$ & $\begin{array}{l}\text { Grade: } 5 \text { th } \\
\text { Teachers: } 6 \\
\text { Students: } 120\end{array}$ & $\begin{array}{l}\text { Quasi-Experimental } \\
\text { Pretest/Posttest } \\
\text { Observation }\end{array}$ & $\begin{array}{l}\text { There was a statistically } \\
\text { significant difference in } \\
\text { student attitudes towards } \\
\text { writing, } t=5.34, p<.01 \text {, and } \\
\text { mathematics, } t=4.97 \text {, } \\
p<.01 \text {, between pretest and } \\
\text { posttest. } \\
\text { Students prefer less friction, } \\
\text { less competition, and more } \\
\text { cohesiveness. }\end{array}$ \\
\hline $\begin{array}{l}\text { Young- } \\
\text { Loveridge } \\
2004\end{array}$ & $\begin{array}{l}\text { Grade: } \\
\text { Kindergarten } \\
\text { Teachers: N/A } \\
\text { Students: } 106 \\
(23 E / 83 C)\end{array}$ & $\begin{array}{l}\text { Quasi-Experimental } \\
\text { Pretest/Posttest }\end{array}$ & $\begin{array}{l}\text { Students in the children's } \\
\text { literature group showed } \\
\text { significantly greater pre/post } \\
\text { improvement in numeracy } \\
\text { scores than the control group, } \\
F(1,97)=45.91, p<.001 \text {, but } \\
\text { the differences diminished } \\
\text { over } 6 \text { months, } F(1,97)=6.95 \text {, } \\
p<.05 \text {. }\end{array}$ \\
\hline
\end{tabular}

$\mathrm{E}=$ Experimental Group; $\mathrm{C}=$ Control Group 
CHAPTER 3

METHODS

The purpose of this chapter is to describe the procedures that were followed to conduct the study. Specifically, this chapter describes: (a) the research design; (b) participant selection and setting; (c) independent variable; (d) dependent measures and recording procedures; (e) reliability and validity, including procedures to collect interobserver agreement, treatment integrity, and social validity; and (e) limitations of the study. The purpose of this study was to examine the effects of integrating children's literature in mathematics instruction on the academic and behavioral outcomes for students with academic difficulty and challenging behaviors. The study attempted to answer the following primary research questions listed in order of importance: (1) Will integrating children's literature in mathematics instruction increase student engagement while reducing disruptive behaviors during mathematics instruction for students with academic difficulties and challenging behaviors?; (2) Does integrating children's literature in mathematics instruction increase the teacher's rate of providing opportunities for students to respond during mathematics instruction?. In addition, the study included a secondary research question: Will integrating children's literature in mathematics instruction increase mathematics achievement for students with academic difficulties and challenging behaviors?. 


\section{Experimental Design}

The study implemented a multimethod design to answer the three research questions. The advantages of using a multimethod design include the ability to obtain multiple levels of data (Morse, 2003). A single subject research design was used to assess teacher and student behavior and two pretest/posttest designs were used to assess academic achievement.

A single subject, multiple baseline design across participants (Gast, 2010) was used to examine the effectiveness of integrating children's literature in mathematics instruction on increasing student engagement while reducing disruptive behaviors for students with academic difficulties and challenging behaviors; and increasing the teacher's rate of providing opportunities for students to respond. Implementation of the design started with baseline measurement of all participants. When baseline data of the first participant were stable for at least three consecutive sessions (i.e., less than ten percent variability of the data points), the intervention was introduced to the first participant only while continuous data was collected on all the other participants under pre-intervention conditions. When the first participant reached the specified criterion of at least three data points of an increasing level or trend and the baseline data were stable for the second participant, the intervention was applied to the second participant while continuous data collection under pre-intervention conditions continued to be collected on the third participant. When the second participant reached the specified criterion of at least three data points of an increasing level or trend and the baseline data were stable for the third participant, the intervention was applied to the third 
participant. When the third participant reached the specified criterion of at least three data points of an increasing level or trend and the baseline data were stable for the fourth participant, the intervention was applied to the fourth participant.

The multiple baseline design across participants offers multiple advantages. First, this design provides practical means for continuous evaluation of intervention programs in which withdrawal of the intervention is not logistically possible. Second, because withdrawal or reversal of the design is not required and every participant receives the intervention, it is viewed as a more practical and ethical design. Third, it helps build external validity due to the inter-subject replication within the design. Finally, this design allows for maintenance data to be collected once a participant reaches a set criterion while other participants are still in the intervention and/or baseline phase.

Two pretest/posttest designs were used to assess academic achievement. A one-group pretest/posttest design (Shadish, et al., 2002) was used to examine the academic achievement of the participants on three general content areas (i.e., basic concepts, operations, and applications) through a norm-referenced, standardized assessment. A single pretest was administered, the intervention occurred, and then a single posttest followed. The diagram for this design is:

$$
\mathrm{O}_{1} \quad \mathrm{X} \quad \mathrm{O}_{2}
$$

According to Shadish, et al. (2002), this design helps with statistical analysis of the dependent variable especially if the reliability of the measure is known but state that this design provides "weak information about the counterfactual inference concerning 
what might have happened to the participants had the treatment not occurred" ( $p$. 108). This is mainly due to threats to validity that include maturation and history effects. To control for maturation, this study attempted to keep the interval between pretest and posttest short with the study lasting approximately eight weeks.

In an attempt to account for the weak inferences of the design described above, a one-group pretest/posttest design using a double pretest (Shadish, et al., 2002) was also used to examine the academic achievement of the participants. The assessments were based on the content being taught during the period in which the study was conducted through a norm-referenced, standardized assessment. A pretest was administered to all participants at the beginning of the study. The second pretest was administered to each participant when the individual participant met the criteria for intervention established in the multiple baseline design across participants and prior to receiving the intervention. The single posttest was administered following the intervention. The diagram for this design is:

$$
\mathrm{O}_{1} \quad \mathrm{O}_{2} \quad \mathrm{X} \quad \mathrm{O}_{3}
$$

The double pretest offers multiple advantages. According to Shadish, et al. (2002), the double pretest allows the researcher to examine pre-treatment growth rates with posttest rate changes, helps in assessing the plausibility of selection-maturation threats, and helps reveal regression effects. Additionally, Shadish, et al. (2002) state:

The double pretest helps estimate more precisely the correlation between observations at different times, something of great value in the statistical analysis. Without the extra time point, the correlation between $\mathrm{O}_{2}$ and $\mathrm{O}_{3}$ in the treated group gives an unclear estimate of what the correlation would have been in the absence of a treatment. (p. 145-146) 


\section{Participants and Setting}

In accordance with the policies set forth by the University of Louisville Institutional Review Board, participant consent forms were obtained from the participating teacher and parent or guardian of the student participants before conducting the study. (See Appendix A for teacher consent form; Appendix B for student consent form; and Appendix C for student assent form.)

\section{Students}

A total of four students (referred to as S1 through S4) were selected as participants. Students eligible for participation in the study were in elementary school, grades three through five, and in separate Tier II mathematics groups from other participants. Students were identified by the following criteria: (a) as performing below grade level in mathematics and receiving Tier II mathematics intervention instruction; (b) receiving three or more office referrals in the current school year; and/or (c) receiving special education services for a learning or behavioral disorder (e.g., mathematics disability, reading disability, Mild Mental Disability, Emotional Behavior Disorder or Other Health Impaired). Students not eligible for participation were those that did not meet the criteria above as well as those in the same Tier II mathematics groups as other participants. Table 1 gives a detailed summary of the participants included in the study. 
Table 3-1: Description of Participants

\begin{tabular}{ccccccc}
\hline Student & Age & Grade & Gender & Ethnicity & $\begin{array}{c}\text { Office } \\
\text { Referrals }\end{array}$ & $\begin{array}{c}\text { Grade Level } \\
\text { Equivalency }\end{array}$ \\
\hline S1 & 11 & 5 & Female & $\begin{array}{c}\text { African } \\
\text { American }\end{array}$ & 3 & 3.6 \\
S2 & 9 & 3 & Male & $\begin{array}{c}\text { African } \\
\text { American }\end{array}$ & 4 & 1.5 \\
S3 & 9 & 3 & Male & Caucasian & 15 & 2.5 \\
S4 & 9 & 3 & Male & Caucasian & 3 & 2.7 \\
\hline
\end{tabular}

${ }^{\text {a }}$ Grade level equivalency score determined using the KeyMath3 Diagnostic Assessment.

Teacher

The teacher eligible for participation was a Caucasian female responsible for the Tier II mathematics instruction of the student participants. The teacher had eight years teaching experience and had been teaching at the current school for the last six years. At the time of the study, she was working towards her master's degree in special education with emphasis in learning and behavior disorders.

\section{Setting and Existing Mathematics Program}

Setting. The setting for the study was a Tier II mathematics intervention classroom in a public elementary school in a large midwestern city. Each observed intervention group consisted of three students and was thirty minutes in duration.

Existing Mathematics Program. The Tier II Mathematics intervention program being implemented by the teacher was SRA Number Worlds: A Prevention/Intervention Math Program (Griffin, 2007). Number Worlds is an intensive intervention program that focuses on elementary students that are one or more grade levels behind in 
mathematics. The core content topics being covered during the study included number sense, addition, geometry and measurement, and data analysis and applications.

\section{Independent Variable}

The independent variable, or intervention, in the study was integrating children's literature in mathematics instruction. Prior to the start of the study, the researcher reviewed the mathematics content and concepts for the six week period using the Number Worlds Teacher Edition (Level D and Level E) and selected children's books that related to the concepts being covered. To locate children's books for inclusion in the study, several strategies were used. The first strategy involved an exhaustive search of children's books related to the concepts of number sense (specifically place value), addition, geometry and measurement, and data analysis and applications. The following resources were used to aid in the search for the children's books: (1) a list of children's books created by a distinguished mathematics professor at the University of Louisville and (2) books pertaining to teaching mathematics and literature such as Math Through Children's Literature: Making the NCTM Standards Come Alive (Braddon, Hall, \& Taylor, 1993; How To Use Children's Literature to Teach Mathematics (Welchman-Tischler, 1992); Exploring Mathematics through Literature: Articles and Lessons for Prekindergarten through Grade 8 (National Council of Teachers of Mathematics, 2004); Math and Literature: Grades K-1 (Burns \& Sheffield, 2004); and Math and Literature: Grades 2-3 (Burns \& Sheffield, 2004).

Once a list of books was created by the researcher, using the website Amazon.com, the researcher searched all the book titles found using the first strategy. 
The search included reviewing the editorial reviews of each book as well as finding additional books that were not previously found using the first strategy. Next, the researcher obtained and reviewed the books from the list to determine if they were related to the concepts being covered (approximately 54 books). Finally, the book selection was narrowed down to thirteen books that were included in the study.

Table 3-2: Books Included in Study

\begin{tabular}{|c|c|c|}
\hline Group & Content Topic & Books \\
\hline \multirow[t]{5}{*}{ S1 Group } & Data Analysis/Place Value & Lemonade for Sale (Murphy, S.J., 1998) \\
\hline & & Fair Is Fair (Dussling, J., 2003) \\
\hline & & Alexander, Who Used to Be Rich Last Sunday \\
\hline & & (Viorst, J., 2003) \\
\hline & & Earth Day - Hooray! (Murph, S.J., 2004) \\
\hline \multirow[t]{4}{*}{ S2 Group } & Addition & $\begin{array}{l}\text { "Band-Aids" from Where the Sidewalk Ends } \\
\text { (Silverstein, S., 1974) }\end{array}$ \\
\hline & & 12 Ways to Get to 11 (Merriam, E., 1993) \\
\hline & & How Many feet in the Bed (Hamm, D.J., 1991) \\
\hline & & Cats Add Up (Ochiltree, D., 1998) \\
\hline \multirow[t]{3}{*}{ S3 Group } & Geometry \& Measurement & Chickens on the Move (Pollack, P., 2002) \\
\hline & & Carrie Measures Up (Aber, L.W., 2001) \\
\hline & & The Greedy Triangle (Burns, M., 1994) \\
\hline \multirow[t]{3}{*}{ S4 Group } & Addition & $\begin{array}{l}\text { "Band-Aids" from Where the Sidewalk Ends } \\
\text { (Silverstein, S., 1974) }\end{array}$ \\
\hline & & 512 Ants on Sullivan Street (Losi, C.A., 1997) \\
\hline & & Guinea Pigs Add Up (Cuyler, M., 2010) \\
\hline
\end{tabular}

\section{Lesson Plans}

The researcher created lesson plans for the unit that supplemented the existing mathematics program with the selected children's books. The lesson plans used the content in the children's books to introduce new concepts, reinforce concepts already learned, and/or expand on previous concepts learned (See Appendix D for lesson plans). 


\section{Procedures}

Instructional Procedures

The lessons lasted approximately ten minutes. During the interactive read aloud, the teacher was expected to use the following guidelines:

1. Read the title and give students an opportunity to predict what the story will be about. This includes prompting students to think about the mathematical concepts to be discussed. Examples of prompts could include "Do you think there will be any mathematics in this book? Why?"

2. Model how to find "how old the book is" or the book's birthday. This is done through showing the students the year of publication and subtracting this number from the present year. Teacher will be required to use strategies other than the standard algorithm and solicit students' ideas and strategies (i.e., tens and ones).

3. Ask students questions related to mathematical concepts in the book during the read aloud. Examples of questions could include "How would you solve this?"

4. Model a strategy for answering a question related to the book during read aloud.

5. Give students manipulatives to work out problems associated with the book, if applicable.

6. Conclude the read aloud by reviewing concepts discussed in the book.

Following the read aloud, the teacher implemented the existing mathematics program for the remainder of the period. The teacher was encouraged to relate concepts being learned during instruction to the concepts discussed earlier during the read aloud. 


\section{Dependent Measures \& Recording Procedures}

The dependent measures for this study were the following: (1) student academic achievement, (2) teacher behavior, and (3) student behavior (See Appendix E for observation coding variables). Academic data was collected at the beginning of the study, just prior to introduction of the intervention, and again at the end of the study. Behavioral data was collected continuously throughout the seven week study. Behavior data collection sessions began at the start of the lessons and were 10 minutes in length.

Student Academic Achievement. Two pretest/posttest designs were used to assess academic achievement. Both designs measured student academic achievement using the KeyMath3 Diagnostic Assessment (Connolly, 2007). The KeyMath3 is organized into 10 subtests (numeration, algebra, measurement, geometry, data analysis and probability, mental computation and estimation, addition and subtraction, multiplication and division, foundations of problem solving, and applied problem solving) that represent three general mathematics content areas [Basic Concepts (conceptual knowledge), Operations (computational skills), and Applications (problem solving)]. This assessment was chosen because it is a norm-referenced assessment designed for students in grades K-12 and assesses mathematical concepts and skills aligned with the five content standards of the National Council of Teachers of Mathematics (NCTM) (Connolly, 2007). In addition, there are two parallel assessments, Form $A$ and Form $B$, which can reduce any threat to testing effects.

The one-group pretest/posttest design was used to measure student academic achievement using the three general mathematics content areas [Basic Concepts 
(conceptual knowledge), Operations (computational skills), and Applications (problem solving)]. The one-group pretest/posttest design using a double pretest was used to measure student academic achievement using the specific subtests related to the content and concepts being taught to each participant during the study. The following subtests were given to the participants: S1 was given the Data Analysis and Probability and Numeration subtests, S2 was given the Addition and Mental Computation and Estimation subtests; $\mathrm{S} 3$ was given the Geometry and Measurement subtests, and S4 was given the Addition and Mental Computation and Estimation subtests.

Teacher Behavior. The teacher behaviors being observed were levels of giving opportunities to respond (OTR) which was measured using frequency recording. The levels of OTR were classified as either OTR group and OTR individual. OTR group was defined as the teacher providing an opportunity to respond that is directed to the whole class. To be considered OTR group, the request or prompt must be related to the lesson content. OTR individual was defined as the teacher providing an opportunity to respond to a student participant in the class. As with OTR group, the request or prompt must be related to the lesson content.

Student Behavior. The observed student behaviors were levels of engagement which was measured using duration recording. According to Kennedy (2005), duration recording is appropriate when measuring how long a behavior occurs and advantages include being more accurate than interval recording and relatively simple to implement. The disadvantage to duration recording is it does not give information about the frequency or mean duration per occurrence (Gast, 2010). 
The levels of engagement were classified as active engagement, passive engagement, and off-task behavior. For the student to be considered actively engaged in the instructional lesson, he or she had to be responding to teacher prompt or instruction which included: (a) choral responding, (b) verbally answering a teacher directed question, (c) raising hand, (d) writing, or (e) reading. For the student to be considered passively engaged in the instructional lesson, he or she had to be looking in the direction of teacher or looking at another student who is called on to speak by the teacher. The student was considered off-task when he or she did not meet the definition of either being actively or passively engaged. Examples of off-task behavior include student out of seat without permission, looking away from teacher or instructional materials, not complying with teacher request, or having head down on desk with eyes closed.

In addition to levels of engagement, disruptive behavior was measured through frequency recording. A disruptive behavior was defined as the student displaying behavior that disrupts, or potentially disrupts, the entire class or an individual peer. Examples of disruptive behavior include such situations as student being out of seat without permission, talking to another student without permission, making noises either verbally or through action (e.g., tapping loudly on desk and crumbling or ripping paper), arguing or threatening student or teacher, or verbally refusing to complete an assignment or comply with teacher direction.

Behavioral data was collected using the MOOSES ${ }^{\text {TM }}$ (Multi-Option Observation System for Experimental Studies) software program (John Tapp, Vanderbilt University) 
on a handheld PDA computer. The system allows for the collection and analysis of continuous data on both the frequency and duration of teacher and student behaviors through allowing the user to produce code sets that are specific to the individual's research questions. For this study, the code sets included OTR group, OTR individual, Disruption, Active Engagement, Passive Engagement, Off-task, and Downtime. For a more detailed description of the MOOSES ${ }^{\mathrm{TM}}$ software program, the MOOSES Version 3 Users Manual can be located at the following web address: (kc.vanderbilt.edu/ mooses/download/Mooses_Manual.pdf).

Behavioral data collection procedures consisted of the observer positioning themselves in an area within the setting that provided constant observational access (i.e., clear vision of the target student and able to hear both teacher and student) without being a disruption to the learning environment. All coding sessions began at the beginning of the mathematics lesson and each coding session was ten minutes in duration. Using the Mini-Moose software on a handheld PDA computer, the observer used the stylus to code student and teacher behaviors during the ten minute observation (See Appendix E for observation coding variables). To ensure accuracy of the observations, the following rules were applied: (1) For duration recording (i.e., active engagement, passive engagement, off-task, and downtime), the observer silently counted five seconds before coding the event; (2) for frequency recording (i.e., OTR group, OTR individual, disruption), the observer waited until the end of the question/prompt before coding. After the coding sessions, the data from the handheld 
PDA computer was synced and transferred to a password-protected computer containing the MOOSES ${ }^{\mathrm{TM}}$ software program for analysis.

\section{Reliability and Validity}

Reliability Observers. The researcher was the main data collector but used two data collectors for interobserver reliability. The data collectors had prior experience using the handheld PDAs for collecting behavioral data in the classroom setting as well as the observational codes being used in the current study. The first data collector had approximately two years experience collecting data with the handheld PDA and the second data collector had four months experience collecting data with the handheld PDA.

Prior to data collection, the researcher met with the first data collector and reviewed the definitions of each observational code as well as answered any questions and/or issues that could arise during data collection sessions. Next, the researcher and data collector conducted a practice session in a live observation setting. The data collector was considered ready for observations once $80 \%$ reliability was achieved in the live observation training session. Furthermore, to control for observer drift, the researcher met with the data collector ten minutes before each observation to review the observational codes as well as answering any questions and/or issues that occurred during the previous observational session. This ensured that the original definitions used by the observers did not change during the course of the study (Kennedy, 2005).

Due to uncontrollable circumstances, the first data collector was no longer available for observations midway through the study and a second data collector was 
used for the remainder of the study. The training for the second data collector was the same as the training for the first data collector. Prior to data collection, the researcher met with the data collector and reviewed the definitions of each observational code as well as answered any questions and/or issues that could arise during data collection sessions. Next, the researcher and data collector conducted a practice session in a live observation setting. The data collector was considered ready for observations once $80 \%$ reliability was achieved in the live observation training session. Furthermore, to control for observer drift, the researcher met with the data collector ten minutes before each observation to review the observational codes as well as answering any questions and/or issues that occurred during the previous observational session.

Interobserver Reliability. Interobserver reliability was conducted to determine the extent to which observers agreed on the data collected from behavioral observations for at least $20 \%$ of the sessions and at least once per condition. The MOOSES ${ }^{\mathrm{TM}}$ software program provided an estimate of agreement using two methods. For reliability of duration recording, a method using second-by-second comparisons was used to calculate the agreement ratio (agreements divided by total seconds). For reliability of frequency recording, a method using time window analysis was used to calculate the agreement ratio (agreements divided by the sum of agreements plus disagreements). An agreement was defined as two independent observers scoring the same code within a 5-second window. It was predetermined that dependent variable reliability data would be at least $80 \%$ across all phases to establish confidence in the data collected. 
Percentages of interobserver agreement are reported in Table 3-3.

Interobserver reliability was conducted for 18 of the 67 overall observations $(M=26 \%)$. Interobserver reliability was conducted for eight of the 29 baseline condition observations $(M=27 \%)$ and for 10 of the 38 intervention condition observations $(M=$ $26 \%)$. The percentage of agreement across all variables was calculated by dividing the total agreements by the sum of total agreements plus total disagreements $(A / A+D)$. The percentage of agreement across all variables using frequency recording (OTR Group, OTR Individual, and disruption) was $94 \%$ during baseline condition, $95 \%$ during intervention condition, and 95\% overall. The percentage of agreement across all variables using duration recording (off-task, passive engagement, and active engagement) was $96 \%$ during baseline condition, $98 \%$ during intervention condition, and $97 \%$ overall.

Table 3-3: Interobserver Agreement Data

\begin{tabular}{lccc}
\hline & \multicolumn{3}{c}{ Percentage of Agreement } \\
\cline { 2 - 4 } & Baseline & Intervention & Overall \\
\hline OTR Group & .91 & .97 & .95 \\
OTR Individual & .95 & .94 & .94 \\
Disruption & .97 & .91 & .95 \\
Off-Task & .96 & .99 & .98 \\
Passive Engagement & .94 & .95 & .94 \\
Active Engagement & .97 & .98 & .98 \\
\hline
\end{tabular}

Procedural Reliability. Independent variable reliability data was collected by using a teacher fidelity checklist for $39 \%$ of the intervention sessions (see Appendix $F$ for Teacher Fidelity Checklist). The number of observed teacher behaviors was recorded 
and divided by the total number of observed teacher behaviors possible and multiplied by 100 . To establish confidence in the implementation of the intervention, the criteria for independent variable reliability was at least $90 \%$ for the observed sessions. Results of the independent reliability data showed the teacher completed 71 of 76 possible observed teacher behaviors which is an average of $93 \%$.

In an effort to provide evidence that the independent variable reliability data was accurate, interobserver reliability was conducted for $26 \%$ of the sessions. The percentage of agreement was calculated by dividing the total agreements by the sum of total agreements plus total disagreements $(A / A+D)$. The percentage of agreement on the fidelity checklist was $91 \%$.

Reliability of Scores. According to Henson (2001), reliability is critical when interpreting the effects of studies and test results. He states "the more measurement error that exists in our scores, the less useful these scores may be for analysis, interpretation, and clinical purposes" (p. 179). The KeyMath3 has been previously validated on a sample of 3,630 students, ages four to twenty-one (Connolly, 2007). Using the mean split-half reliability method, they reported the internal consistency reliability coefficient for Form A was .95 for grades kindergarten through five and .98 for grades six through twelve. The internal consistency reliability coefficient for Form B was .96 for grades kindergarten through five and .97 for grades six through twelve. Henson (2001) suggests that a reliability coefficient of .80 is very good, meaning that $80 \%$ of the total score variance is due to true score variance. 
Threats to Validity. Single subject research is concerned with establishing a functional relationship between the independent variable and the dependent variable. Furthermore, experimental control is established when the dependent variable changes due to the intervention only, not any extraneous variables. Threats to internal validity associated with this design include history effects, maturation effects, and attrition. Although there is no way to eliminate threats to validity, there are ways that this study attempted to limit or control these threats. To possibly control for history effects, the teacher was asked to refrain from giving students additional interventions related to the concepts being covered that were not already established. Attrition effects were controlled by selecting students with a consistent attendance record and no plans for moving in the near future. Maturation effects were controlled through limiting the length of the study as much as possible.

\section{Social Validity}

As with all intervention programs for classroom settings, providing efficient, teacher-friendly interventions that foster student engagement is necessary for continued implementation. Both the teacher who implemented the intervention and the student participants were given a questionnaire following the completion of the study. The questionnaire provided the participants an opportunity to give feedback regarding their experience with integrating children's literature in mathematics instruction.

Student Questionnaire. The student questionnaire consisted of multiple choice and open response questions. The multiple choice questions included (1) Did you like 
reading books during mathematics?; (2) Do you think that reading the books helped you learn mathematics better, worse, or the same?; and (3) Would you like your teacher to continue reading books during mathematics?. The open response questions included (1) What did you like best about reading books during mathematics? and (2) What, if anything, did you dislike about reading books during mathematics?. (See Appendix G for Student Questionnaire)

Teacher Questionnaire. The teacher questionnaire consisted of multiple choice and open response questions. Each multiple choice question included a space for additional comments and were as followed: (1) Did you like using children's literature to teach mathematics?; (2) Do you think that this helped your students learn mathematics concepts better, the same, or worse?; (3) How would you describe the overall engagement when implementing the children's literature lessons compared to your regular instruction?; (4) How would you describe the level of student disruptions when implementing the children's literature lessons compared to your regular instruction?; (5) How would you describe the amount of opportunities students had to respond through either questions or verbal prompts when implementing the children's literature mathematics lessons compared to your regular instruction?; and (6) Please rate the ease of implementing the children's literature mathematics lessons.; (7) Will you use children's literature to teach mathematics concepts in the future?; (8) What would you tell other teachers about using children's literature to teach mathematics?. The open response questions included (1) What did you like best about using children's literature to teach mathematics?; and (2) What, if applicable, did you dislike about using children's 
literature to teach mathematics?; (3) Please include any comments, suggestions, or ideas you may have for integrating children's literature in mathematics instruction. (See Appendix H for Teacher Questionnaire)

\section{Data Analysis}

A dependent samples t-test was performed to examine changes form pretest to posttest performance on the three general mathematics content areas [Basic Concepts (conceptual knowledge), Operations (computational skills), and Applications (problem solving)] and a single-group repeated-measures ANOVA was performed to examine student performance on specific subtests related to the content and concepts being taught to each participant during the study. Both the dependent samples t-test and single-group repeated-measures ANOVA are appropriate to examine data from designs that use two or more assessments on each subject (Shavelson, 1996). Advantages of using a dependent samples t-test or repeated measures design include being more powerful than completely randomized designs (between-subjects) since each participant is his or her own control (within-subjects). This reduces error and increases the likelihood of detecting a significant difference, if one is present (Stevens, 2009). Furthermore, these designs require fewer subjects than a randomized design (Stevens, 2009). The alpha level was set at .05 for all statistical testing.

Visual data analysis was used by the researcher to make important decisions as

well as determining if there was a functional relationship between the intervention and the targeted behaviors. In each phase or condition, the data for each student was graphed and visually inspected by the researchers to help determine the level of 
performance, variability of performance, and direction and degree of trends. The data also determined when to implement the next phase of the study. Once a stable rate was established or definite trend, level, and variability in the desired direction was observed within a phase, the next phase was implemented.

\section{Limitations}

There were limitations to the study that should be noted. First, the sample size of this study $(n=4)$ was very small for statistical analysis. Keppel and Wickens (2004) state "when you have only a small number of subjects, you are unlikely to detect anything but a large effect" (p. 169) which increases the difficulty of detecting significance. Furthermore, Stevens (2009) states the power of a statistical test is the "probability of making a correct decision, or saying the groups differ when in fact they do" (p. 4) and is heavily influenced by sample size. Low power can increase the likelihood of a Type II error occurring and result in not detecting a significant difference between pretest and posttest measures when there actually is a difference.

Although increasing the sample size improves the chances of detecting whether integrating children's literature in mathematics instruction makes a statistically significant difference in students' academic achievement, it would have effects on other variables being examined in this study. In order to have a $70 \%$ chance of finding a difference if there is one (power of .70) with the alpha level of .05 and a medium effect size of .5 standard deviations, a minimum of fifty subjects would be needed (Stevens, 2009). A sample size this large would have a substantial effect on the measurement of student behaviors. The multiple baseline design across participants being used to 
examine the effects of integrating children's literature in mathematics on student engagement and disruptive behaviors could not be practically implemented with a sample size this large without adding numerous threats to validity. Shaddish, et al. (2002) state "such countervailing relationships suggest how crucial it is in planning any experiment to be explicit about the priority ordering among validity types. Unnecessary tradeoffs between one kind of validity and another have to be avoided, and the loss entailed by necessary tradeoffs has to be estimated and minimized" (p. 96). Since student behavior is the primary variable under examination, the researcher decided to keep the sample size small although it may affect the statistical analysis of student achievement.

The second limitation to this study is the absence of a control group. This has a significant effect on student academic achievement analysis. The lack of a control group adds threats to validity such as maturation and history. Shaddish, et al. (2002) state without a control group, it is rare to "be able to construct confident causal knowledge with the simple pretest-posttest design unless the outcomes are particularly well behaved and the interval between pretest and posttest is short" (p. 110). Although the seven week period controls for maturation effects by keeping the intervals short, the absence of a control group weakens the causal inference that integrating children's literature in mathematics increased student mathematics achievement.

The final limitation is in regards to external validity and reliability of the multiple baseline design across participants. External validity refers to whether the relationship between the independent variable(s) and dependent variable(s) hold across persons, 
settings, treatments, and outcomes that were in the experiment and across persons, settings, treatments, and outcomes not in the experiment (Shadish, et al., 2002). Due to the small number of participants inherent in single subject designs, external validity "is primarily accomplished through a series of systematic replication studies in which investigators, participants, settings, etc. differ from previous studies and yield the same outcome" (Gast, 2010, p. 124-125). Furthermore, although the multiple baseline design across participants builds limited external validity due to the intersubject replication within the design, it lacks intra-subject replication. Gast (2010) describes intra-subject replication as "repeating the experimental effect with the same participant more than once in the same study" (p. 113). Intra-subject replication allows for greater confidence in demonstrating reliability of the effects of the intervention which, according to Gast (2010), is "a more convincing demonstration of reliability than inter-subject replication, a design characteristic and limitation of many, if not most, large-group research designs, as well as some single subject research designs, most notably multiple baseline design across participants" (p. 124). In order to increase the external validity and the reliability of integrating children's literature in mathematics instruction on students with academic difficulties and challenging behaviors, future direct and systematic replications will be needed.

\section{Summary}

The purpose of this chapter was to delineate the research design and methodology of the study. The purpose of this study was to examine the effects of integrating children's literature in mathematics instruction on the academic and 
behavioral outcomes for students with academic difficulty and challenging behaviors. The study attempted to answer the following primary research questions listed in order of importance: (1) Will integrating children's literature in mathematics instruction increase student engagement while reducing disruptive behaviors during mathematics instruction for students with academic difficulties and challenging behaviors; and (2) does integrating children's literature in mathematics instruction increase the teacher's rate of providing opportunities for students to respond during mathematics instruction? In addition, the study included a secondary research question: Will integrating children's literature in mathematics instruction increase mathematics achievement for students with academic difficulties and challenging behaviors? 


\section{CHAPTER 4}

RESULTS

The purpose of this study was to examine the effects of integrating children's literature in mathematics instruction on the academic and behavioral outcomes of students with academic difficulty and challenging behaviors. Specifically, the study's primary goal was to examine the effects of this curricular approach on increasing student engagement, reducing disruptive behaviors, and increasing the teacher's rate of providing opportunities to respond for four students identified as exhibiting academic difficulty and challenging behaviors during Tier II mathematics instruction. These effects were determined by collecting behavioral observation data on the teacher and students during mathematics instruction using a multiple baseline across participants design. Data were recorded and then displayed in graphs for visual analysis.

In addition, a secondary goal was to examine the effects of integrating children's literature on the academic performance of four students identified as exhibiting academic difficulty and challenging behaviors during Tier II mathematics instruction. These effects were determined by the administration of a norm-referenced assessment at the beginning of the study, just prior to introduction of the intervention, and again at the end of the study. A dependent samples t-test and single-group repeated-measures ANOVA were performed on the data using the statistical software package SPSS Statistics. 
This chapter reports the results of the efforts described above in greater detail. It will begin with reporting the analysis of student behaviors (i.e., student engagement and disruptions), then report the results of teacher behaviors (i.e., group opportunities to respond and individual opportunities to respond), and followed by the results of student academic performance. This chapter will conclude by reporting the results of social validity data.

\section{Intervention Results}

\section{Student Behavior}

A summary of mean percentages of student engagement, rate of student disruptive behavior, and rate of teacher providing students opportunities to respond (OTR) is presented for each participant in Table 4-1. Data were plotted on graphs regularly to aid in the evaluation in level, trend, and variability of the total engagement data. which determined each phase of the design. Level stability was determined by using the " $80 \%-20 \%$ " criteria of the stability envelope (Gast, 2010). If $80 \%$ of the data points fell on or within the $20 \%$ of the stability envelope, the data would be considered stable. Trend lines were determined by using regression trend lines in Microsoft Excel. In addition, the percentages of non-overlapping data point values (PND) were calculated to compare the data of the baseline and intervention conditions. The PND values were calculated by dividing the number of data points that fell outside the range of data-point values of the baseline condition by the number of data points in the intervention condition and multiplying by 100 . 
Table 4-1. Mean Percentages of Student Engagement and Rate of Student Disruptive Behavior.

\begin{tabular}{|c|c|c|c|c|c|c|c|c|}
\hline \multirow[t]{2}{*}{ Student } & \multicolumn{2}{|c|}{$\begin{array}{c}\text { Total } \\
\text { Engagement }\end{array}$} & \multicolumn{2}{|c|}{$\begin{array}{c}\text { Passive } \\
\text { Engagement }\end{array}$} & \multicolumn{2}{|c|}{$\begin{array}{c}\text { Active } \\
\text { Engagement }\end{array}$} & \multicolumn{2}{|c|}{ Disruption } \\
\hline & BL & INT & BL & INT & BL & INT & BL & INT \\
\hline S1 & 74.92 & 96 & 31.2 & 59.02 & 43.73 & 36.98 & 1.25 & 0.31 \\
\hline S2 & 64.24 & 91.24 & 40.09 & 60.47 & 24.15 & 30.77 & 6.38 & 2.6 \\
\hline S3 & 72.63 & 94.6 & 57.91 & 62.37 & 14.66 & 31.51 & 7.38 & 2.33 \\
\hline S4 & 70.54 & 92.77 & 49.53 & 55.8 & 19.9 & 36.97 & 4.89 & 2.83 \\
\hline TOTAL & 69.98 & 93.91 & 46.71 & 59.69 & 22.91 & 34.05 & 5.48 & 1.79 \\
\hline
\end{tabular}

Note: $\mathrm{BL}=$ Baseline Condition; INT = Intervention Condition

Engagement. Student engagement was measured using duration recording and calculated as a percentage. As seen in Figure 4-1, four out of four students demonstrated a higher percentage of engagement during the intervention condition when compared to the baseline condition. The mean percentage of engagement for all participants was $69.98 \%$ during baseline condition and $93.91 \%$ during intervention condition. Furthermore, there were no overlapping data points between conditions and the data remained stable during the intervention condition for all four students, with $100 \%$ falling on or within the stability envelope.

Student 1. Visual analysis of the data showed an immediate change in level of engagement from the last data point of the baseline condition (76.5\%) to the first data point of the intervention (95.8\%). S1's mean percentage of engagement increased $21.08 \%$ from baseline condition ( $M=74.92 \%)$ to intervention condition ( $M=96 \%)$. During the intervention condition, there was a small upward trend in engagement 
$(y=0.0441 x+95.44)$ and the data were stable with $100 \%$ of data points falling on or within the stability envelope $(86.22-73.87)$. In addition, there were no overlapping data points between conditions (PND $=100 \%$ ).

Student 2. There was an immediate change in level of engagement from the last data point of the baseline condition (65.8\%) to the first data point of the intervention (85.9\%). S2's mean percentage of engagement increased $27 \%$ from baseline condition $(M=64.24 \%)$ to intervention condition $(M=91.24 \%)$. During the intervention condition, there was a very small upward trend in engagement $(y=0.0209 x+90.93)$ and the data were stable with $100 \%$ of data points falling on or within the stability envelope (82.04 - 100). In addition, there were no overlapping data points between conditions $(\mathrm{PND}=100 \%)$

Student 3. There was an immediate change in level of engagement from the last data point of the baseline condition (70.9\%) to the first data point of the intervention (95.8\%). S3's mean percentage of engagement increased $21.97 \%$ from baseline condition $(M=72.63 \%)$ to intervention condition $(M=94.6 \%)$. During the intervention condition, there was a small downward trend in engagement $(y=-0.11562 x+97.134)$ and the data were stable with $100 \%$ of data points falling on or within the stability envelope (85.32 - 100). In addition, there were no overlapping data points between conditions (PND $=100 \%)$.

Student 4. There was an immediate change in level of engagement from the last data point of the baseline condition (71.2\%) to the first data point of the intervention (92\%). S4's mean percentage of engagement increased $22.23 \%$ from baseline condition 
$(M=70.54 \%)$ to intervention condition $(M=92.77 \%)$. During the intervention

condition, there was a small upward trend in engagement $(y=0.3643 x+86.21)$ and the data were stable with $100 \%$ of data points falling on or within the stability envelope $(83.75-100)$. In addition, there were no overlapping data points between conditions $($ PND $=100 \%)$.

In addition to examining the overall engagement of the participants, this study also examined two types of engagement which were classified as passive engagement and active engagement. Graphic results of the percentages of passive engagement and active engagement are presented in Figures 4-2 and 4-3.

Passive Engagement. For the student to be considered passively engaged in the instructional lesson, he or she had to be looking in the direction of teacher or looking at another student who is called on to speak by the teacher. The mean percentage of passive engagement for all participants was $46.71 \%$ during baseline condition and $59.69 \%$ during intervention condition. Although the mean percentages were higher, the non-overlapping data points between conditions ranged from $23 \%$ to $89 \%$ and the variability of the data were moderate to high during the intervention condition for all four students, with a range of $15 \%$ to $67 \%$ falling on or within the stability envelope.

Student 1. S1's mean percentage of passive engagement increased $27.82 \%$ from baseline condition ( $M=31.20 \%)$ to intervention condition $(M=59.02 \%)$. During the intervention condition, there was a small downward trend in passive engagement $(y=-0.2285 x+61.923)$ and the data had very high variability with only $15 \%$ of data 
points falling on or within the stability envelope $(52.83-64.57)$. There was also a high percentage of overlapping data points between conditions (PND $=23 \%$ ).

Student 2. S2's mean percentage of passive engagement increased $20.38 \%$ from baseline condition ( $M=40.09 \%)$ to intervention condition $(M=60.47 \%)$. During the intervention condition, there was a small downward trend in passive engagement $(y=-0.9249+74.158)$ and the data had very high variability with only $20 \%$ of data points falling on or within the stability envelope (57.02 - 69.69). There was also a moderate percentage of overlapping data points between conditions (PND $=50 \%$ ).

Student 3. S3's mean percentage of passive engagement increased $4.46 \%$ from baseline condition ( $M=57.91 \%)$ to intervention condition $(M=62.37 \%)$. During the intervention condition, there was a moderate upward trend in passive engagement $(y=1.1153 x+44.274)$ and the data had moderate variability with $67 \%$ of data points falling on or within the stability envelope (57.6 - 70.40). In addition, there was a low percentage of overlapping data points between conditions (PND $=89 \%$ ).

Student 4. S4's mean percentage of passive engagement increased $6.27 \%$ from baseline condition ( $M=49.53 \%)$ to intervention condition $(M=55.8 \%)$. During the intervention condition, there was a moderate upward trend in passive engagement $(y=3.6571 x+10.029)$ and the data had high variability with only $34 \%$ of data points falling on or within the stability envelope $(57.87-70.73)$. There was also a moderate percentage of overlapping data points between conditions (PND $=50 \%$ ).

Active Engagement. For the student to be considered actively engaged in the instructional lesson, he or she had to be responding to teacher prompt or instruction 
which included: (a) choral responding, (b) verbally answering a teacher directed question, (c) raising hand, (d) writing, or (e) reading. The mean percentage of active engagement for all participants was $22.91 \%$ during baseline condition and $34.05 \%$ during intervention condition. Although the mean percentages were higher, the nonoverlapping data points between conditions ranged from $10 \%$ to $39 \%$ and the variability of the data were high during the intervention condition for all four students, with a range of $0 \%$ to $34 \%$ falling on or within the $20 \%$ of the stability envelope.

Student 1. S1's mean percentage of active engagement decreased $6.75 \%$ from baseline condition ( $M=43.73 \%$ ) to intervention condition ( $M=36.98 \%$ ). During the intervention condition, there was a small upward trend in active engagement $(y=0.2726 x+33.517)$ and the data had very high variability with only $8 \%$ of data points falling on or within the stability envelope (31.95 - 39.05). There was also a high percentage of overlapping data points between conditions (PND $=39 \%$ ).

Student 2. S2's mean percentage of active engagement increased $6.75 \%$ from baseline condition $(M=24.15 \%)$ to intervention condition $(M=30.77 \%)$. During the intervention condition, there was an upward trend in active engagement $(y=0.9458 x+$ 16.772) and the data had very high variability with $0 \%$ of data points falling on or within the stability envelope (26.24 - 32.07). There was also a very high percentage of overlapping data points between conditions (PND $=10 \%$ ).

Student 3. S3's mean percentage of active engagement increased $16.85 \%$ from baseline condition $(M=14.66 \%)$ to intervention condition $(M=31.51 \%)$. During the intervention condition, there was a moderate downward trend in active engagement 
$(y=-1.2524 x+51.827)$ and the data had very high variability with only $15 \%$ of data points falling on or within the stability envelope $(27.90-34.1)$. There was also a high percentage of overlapping data points between conditions (PND $=34 \%$ ).

Student 4. S4's mean percentage of active engagement increased $17.07 \%$ from baseline condition $(M=19.9 \%)$ to intervention condition $(M=36.97 \%)$. During the intervention condition, there was a large downward trend in active engagement $(y=-3.2929 x+96.238)$ and the data had very high variability with $0 \%$ of data points falling on or within the stability envelope (25.34 - 30.97). There was also a high percentage of overlapping data points between conditions (PND $=33 \%$ ).

Disruption. Disruptive behavior was measured through frequency recording. A disruptive behavior was defined as the student displaying behavior that disrupts, or potentially disrupts, the entire class or an individual peer. Graphic results of the number of disruptive behaviors are presented in Figure 4-4.

The mean number of disruptions for all participants was 5.48 during baseline condition and 1.79 during intervention condition. The non-overlapping data points between conditions ranged from $0 \%$ to $33 \%$ and the variability of the data were moderate to high during the intervention condition, with a range of $0 \%$ to $69 \%$ falling on or within the stability envelope.

Student 1. There was an immediate drop in the number of disruptions from the last data point of the baseline condition (3) to the first data point of the intervention condition (0). S1's mean number of disruptions decreased by almost one (.94) from baseline condition $(M=1.25)$ to intervention condition $(M=0.31)$. During the 
intervention condition, there was a very small downward trend in disruptions $(y=-0.006 x+0.3834)$ and the data had moderate variability with $69 \%$ of data points falling on or within the stability envelope (0). There was $100 \%$ overlapping data points between conditions (PND $=0 \%$ ).

Student 2. There was an immediate drop in the number of disruptions from the last data point of the baseline condition (10) to the first data point of the intervention condition (5). S2's mean number of disruptions decreased by 3.78 from baseline condition $(M=6.38)$ to intervention condition $(M=2.6)$. During the intervention condition, there was a slight upward trend in disruptions $(y=0.0074 x+2.4901)$ and the data had high variability with $30 \%$ of data points falling on or within the stability envelope $(1.8-2.2)$. There was $100 \%$ overlapping data points between conditions $($ PND $=0 \%)$.

Student 3. There was an immediate drop in the number of disruptions from the last data point of the baseline condition (9) to the first data point of the intervention condition (1). S3's mean number of disruptions decreased by 5.05 from baseline condition $(M=7.38)$ to intervention condition $(M=2.33)$. During the intervention condition, there was a downward trend in disruptions $(y=-0.1544 x+4.8382)$ and the data had moderate variability with $45 \%$ of data points falling on or within the stability envelope (2.7 - 3.3). There was a high percentage of overlapping data points between conditions (PND $=33 \%$ ).

Student 4. There was an immediate drop in the number of disruptions from the last data point of the baseline condition (13) to the first data point of the intervention 
condition (1). S4's mean number of disruptions decreased by 2.06 from baseline condition $(M=4.89)$ to intervention condition $(M=2.83)$. During the intervention condition, there was a small upward trend in disruptions $(y=0.0714 x+1.5476)$ and the data had very high variability with $0 \%$ of data points falling on or within the stability envelope $(2.25-2.75)$. There was also $100 \%$ overlapping data points between conditions (PND $=0 \%)$.

\section{Teacher Behavior}

A summary of mean rates of teacher providing students opportunities to respond (OTR) is presented for each participant in Table 4-2. As with student behavior, data were plotted on graphs to aid in the evaluation in level, trend, and variability of the data and condition comparisons.

Table 4-2. Mean rate of teacher providing opportunities for students to respond.

\begin{tabular}{|c|c|c|c|c|c|c|}
\hline \multirow[t]{2}{*}{ Student } & \multicolumn{2}{|c|}{ Total OTR } & \multicolumn{2}{|c|}{ OTR Group } & \multicolumn{2}{|c|}{ OTR Individual } \\
\hline & BL & INT & BL & INT & BL & INT \\
\hline S1 & 5.5 & 14.85 & 2.5 & 11.23 & 3 & 4.38 \\
\hline S2 & 5.75 & 15.2 & 3.75 & 11 & 2 & 4.2 \\
\hline S3 & 5.88 & 15.78 & 4.75 & 12.33 & 1.13 & 3.44 \\
\hline S4 & 6.11 & 18.83 & 3.78 & 13.33 & 2.33 & 5.5 \\
\hline TOTAL & 5.81 & 16.17 & 3.87 & 11.76 & 2 & 4.29 \\
\hline
\end{tabular}

Opportunities to Respond (OTR). The teacher behavior being observed was giving opportunities to respond (OTR) which was measured using frequency recording. As seen in Figure 4-5, four out of four students demonstrated a higher rate of OTR during the intervention condition when compared to the baseline condition. The mean 
rate of OTR for all participants was 5.81 during baseline condition and 16.17 during intervention condition. Furthermore, three students (S2, S3, and S4) had no overlapping data points between conditions and one student (S1) had 15\% overlapping data points between conditions. The variability of the data was moderate during the intervention condition, with a range of $46 \%$ to $60 \%$ falling on or within the stability envelope.

Student 1. There was an immediate increase in the number of OTR from the last data point of the baseline condition (10) to the first data point of the intervention condition (14). The teacher's mean number of OTR during S1's group increased by 9.35 from baseline condition $(M=5.5)$ to intervention condition $(M=14.85)$. During the intervention condition, there was an upward trend in OTR $(y=0.0687 x+13.974)$ and the data had moderate variability with $46 \%$ of data points falling on or within the stability envelope (12.6 - 15.4). In addition, there was a low percentage of overlapping data points between conditions (PND $=85 \%$ ).

Student 2. There was an immediate increase in the number of OTR from the last data point of the baseline condition (8) to the first data point of the intervention condition (13). The teacher's mean number of OTR during S2's group increased by 9.45 from baseline condition ( $M=5.75)$ to intervention condition $(M=15.2)$. During the intervention condition, there was an upward trend in OTR $(y=0.1015 x+13.698)$ and the data had moderate variability with $60 \%$ of data points falling on or within the stability envelope $(13.5-16.5)$. In addition, there were no overlapping data points between conditions (PND = 100\%). 
Student 3. There was an immediate increase in the number of OTR from the last data point of the baseline condition (7) to the first data point of the intervention condition (18). The teacher's mean number of OTR during S3's group increased by 9.9 from baseline condition $(M=5.88)$ to intervention condition $(M=15.78)$. During the intervention condition, there was a downward trend in OTR $(y=-0.2324 x+19.547)$ and the data had moderate variability with $56 \%$ of data points falling on or within the stability envelope (14.4-17.6). In addition, there were no overlapping data points between conditions (PND $=100 \%)$.

Student 4. There was an immediate increase in the number of OTR from the last data point of the baseline condition (10) to the first data point of the intervention condition (20). The teacher's mean number of OTR during S4's group increased by 12.72 from baseline condition $(M=6.11)$ to intervention condition $(M=18.83)$. During the intervention condition, there was a downward trend in OTR $(y=0.1786 x+22.048)$ and the data had moderate variability with $50 \%$ of data points falling on or within the stability envelope (17.55-21.45). In addition, there were no overlapping data points between conditions (PND = 100\%).

In addition to examining the overall teacher OTR, this study also examined two types of OTR which were classified as OTR group and OTR individual. Graphic results of the percentages of passive engagement and active engagement are presented in Figures 4-5 and 4-6.

OTR Group. OTR group was defined as the teacher providing an opportunity to respond that is directed to the whole class. As seen in Figure 4-5, the teacher provided 
a higher rate of group OTR during the intervention condition when compared to the baseline condition. The mean number of group OTR for all participants was 3.87 during baseline condition and 11.76 during intervention condition. Furthermore, there were no overlapping data points between conditions and the variability of the data were moderate to small during the intervention condition, with a range of $46 \%$ to $80 \%$ falling on or within the stability envelope.

Student 1. There was an immediate increase in the number of group OTR from the last data point of the baseline condition (5) to the first data point of the intervention condition (10). The teacher's mean number of group OTR during S1's group increased by almost nine $(8.73)$ from baseline condition $(M=2.5)$ to intervention condition $(M=$ 11.23). During the intervention condition, there was an upward trend in group OTR $(y=0.0402 x+10.721)$ and the data had moderate variability with $46 \%$ of data points falling on or within the stability envelope (9-11). In addition, there were no overlapping data points between conditions (PND $=100 \%$ ).

Student 2. There was an immediate increase in the number of group OTR from the last data point of the baseline condition (3) to the first data point of the intervention condition (10). The teacher's mean number of group OTR during S2's group increased by 7.25 from baseline condition $(M=3.75)$ to intervention condition $(M=11)$. During the intervention condition, there was an upward trend in group OTR $(y=0.1919 x+$ 8.1609 ) and the data remained stable with $80 \%$ of data points falling on or within the stability envelope (9-11). In addition, there were no overlapping data points between conditions (PND $=100 \%)$. 
Student 3. There was an immediate increase in the number of group OTR from the last data point of the baseline condition (5) to the first data point of the intervention condition (14). The teacher's mean number of group OTR during S3's group increased by 7.58 from baseline condition $(M=4.75)$ to intervention condition $(M=12.33)$.

During the intervention condition, there was a downward trend in group OTR $(y=-0.1279 x+14.409)$ and the data had moderate variability with $56 \%$ of data points falling on or within the stability envelope (10.8 - 13.2). In addition, there were no overlapping data points between conditions (PND $=100 \%$ ).

Student 4. There was an immediate increase in the number of group OTR from the last data point of the baseline condition (9) to the first data point of the intervention condition (13). The teacher's mean number of group OTR during S4's group increased by 9.55 from baseline condition $(M=3.78)$ to intervention condition $(M=13.33)$. During the intervention condition, there was an upward trend in group OTR $(y=0.0714 x$ $+12.048)$ and the data had moderate variability with $50 \%$ of data points falling on or within the stability envelope $(12.15-14.85)$. In addition, there were no overlapping data points between conditions (PND = 100\%).

OTR Individual. OTR individual was defined as the teacher providing an opportunity to respond to the student participant in the class. As seen in Figure 4-6, results of teacher providing individual OTR during the intervention condition when compared to the baseline condition were mixed. The mean number of individual OTR for all participants was two during baseline condition and 4.29 during intervention condition. Although the mean number of individual OTR was higher for the intervention 
condition, the non-overlapping data points between conditions ranged from $10 \%$ to $67 \%$ and the variability of the data were moderate to high during the intervention condition, with a range of $17 \%$ to $40 \%$ falling on or within the stability envelope.

Student 1. There was a decrease in the number of individual OTR from the last data point of the baseline condition (5) to the first data point of the intervention condition (4). The teacher's mean number of individual OTR during S1's group increased by 1.38 from baseline condition $(M=3)$ to intervention condition $(M=4.38)$. During the intervention condition, there was a small downward trend in individual OTR $(y=-0.1296 x+6.0295)$ and the data had high variability with $38 \%$ of data points falling on or within the stability envelope (3.6 -4.4). There was also a high percentage of overlapping data points between conditions (PND $=23 \%$ ).

Student 2. There was a decrease in the number of individual OTR from the last data point of the baseline condition (5) to the first data point of the intervention condition (3). The teacher's mean number of individual OTR during S2's group increased by 2.2 from baseline condition $(M=2)$ to intervention condition $(M=4.2)$. During the intervention condition, there was a small downward trend in individual OTR $(y=-0.0903 x+5.5371)$ and the data had high variability with $40 \%$ of data points falling on or within the stability envelope $(3.6-4.4)$. There was also a very high percentage of overlapping data points between conditions (PND = 10\%).

Student 3. There was an increase in the number of individual OTR from the last data point of the baseline condition (2) to the first data point of the intervention condition (4). The teacher's mean number of individual OTR during S3's group increased 
by 2.31 from baseline condition ( $M=1.13)$ to intervention condition $(M=3.44)$. During the intervention condition, there was a downward trend in individual OTR $(y=-0.1044 x$ +5.1382 ) and the data had high variability with $33 \%$ of data points falling on or within the stability envelope $(3.6-4.4)$. There was also a moderate percentage of overlapping data points between conditions (PND $=56 \%$ ).

Student 4. There was an increase in the number of individual OTR from the last data point of the baseline condition (1) to the first data point of the intervention condition (7). The teacher's mean number of individual OTR during S3's group increased by 3.17 from baseline condition $(M=2.33)$ to intervention condition $(M=5.5)$. During the intervention condition, there was a downward trend in individual OTR $(y=-0.25 x+$ 10) and the data had very high variability with $17 \%$ of data points falling on or within the stability envelope $(4.95-6.10)$. There was also a moderate percentage of overlapping data points between conditions (PND $=67 \%$ ).

\section{Student Academic Achievement}

Two pretest/posttest designs were used to assess academic achievement of the participants $(n=4)$. Both designs measured student academic achievement using the KeyMath3 Diagnostic Assessment (Connolly, 2007). The one-group pretest/posttest design was used to measure student academic achievement using the three general mathematics content areas of the KeyMath 3 assessment: Basic Concepts, Operations, and Applications. The one-group pretest/posttest design using a double pretest was used to measure student academic achievement using the specific subtests related to the content and concepts being taught to each participant during the study. Form A was 
administered to all participants during the first pretest and posttest while Form B was administered to all participants during the second pretest.

After administration of the assessments, all raw scores were converted to standard scores. Since standard scores represent an equal-interval type of measurement, it allows for mathematical manipulation of the scores (e.g., added, subtracted, averaged)( Connolly, 2007). The individual standard scores for the three content areas and total scores can be seen in Table 4-3 and the individual standard scores of the specific subtests can be seen in Table 4-4.

Table: 4-3. Individual Content Area/Total Standard Scores

\begin{tabular}{llll}
\hline Subject & Content Area/Total & Pretest Score & Posttest Score \\
\hline Student 1 & Basic Concepts & 85 & 90 \\
& Operations & 78 & 78 \\
& Applications & 78 & 83 \\
& Total & 81 & 85 \\
Student 2 & Basic Concepts & 72 & 70 \\
& Operations & 71 & 72 \\
& Applications & 72 & 77 \\
& Total & 71 & 71 \\
Student 3 & Basic Concepts & 90 & 92 \\
& Operations & 82 & 82 \\
& Applications & 80 & 84 \\
& Total & 85 & 86 \\
Student 4 & Basic Concepts & 86 & 95 \\
& Operations & 78 & 85 \\
& Applications & 84 & 86 \\
& Total & 82 & \\
\hline
\end{tabular}


Table: 4-4. Individual Subtest Standard Scores

\begin{tabular}{llccc}
\hline Subject & Subtests & $\begin{array}{l}\text { Pretest 1 } \\
\text { (Form A) }\end{array}$ & $\begin{array}{c}\text { Pretest 2 } \\
\text { (Form B) }\end{array}$ & $\begin{array}{c}\text { Posttest } \\
\text { (Form A) }\end{array}$ \\
\hline Student 1 & $\begin{array}{l}\text { Data Analysis \& Probability } \\
\text { Numeration }\end{array}$ & 64 & 62 & 65 \\
Student 2 & $\begin{array}{l}\text { Addition \& Subtraction } \\
\text { Mental Computation \& } \\
\text { Estimation }\end{array}$ & 71 & 72 & 72 \\
Student 3 & $\begin{array}{l}\text { Addition \& Subtraction } \\
\text { Mental Computation \& } \\
\text { Estimation }\end{array}$ & 64 & 65 & 66 \\
Student 4 & $\begin{array}{l}\text { Geometry } \\
\text { Measurement }\end{array}$ & 78 & 84 & 85 \\
\hline
\end{tabular}

General Mathematics Content. To determine if there was a statistically significant difference between pretest and post performance on the three general content areas and total score, a dependent samples t-test, or paired samples t-test, was performed. Descriptive statistics show the mean score for the content area Basic Concepts was $83.25(S D=7.80)$ for pretest and $89.00(S D=12.98)$ for posttest, which is an increase of 5.75. The mean score for the content area Operations was 77.25 (SD = 4.57) for pretest and $79.25(S D=4.57)$ for posttest, which is an increase of two. The mean score for the content area Applications was $78.5(S D=5.00)$ for pretest and 81.25 $(S D=4.42)$ for posttest, which is an increase of 2.75 . Finally, the mean score for the total test was $79.75(S D=6.07)$ for pretest and $82.75(S D=4.00)$ for posttest, which is an increase of 3.

Results from the paired samples t-test show that the obtained $t$ values were not statistically different at the .05 alpha level for Basic Concepts, $t(3)=1.612, p=.205$; Operations, $t(3)=1.188, p=.320 ;$ or Applications $t(3)=2.480, p=.089$. In addition, the 
obtained $t$ value was not statistically different at the .05 alpha level for total score, $t(3)=1.897, p=.154$. Therefore, there is no statistically significant difference between the students' pretest and posttest scores on the three general content areas and total scores.

Table: 4-5. Paired Samples t-test Summary Table

\begin{tabular}{llllllllll}
\hline & \multicolumn{2}{c}{ Pretest } & \multicolumn{2}{c}{ Posttest } & & \multicolumn{2}{c}{$95 \% \mathrm{Cl}$} \\
\cline { 2 - 4 } \cline { 8 - 10 } Content Area/Total & Mean & SD & Mean & SD & $t(3)$ & $p$ & & LL & UL \\
\hline Basic Concepts & 83.25 & 7.80 & 89.00 & 12.98 & 1.612 & .205 & -17.10 & 5.60 \\
Operations & 77.25 & 4.57 & 79.25 & 4.57 & 1.188 & .320 & -7.36 & 3.36 \\
Applications & 78.5 & 5.00 & 81.25 & 4.42 & 2.480 & .089 & -6.28 & .78 \\
Total & 79.75 & 6.07 & 82.75 & 4.00 & 1.897 & .154 & -8.03 & 2.03 \\
\hline
\end{tabular}

Note. $\mathrm{Cl}$ - confidence interval; $\mathrm{LL}=$ lower limit; $\mathrm{UL}=$ upper limit

Specific Mathematics Content. A single-group repeated-measures ANOVA was performed to examine student performance on specific subtests related to the content and concepts being taught to each participant during the study. The single withinsubjects variable had three levels corresponding to the three administrations of the subtests at the beginning of the study (pretest 1), just prior to intervention (pretest 2), and at the end of the study (posttest). The following subtests were given to the participants: S1 was given the Data Analysis and Probability and Numeration subtests, S2 was given the Addition and Mental Computation and Estimation subtests; S3 was given the Geometry and Measurement subtests, and S4 was given the Addition and Mental Computation and Estimation subtests. Mauchly's test of sphericity was not significant, $x^{2}(2)=2.090, p=.352$, thus nominal degrees of freedom were used to test the hypothesis that the three mean scores were equal. 
Results from the single-group repeated-measures ANOVA summary table below show that the obtained $F$ value, $F(2,6)=2.184, p=.194$, was not statistically significant at the .05 alpha level, therefore, there was no significant main effect of test scores. Table 4-6. Single-Group Repeated-Measures ANOVA Summary Table

\begin{tabular}{llllll}
\hline Source & $S S$ & $d f$ & $M S$ & $F$ & Significance $F$ \\
\hline Scores & 15.167 & 2 & 7.583 & 2.184 & .194 \\
Error & 20.833 & 6 & 3.472 & & \\
Total & 36 & 8 & & & \\
\hline
\end{tabular}

A post-hoc analysis using the Bonferroni adjustment for multiple comparisons was used to determine if there was a significant difference between the three mean scores (see Table 4-7 for summary). The mean of pretest $1\left(M_{1}=69.25 ; S D=6.702\right)$ was not significantly lower than pretest $2\left(M_{2}=70.75 ; S D=9.78\right)$ or the posttest $\left(M_{3}=72 ; S D=\right.$ 9.201). In addition, the mean of pretest $2\left(M_{2}=70.75 ; S D=9.78\right)$ was not significantly lower than the posttest $\left(M_{3}=72 ; S D=9.201\right)$.

Table 4-7. Pairwise Comparison of Mean Scores Based on Estimated Marginal Means

\begin{tabular}{ccccc}
\hline Comparisons & Mean Difference & Significance $^{\mathrm{a}}$ & \multicolumn{2}{c}{$95 \% \mathrm{Cl}_{\text {for Difference }}{ }^{\mathrm{a}}$} \\
\cline { 4 - 5 } & & & LB & UB \\
\hline Pretest 1 - Pretest 2 & -1.500 & 1.00 & -9.54 & 6.554 \\
Pretest 1 - Posttest & -2.75 & .454 & -9.725 & 4.225 \\
Pretest 2 - Posttest & -1.25 & .423 & -4.306 & 1.806 \\
\hline
\end{tabular}

Note. $\mathrm{Cl}$ - confidence interval; $\mathrm{LB}=$ lower bound; $\mathrm{UB}=$ upper bound.

${ }^{a}$ Bonferroni Adjustment for multiple comparisions 


\section{Social Validity Results}

As with all intervention programs for classroom settings, providing efficient, teacher-friendly interventions that foster student engagement is necessary for continued implementation. Both the teacher who implemented the intervention and the student participants were given a questionnaire following the completion of the study to assess the social validity of integrating children's literature in mathematics instruction.

Teacher. The teacher questionnaire consisted of eight multiple choice questions that included an option for additional comments and three open response questions (See Appendix H for Teacher Questionnaire).

Question one. Teacher replied that she liked using children's literature to teach mathematics and added, "I think literature helps connect math to real world situations".

Question two. Teacher replied that integrating children's literature helped her students learn mathematics concepts better and added that "it kept them engaged and on-task".

Question three. Teacher replied that implementing the children's literature mathematics lessons increased student engagement compared to her regular instruction and added the students "loved the lessons and looked forward to it".

Question four. Teacher replied that implementing the children's literature mathematics lessons decreased student disruptions compared to her regular instruction. 
Question five. Teacher replied that her rate of providing opportunities for students to respond through either questions or verbal prompts increased when implementing the children's literature mathematics lessons compared to her regular instruction.

Question six. Teacher replied that it was easy to implement the children's literature mathematics lessons. The teacher elaborated by saying, "The lessons were easy because you don't have to completely stick to the script. Things often came up that weren't expected and that was okay".

Question seven. Teacher replied that she would use children's literature to teach mathematics concepts in the future. The teacher commented, "Since I have the materials and lessons, it will be easy to implement. The lessons are adaptable to any grade level".

Question eight. Teacher replied that she would recommend using children's literature to teach mathematics to other teachers. The teacher commented, "I am going to give the list of books and lessons to teachers so they can use in their classrooms".

Question nine. In response to what she liked best about using children's literature to teach mathematics, teacher replied "the level of engagement and hands-on activities".

Question ten. In response to what she disliked about using children's literature to teach mathematics, teacher replied "nothing".

Question eleven. In response to comments, suggestions, or ideas that she may have for integrating children's literature in mathematics, teacher replied, "I would say to 
take the opportunity to use the lesson for teachable moments. Don't stick so much to the script. Sometimes one group might lead you in one direction, where another group might take a totally different view on the lesson. That's okay; let students lead the lesson where they need to be taught".

Student Results. The student questionnaire consisted of three multiple choice questions and three open response questions (See Appendix G for Student Questionnaire).

Question one. In response to whether or not the students liked the children's literature mathematics lesson, four out of four students answered yes.

Question two. Two students answered that the children's literature mathematics lessons helped them learn mathematics better and two students answered that the children's literature mathematics lessons helped them the same as their regular instruction.

Question three. Four out of four students answered that they would like their teacher to continue using children's literature during mathematics instruction.

Question four. In response to what they liked best about the children's literature mathematics lessons, the students replied "it helps you more", "that I learn more math", "it made math more easier", and "adding up the number of stuff that you can add up".

Question five. In response to what they disliked about the children's literature mathematics lessons, the students replied "nothing", "none", "the things I dislike is the easy questions", and "adding up hard numbers". 
Question six. In response to additional comments regarding their experience with the children's literature mathematics lessons, two students replied they would like to use it for other areas such as multiplication, division and addition; one student replied that "it is really fun"; and one student replied "I don't know".

\section{Summary}

Based on the reported results of individual participant's data, conclusions can be drawn across the four participants. In regards to student behavior, results of overall engagement of the participants suggest there is a functional relationship between integrating children's literature in mathematics instruction on student engagement. Four out of four students demonstrated a higher mean percentage of engagement during the intervention condition when compared to the baseline condition under the conditions of the study. Furthermore, there were no overlapping data points between conditions and the data remained stable during the intervention condition for all four students.

Results for the levels of student engagement (i.e., active engagement and passive engagement) and student disruptions were not as clear. In regards to student passive engagement, although the mean percentage for all four participants was higher during intervention condition than during baseline condition, only S3 had a low percentage of overlapping data points between conditions and the variability of the data were moderate to high during the intervention condition for all four students. In regards to student active engagement, the mean percentage for S2, S3, and S4 increased from baseline condition to intervention condition but the mean percentage of 
S1 decreased from baseline condition to intervention condition. Furthermore, the nonoverlapping data points between conditions and variability of the data were high for all four participants. In regards to student disruptions, although the mean number for all participants decreased from baseline condition to intervention condition, the nonoverlapping data points between conditions and variability of the data were high for all four participants.

In regards to teacher behavior, results of the teacher giving opportunities to respond (OTR) suggest there may be a functional relationship between integrating children's literature in mathematics instruction on the teacher's rate of OTR. The teacher provided a higher rate of OTR for all students during the intervention condition when compared to the baseline condition. Furthermore, three students had no overlapping data points between condition while one student had low overlapping data points between conditions and the variability of the data were moderate during the intervention condition.

Results of the levels of teacher OTR were mixed. The teacher provided a higher rate of group OTR during the intervention condition for all students when compared to the baseline condition. Furthermore, there were no overlapping data points between conditions and the variability of the data were moderate to small during the intervention condition. These results suggest there may be a functional relationship between integrating children's literature in mathematics instruction on the teacher's rate of providing group OTR. The results of individual OTR are not as clear. Although the mean number of individual OTR for all four participants were higher during baseline 
condition than during intervention condition, the overlapping data points between conditions and the variability of the data were moderate to high during the intervention condition.

Statistical analysis of student academic achievement data showed that there was no statistically significant difference between the students' pretest and posttest scores on the three general content areas and total score. In addition, there was no significant main effect of subtest scores and no significant differences between the three mean subtest scores. These results do not support that integrating children's literature in mathematics instruction increases mathematics achievement for students with academic difficulties and challenging behaviors. 
Figure 4-1. Percentage of Total Student Engagement

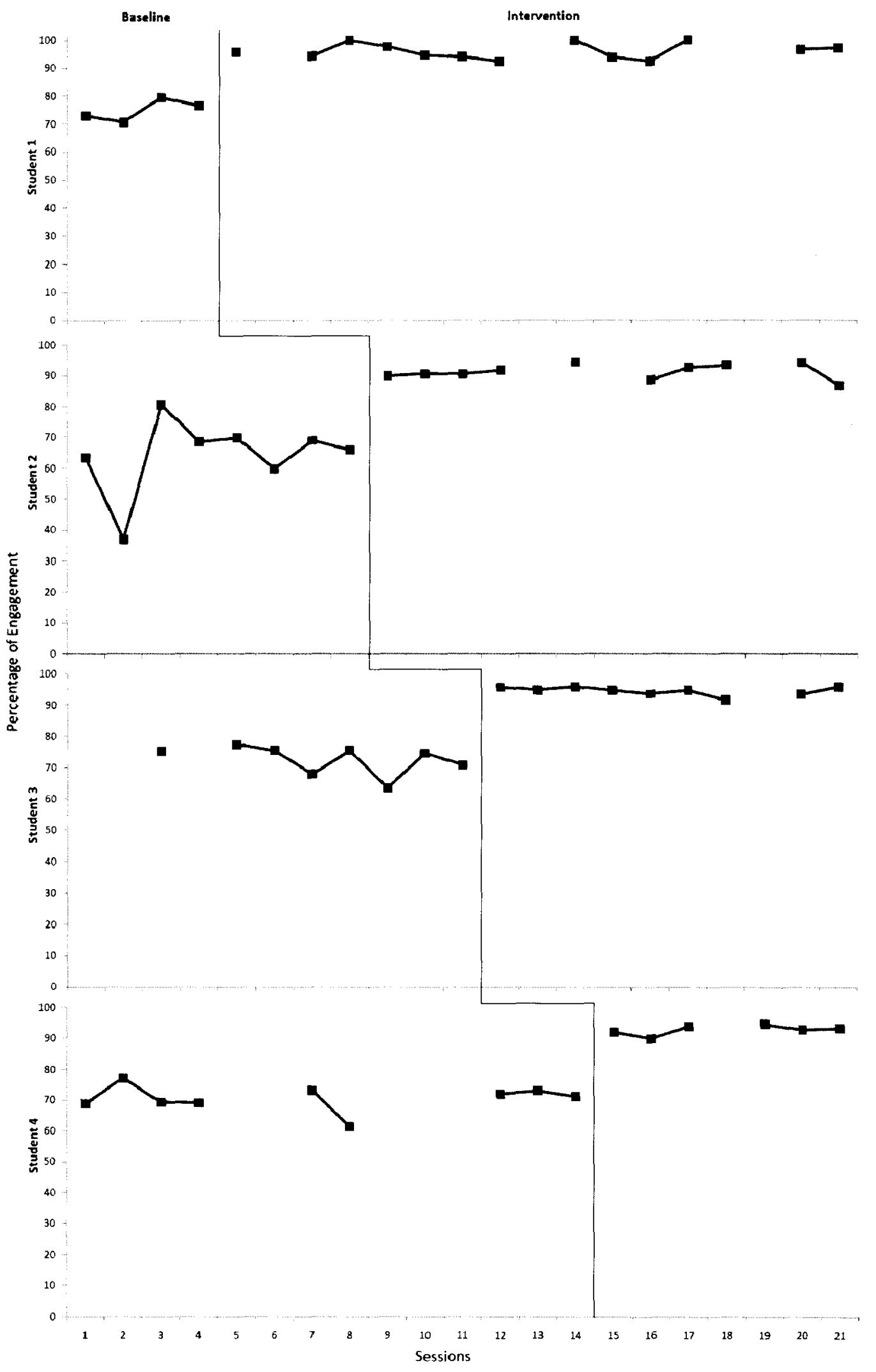


Figure 4-2. Percentage of Student Passive Engagement

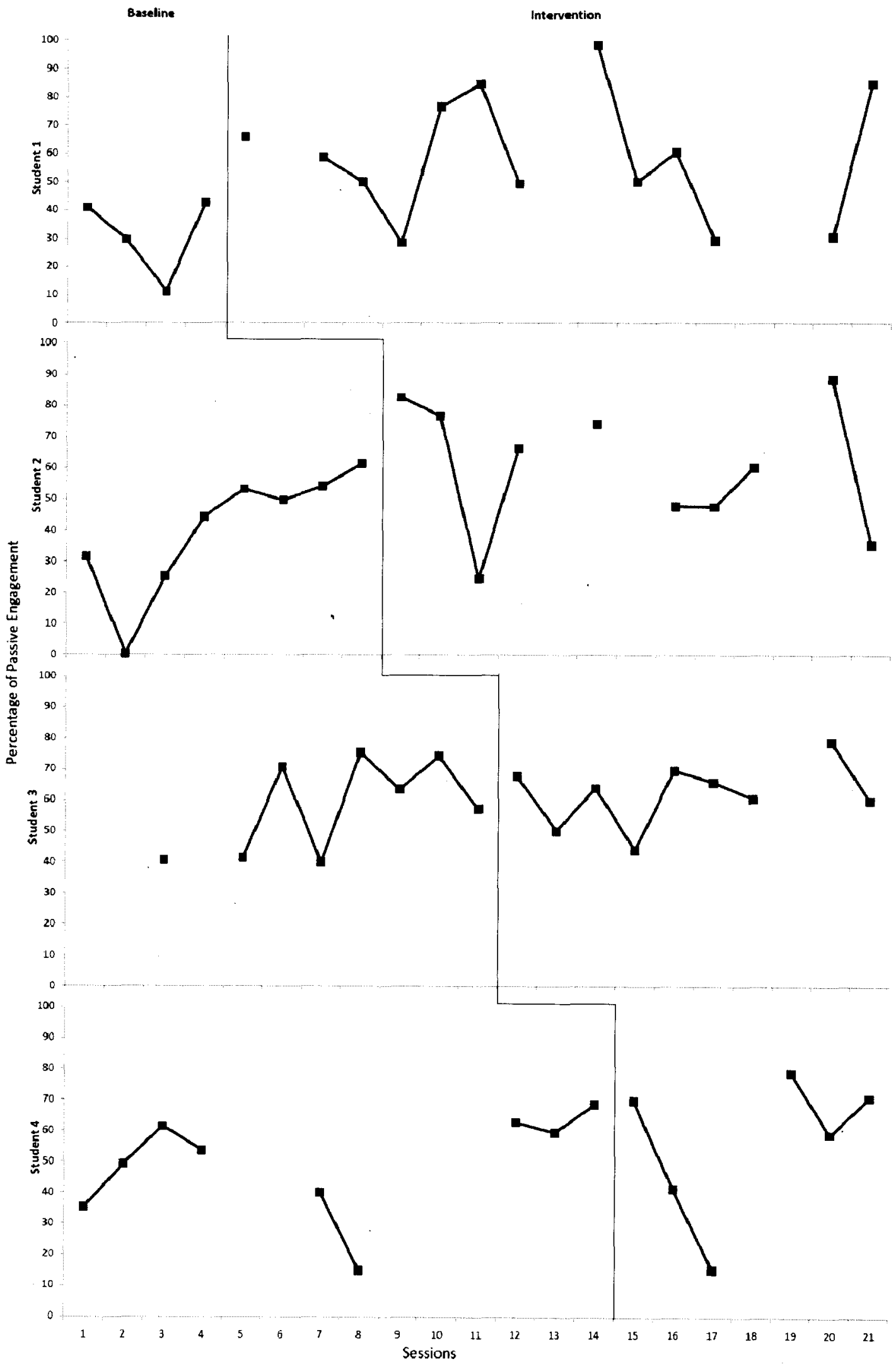

98 
Figure 4-3. Percentage of Student Active Engagement

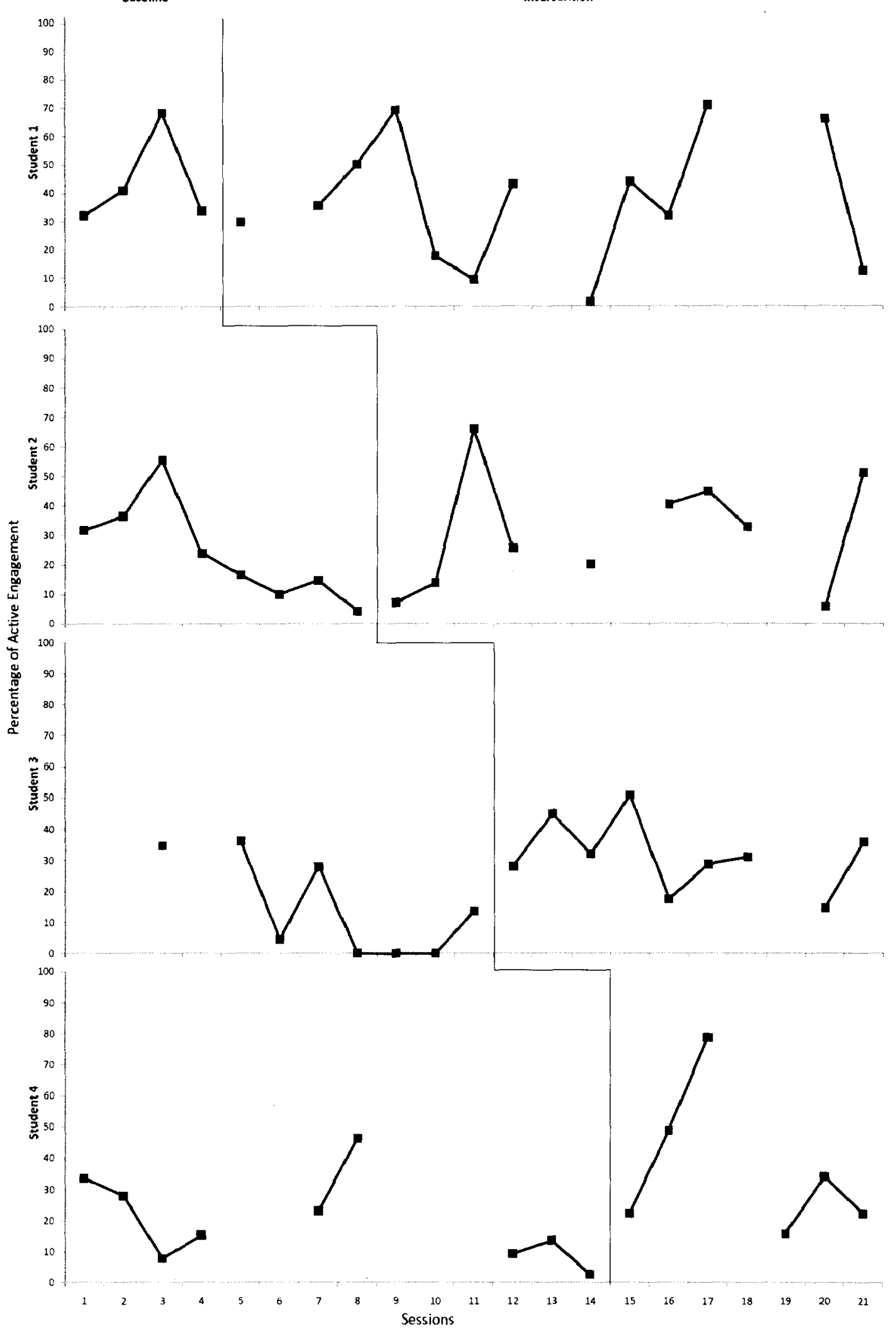

99 
Figure 4-4. Number of Student Disruptions

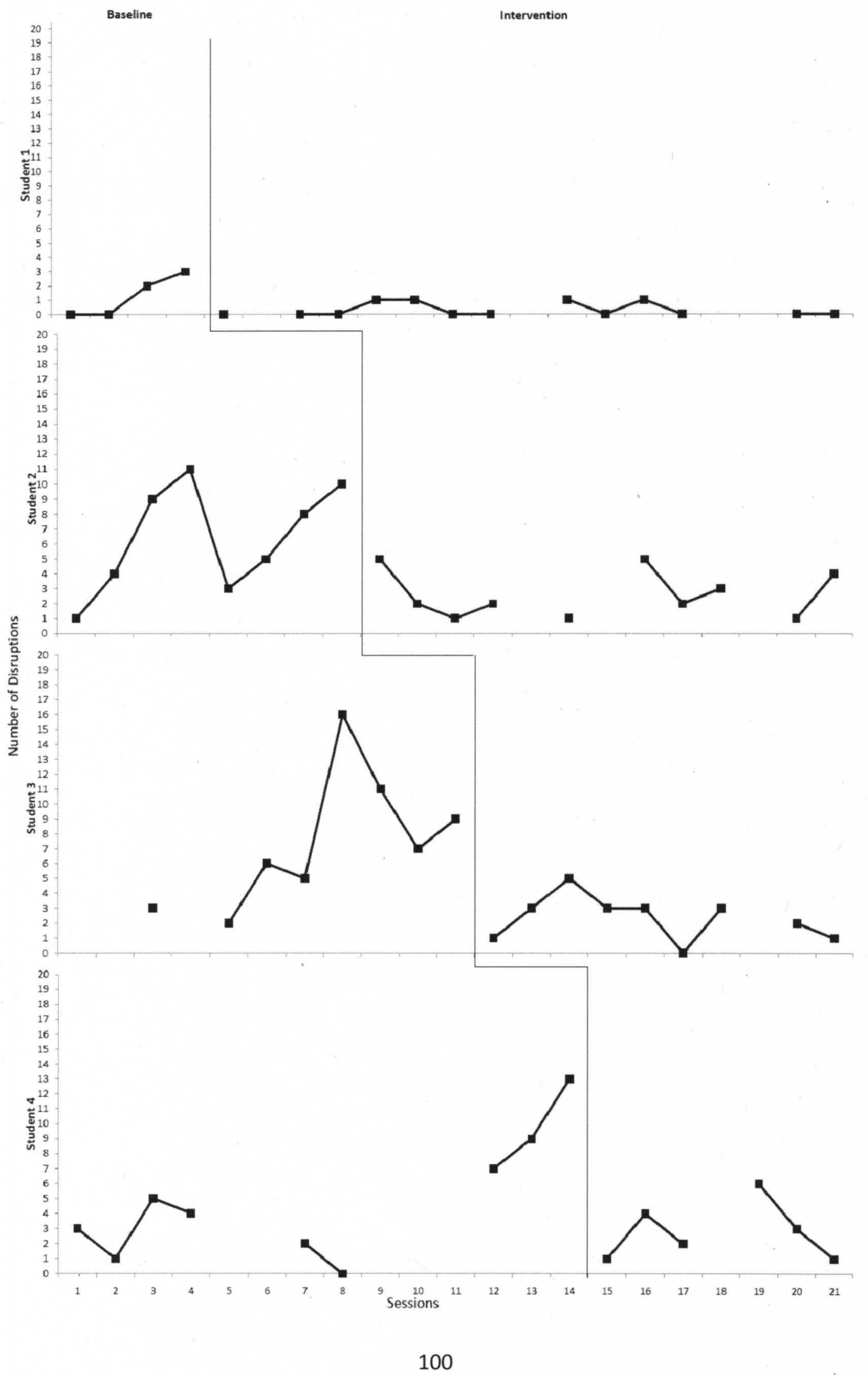


Figure 4-5. Rate of Total Teacher OTR

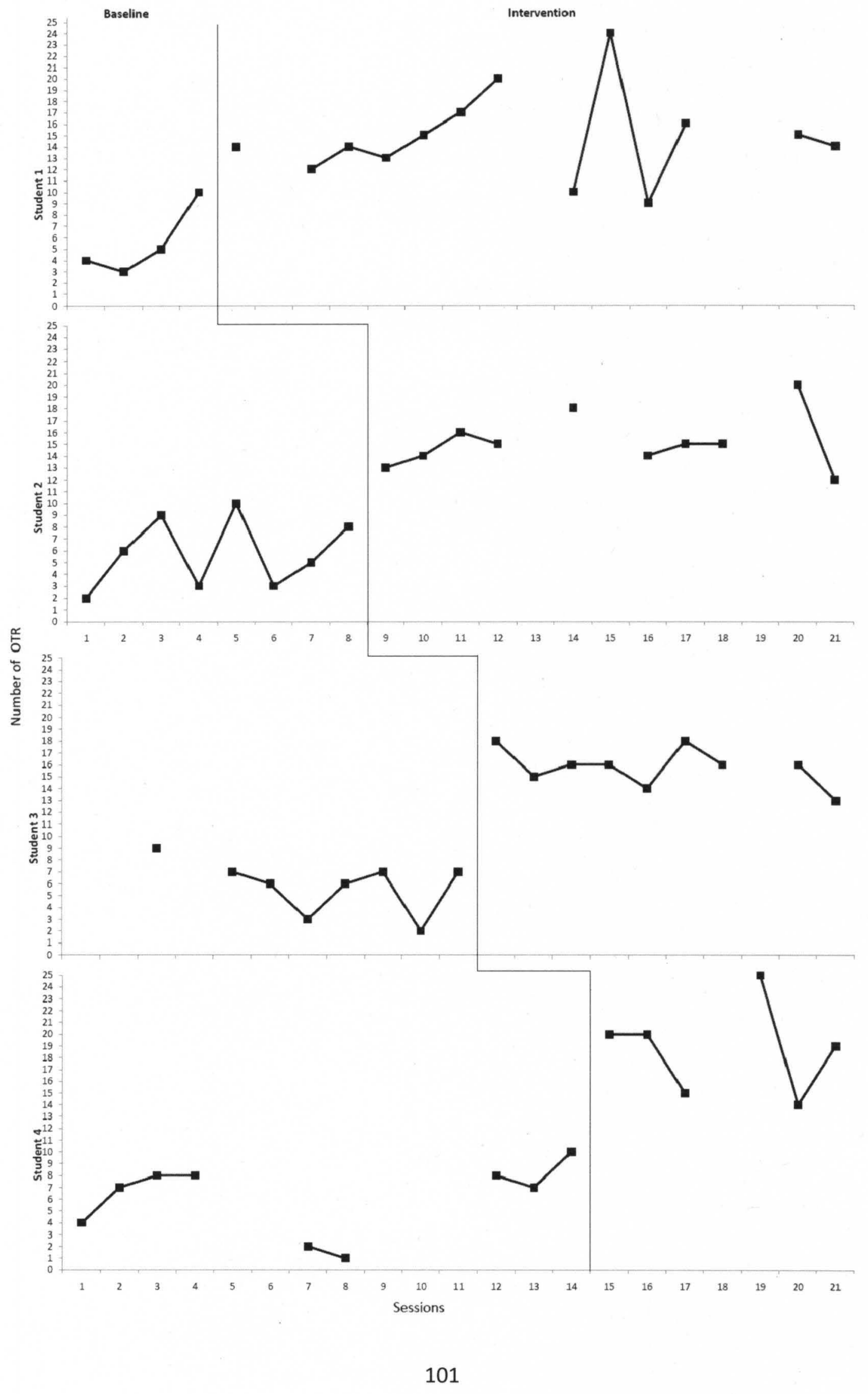


Figure 4-6. Rate of Teacher OTR Group

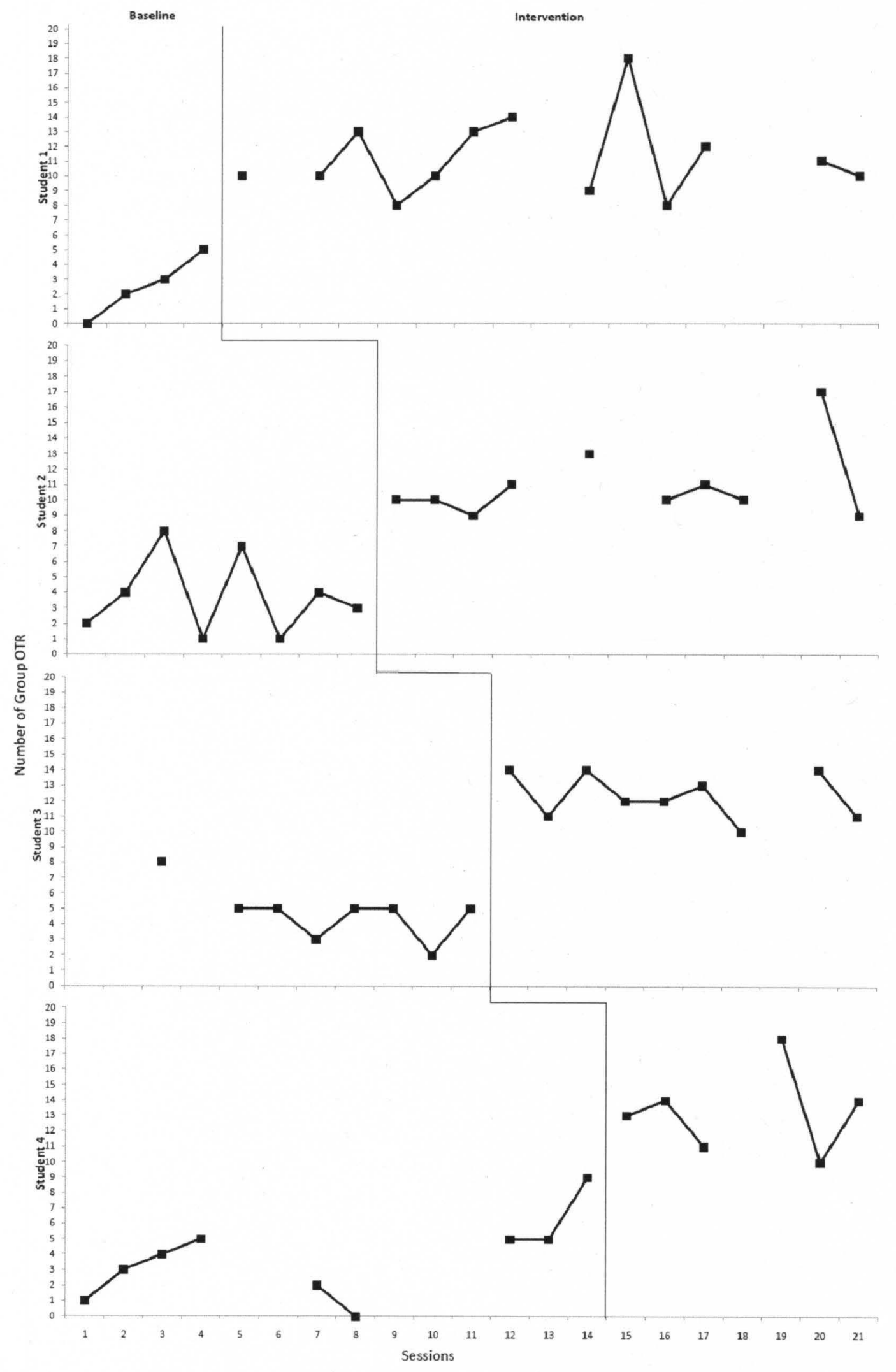


Figure 4-7. Rate of Teacher OTR Individual

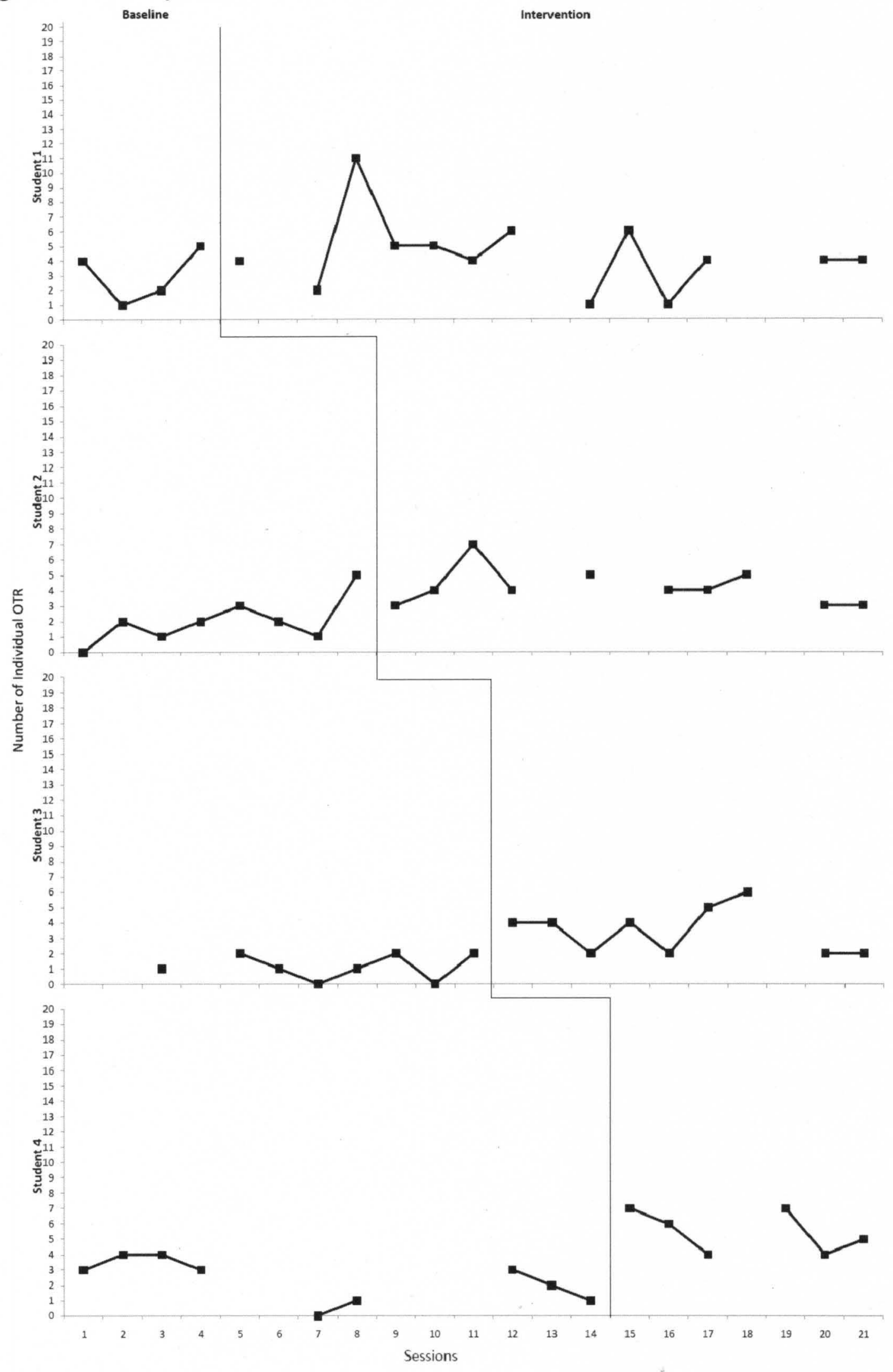




\section{CHAPTER 5}

DISCUSSION

The purpose of this chapter is to interpret and explain the results of the current study which examined the effects of integrating children's literature in mathematics instruction on the academic and behavioral outcomes of elementary students with academic difficulty and challenging behaviors. Specifically, the study examined the effects of this curricular approach on increasing student engagement, reducing disruptive behaviors, and increasing the teacher's rate of providing opportunities to respond for four students, grades three through five, identified as exhibiting academic difficulty and challenging behaviors during Tier II mathematics instruction. In addition, a secondary goal was to examine the effects of integrating children's literature on the academic performance of four students identified as exhibiting academic difficulty and challenging behaviors during Tier II mathematics instruction. The discussion will focus on how these findings contribute to the existing literature and educational implications. This will include a discussion of limitations and suggestions for future research.

\section{Key Findings}

This study identifies several key findings. A detailed discussion of these findings in relation to each research question will follow. The discussion will include an interpretation of the results as well as how the results support and extend the research in the field on integrating children's literature in mathematics instruction. 


\section{Effects of Integrating Children's Literature in Mathematics Instruction on Increasing Student Engagement While Decreasing Disruptive Behaviors}

This study investigated if integrating children's literature in mathematics instruction can be effective in increasing student engagement while decreasing disruptive behaviors during mathematics instruction for students with academic difficulties and challenging behaviors.

Student Engagement. For the student to be considered engaged, or on-task, he or she had to be responding to teacher prompt or instruction which included: (a) choral responding, (b) verbally answering a teacher directed question, (c) raising hand, (d) writing, or (e) reading; or looking in the direction of teacher or at another student who is called on to speak by the teacher. Results indicated that integrating children's literature in mathematics instruction is an effective curricular approach in increasing engagement for students with academic difficulties and challenging behaviors. Four out of four participants had higher mean percentages of engagement during the intervention condition when compared to the baseline condition. The mean percentage of engagement for all participants was $69.98 \%$ during baseline condition and $93.91 \%$ during intervention condition. Experimental control was demonstrated when students exhibited increasing percentages of engagement only after the intervention was introduced. Replicating the positive results across each of the four participants in a time-lagged manner strengthened the external validity of the results. Data collected during the intervention condition indicated there were no overlap with data collected during the baseline condition for all four participants. The lack of overlap provides additional evidence to the effectiveness of this approach in increasing student 
engagement because it gives a convincing demonstration that the intervention was responsible for the experimental effect and not confounding variables (Gast, 2010). It implies that the change in the dependent variable, student engagement, only occurred when the independent variable, children's literature mathematics lessons, was introduced.

Previous studies have suggested that integrating children's literature in mathematics had a positive impact on factors related to student engagement in mathematics such as student interest (Jennings, et al., 1992), student disposition (Hong, 1996), student mathematical communication (Capraro \& Capraro, 2006), and student confidence in mathematics (Keat \& Wilburne, 2009). Although these variables are related to student engagement, no prior study investigated the effects of integrating children's literature in mathematics instruction on increasing student on-task behavior. Therefore, the results of this study extend the research in the field on integrating children's literature in mathematics instruction on student engagement.

Levels of Engagement. Although examining the effects of children's literature in mathematics on overall student engagement was the primary goal of this study, types of engagement were also examined to see if this curricular approach increased passive engagement, active engagement, or both. As previously mentioned, for the student to be considered passively engaged in the instructional lesson, he or she had to be looking in the direction of teacher or looking at another student who is called on to speak by the teacher; and for the student to be considered actively engaged in the instructional lesson, he or she had to be responding to teacher prompt or instruction which included: 
(a) choral responding, (b) verbally answering a teacher directed question, (c) raising hand, (d) writing, or (e) reading. The mean percentage of passive engagement for all participants was $59.69 \%$ during intervention condition compared to $46.71 \%$ during baseline condition; and the mean percentage of active engagement for all participants was $34.05 \%$ during intervention condition compared to $22.91 \%$ during baseline condition. Furthermore, the individual mean percentage of passive engagement for all four participants increased during intervention condition while the individual mean percentage of active engagement increased for three of four participants, with one participant having a decrease in active engagement.

Although the mean percentages may suggest that integrating children's literature is associated with higher passive engagement, this conclusion cannot be made. The data for both passive engagement and active engagement had high variability during baseline and intervention conditions as well as a high percentage of overlapping data points. This makes it difficult to demonstrate experimental control. Therefore, under conditions of this study, integrating children's literature in mathematics instruction is an effective curricular approach in increasing the overall engagement for students with academic difficulties and challenging behaviors but the type of engagement this curricular approach increases cannot be determined.

Disruptive Behavior. Results were not definitive regarding the effectiveness of integrating children's literature in mathematics instruction on decreasing disruptive behavior for students with academic difficulties and challenging behaviors. The mean number of disruptions decreased from baseline condition to intervention condition for 
four out of four participants, ranging from a decrease of .94 disruptions (S1) to a decrease of 5.05 disruptions (S3). Although student participants in this study showed a decrease in disruptions, the non-overlapping data points between conditions and variability of the data were high for all four participants. The high variability and overlapping data make it difficult to infer a functional relationship between integrating children's literature in mathematics instruction and decreasing disruptive behaviors for students with academic difficulties and challenging behaviors.

It is important to note that baseline disruptive behavior levels were not drastically high, ranging from 1.25 (S1) to 7.38 (S3). In addition, individual baseline data points of disruptive behavior during baseline condition show two participants had at least one session of zero disruptions (\$1, S4), one participant had at least one session of one disruption (S3), and one participant had at least one session of two disruptions (S2). Based on this information, the high overlapping data is not surprising. Furthermore, although the data during the intervention condition did not meet the criteria of being stable, it showed more stability than data in the baseline condition. Nonetheless, although a functional relationship cannot be established, any decrease in student disruptions can be beneficial to educators since fewer student disruptions can lead to more time spent on instruction.

Effects of Integrating Children's Literature in Mathematics Instruction on Increasing the Teacher's Rate of Providing Opportunities to Respond

This study examined the effects of integrating children's literature in mathematics instruction on teacher behaviors such as increasing students' opportunities to respond. This teacher behavior has not been addressed in previous 
research studies regarding this curricular approach. Results of the teacher giving opportunities to respond (OTR) suggest there may be a functional relationship between integrating children's literature in mathematics instruction and the teacher's rate of OTR. Results indicate the teacher provided a higher rate of OTR for four out of four participants during the intervention condition when compared to the baseline condition. Experimental control was demonstrated when the teacher exhibited increasing rates of providing opportunities to respond only after the intervention was introduced and replicating the positive results across each of the four participants in a time-lagged manner strengthened the external validity. Data collected during the intervention condition indicated there was no overlap with data collected during the baseline condition for three participants and only $15 \%$ overlap for one participant. The low percentage of overlap provides additional evidence to the effectiveness of this approach in increasing the teacher's rate of OTR because it gives a convincing demonstration that the intervention was responsible for the experimental effect and not confounding variables (Gast, 2010). These results are promising since increasing the rate of OTR has been shown to improve student mathematics performance (Christle \& Schuster, 2003; Lambert, et al., 2006; Skinner, et al., 1997; Skinner, et al., 1991; Sutherland, et al., 2003), increase student engagement during mathematics instruction (Carnine, 1976; Christle \& Schuster, 2003; Davis \& O’Neil, 2004; Haydon, et al., 2010; Haydon, et al., 2009; McKenzie \& Henry, 1979; Sutherland, et al., 2003), and decrease disruptive behavior during mathematics instruction (Armendariz \& Umbreit, 1999; 
Haydon, et al., 2010; Haydon, et al., 2009; Lambert, et al., 2006; Sutherland, et al., 2003;

West \& Sloan, 1986).

Levels of OTR. Although examining the effects of children's literature in mathematics on the teacher's rate of OTR was the primary goal of this study, types of OTR were also examined to see if this curricular approach increased individual OTR, group OTR, or both. OTR group was defined as the teacher providing an opportunity to respond that is directed to the whole class and OTR individual was defined as the teacher providing an opportunity to respond to the student participant in the class. Results of group OTR suggest there may be a functional relationship between integrating children's literature in mathematics instruction and the teacher's rate of providing group OTR. The teacher provided a higher rate of group OTR during the intervention condition for all students when compared to the baseline condition. Furthermore, there were no overlapping data points between conditions and the variability of the data was moderate to small during the intervention condition. On the other hand, the results of individual OTR were not as clear. Although the mean number of individual OTR for all four participants was higher during intervention condition than during baseline condition, the non-overlapping data points between conditions and the variability of the data were moderate to high during the intervention condition. This makes it difficult to demonstrate experimental control and weakens the demonstration that the intervention was responsible for the experimental effect and not due to confounding variables (Gast, 2010). 
These results can be interpreted as positive based on previous literature. First, prior research has shown that providing group OTR is a more effective instructional strategy than individual OTR in decreasing disruptive behavior and increasing on-task behavior (McKenzie \& Henry, 1979; Sutherland, et al., 2003; Haydon, et al., 2009). Furthermore, Haydon, et al. (2010) found that mixed responding (70\% choral responding; $30 \%$ individual responding) was a more effective instructional strategy than only using choral responding or only using individual responding in reducing disruptive behaviors and increasing on-task behaviors on elementary students with behavior problems. When comparing the total mean rate of teacher OTR in this study, the teacher averaged 11.16 OTR group and 4.29 OTR individual during the intervention condition, which is a ratio of $73 \%$ OTR group and $27 \%$ OTR individual. Although OTR group was not defined solely as choral responding in this current study, the outcomes of this study could potentially support the previous findings regarding mixed responding.

\section{Effects of Integrating Children's Literature in Mathematics Instruction on Student Academic Achievement}

Results pertaining to the secondary research question, which examined the effects of this curricular approach on increasing mathematics achievement for students with academic difficulties and challenging behaviors during mathematics instruction, yielded no results of significance. Statistical analysis of scores from the KeyMath3 Diagnostic Assessment (Connolly, 2007)showed that there was no statistically significant difference between the students' pretest and posttest scores on the three general content areas (basic concepts, operations, and applications) and total score. In addition, there was no significant main effect of subtest scores related to the content and 
concepts being taught to each participant in the study and no significant differences between the three mean subtest scores. These results do not support integrating children's literature in mathematics instruction increases mathematics achievement for students with academic difficulties and challenging behaviors.

These results are similar to prior studies that used standardized assessments to evaluate the effects of children's literature in mathematics on student achievement. Jennings, et al. (1992) found no statistically significant difference between the experimental and control group on the Operations or the Concepts subtests of the Metropolitan Readiness Test (MRT). In addition, Hong (1996) found no significant differences in achievement between the experimental and control group using the Early Mathematics Achievement Test (EMAT). The consistency of insignificant results using standardized achievement assessments to examine this curricular approach raises questions that will be discussed in further detail in the limitations section.

\section{Importance of Findings}

The key findings of this study suggest that integrating children's literature in mathematics instruction is effective for increasing student engagement and increasing the rate of teacher OTR. These results are promising when relating to the conceptual model for integrating children's literature in mathematics instruction (see Chapter 2, Figure 2-1). The researcher-created lessons established a different context as well as provided a real-world connection to mathematical problems. This, in turn, increased student engagement through providing an increase in opportunities for students to respond and modeling of mathematics concepts by both the teacher and peers. 
Although a functional relationship cannot be established between integrating children's literature in mathematics instruction and a decrease in disruptive behavior and there were no results of significance on student mathematics achievement, this is not to say that it will not have an effect in time. Barrentine (1996) states "with repeated engagement in demonstrations children internalize the ability to use process and strategy information" (p. 38). An increase in engagement can potentially lead to an increase in mathematics performance and a decrease in inappropriate behavior.

\section{Limitations and Future Research}

Several limitations of this study have been identified and should be considered when interpreting current findings as well as conducting future research pertaining to integrating children's literature in mathematics. The most serious limitations of this study are in regards to examining the effects of this curricular approach on increasing mathematics achievement. First, the sample size of the proposed study $(n=4)$ is very small for statistical analysis which could have led to the lack of a statistically significant difference in student scores. Keppel and Wickens (2004) state "when you have only a small number of subjects, you are unlikely to detect anything but a large effect" (p. 169) which increases the difficulty of detecting significance. Furthermore, Stevens (2009) states the power of a statistical test is the "probability of making a correct decision, or saying the groups differ when in fact they do" (p. 4) and is heavily influenced by sample size. Low power can increase the likelihood of a Type II error occurring and result in not detecting a significant difference between pretest and posttest measures when there actually is a difference. Future research studies should consider using a larger sample 
size when examining the effects of this curricular approach on student mathematics performance.

Secondly, the instrument used to assess student academic achievement, the KeyMath3 Diagnostic Assessment, may not have been sensitive enough to detect small differences in student achievement in such a short period of time (i.e., eight weeks). This assessment was chosen because it is a norm-referenced assessment that had been previously validated and had high reliability. According to Henson (2001), reliability is critical when interpreting the effects of studies and test results. He states "the more measurement error that exists in our scores, the less useful these scores may be for analysis, interpretation, and clinical purposes" (p. 179). Creating an assessment that would be more specific to the content being taught (e.g., diagnostic interview), thus having the potential to detect small differences in achievement if one was present, was not possible in this study without losing validity and reliability. Shaddish, et al. (2002) state, "Unnecessary tradeoffs between one kind of validity and another have to be avoided, and the loss entailed by necessary tradeoffs has to be estimated and minimized" (p. 96). Future research studies should consider one of two options. If a standardized assessment is going to be used, the length of the study should be longer (e.g., at least six months); or if creating a new instrument, the instrument should be validated on a sample of students prior to the study as well as measuring the reliability.

The third limitation of the study is in regards to the loss of instructional sessions due to history effects. Prior to the start of the study, it was estimated that there would be between 30 to 35 instructional sessions for all student participants. This number was 
reduced to S1 having a total of 17 observed lessons, S2 having a total of 18 observed lessons, S3 having a total of 17 observed lessons, and S4 having a total of 15 observed lessons. Events that were uncontrollable to the researcher included: student and teacher absences, student in-school suspensions, school assemblies, state-wide testing, class field trips, and teacher cancelling groups to cover other teacher absences. The loss of instructional time limited the length of the intervention which could have possibly affected student achievement data as well as student and teacher behavior data.

The final limitation of the study is in regards to external validity and reliability of the multiple baseline design across participants. Due to the small number of participants inherent in single subject designs, external validity "is primarily accomplished through a series of systematic replication studies in which investigators, participants, settings, etc. differ from previous studies and yield the same outcome" (Gast, 2010, p. 124-125). Furthermore, although the multiple baseline design across participants builds external validity due to the inter-subject replication within the design, it lacks intra-subject replication. Gast (2010) describes intra-subject replication as "repeating the experimental effect with the same participant more than once in the same study" (p. 113). Intra-subject replication allows for greater confidence in demonstrating reliability of the effects of the intervention which, according to Gast (2010), is "a more convincing demonstration of reliability than inter-subject replication, a design characteristic and limitation of many, if not most, large-group research designs, as well as some single subject research designs, most notably multiple baseline design across participants" (p. 124). In order to increase the external validity and the reliability 
of integrating children's literature in mathematics instruction on students with academic difficulties and challenging behaviors, future direct and systematic replications will be needed. Specifically, future research should use the same procedures described in this study to add to the external validity and reliability of the results for the current study. In addition, future studies examining the effectiveness of integrating children's literature in mathematics instruction are needed across persons to support and extend this study's findings as well as prior research. The current study examined the effectiveness of integrating children's literature in mathematics instruction on students potentially at-risk for learning or behavioral disorders. Future research should be conducted for students already identified with a learning or behavioral disorder (e.g., mathematics disability, reading disability, Mild Mental Disability, Emotional Behavior Disorder or Other Health Impaired). There is also a need for research on integrating children's literature in mathematics instruction across settings. Settings should not only include other grade levels in elementary, but also evaluate the effectiveness of this practice in middle and high school settings. Future research should also be conducted in other small group settings which could include self-contained classrooms for students with learning disabilities (LD) or emotional behavior disorders (EBD) and Tier III mathematics intervention groups.

\section{Educational Implications}

Nationally, there are increasing numbers of students who are at-risk for academic and/or social failure (U.S. Department of Education, 2009). In an attempt to address this trend, the 2004 reauthorization of the Individuals with Disabilities 
Education Act (PL 108-446) encouraged educators to provide early and appropriate interventions not only to identify and help children with disabilities, but to also provide additional supports for students with academic difficulties and challenging behaviors. Although there have been evidenced-based academic interventions pertaining to students with challenging behaviors, most of the literature has been focused on reading interventions rather than mathematics interventions (Bos \& Vaughn, 2005). This study suggests that integrating children's literature in mathematics instruction is a curricular approach that educators can implement in an effort to increase the engagement of students with academic difficulties and challenging behaviors in mathematics which can potentially decrease disruptions and increase mathematics achievement. This finding has implications for students with academic difficulties and challenging behaviors and the teachers who provide their mathematics instruction. This includes regular education teachers and special educators.

\section{Implications for Students with Academic Difficulties and Challenging Behaviors}

Academic engagement is imperative for the learning and success for all students, including students with academic difficulties and challenging behaviors. Students who are engaged in the learning process are less likely to exhibit inappropriate behaviors and more likely to achieve academic success (Conroy, et al., 2008; Simonsen, et al., 2008; Sutherland \& Wehby, 2001). Conversely, if students are not academically engaged, it increases the likelihood of negative behavioral outcomes and increases the chances of falling behind academically. Scott, Nelson, and Liaupsin (2001) state "academic failure leads to student avoidance of academic tasks, which, in turn, sets the occasion for 
increasing academic deficits and further negative interactions with teachers" (p. 313) but "there is substantial evidence that early identification of, and intervention for, academic learning problems reduces the likelihood that students will engage in disruptive classroom behavior" (p. 311). This study suggests that integrating children's literature in mathematics instruction is a curricular approach that promotes engagement, as it was defined in the study, for students with academic difficulties and challenging behaviors in mathematics. This can not only be seen in the data previously reported on student engagement, but also in the responses of the students on the social validity questionnaire. When asked whether they liked the children's literature mathematics lessons, four out of four student participants indicated that they did. Students responded that they liked that the children's literature mathematics lessons "helps you more", that it helped them "learn more math", and "made math more easier". Furthermore, all four students wanted their teacher to continue using children's literature during mathematics instruction and two students suggested that they would like to use this curricular approach for the learning of other mathematics content areas such as addition, multiplication, and addition.

\section{Implications for Teachers}

Because of national legislation and high-stakes accountability, teachers have been challenged to teach mathematics in different ways from those of the past. The findings in this study indicate that integrating children's literature in mathematics can be implemented in a Tier II intervention setting to provide additional supports for students with academic difficulties and challenging behaviors. This integration offers 
both regular education and special education teachers another resource to use in their efforts to provide these students with research-based academic interventions. This is especially important when specifically targeting students with challenging behaviors since most of the literature has been focused on reading interventions rather than mathematics interventions (Bos \& Vaughn, 2005).

In addition, the researcher-created lessons incorporated explicit instruction that included modeling, talk alouds, guided practice, corrective feedback, and formative assessment; and the lessons incorporated solving word problems based on common underlying structures. The Institute of Education Sciences (IES) has determined there is strong evidence (i.e., studies with high internal validity and high external validity) supporting these practices to assists students struggling in mathematics (Gersten, R., Beckmann, S., Clarke, B., Foegen, A., Marsh, L., Star, J. R., \& Witzel, B., 2009). The lessons also incorporated the use of visual representations (i.e, manipulatives, drawings, and charts) which, according to IES, has moderate evidence (i.e., high internal validity but moderate external validity or high external validity but moderate internal validity) of support (Gersten, et al., 2009).

The findings in this study indicate that the interactive read aloud was effective in raising the teacher's rate of providing students an opportunity to respond. Furthermore, it increased both types of opportunities to respond, but had a bigger increase for group opportunities to respond. The implications of this finding for teachers are important in several ways. As previously mentioned, increasing the rate of OTR has been shown to improve student mathematics performance, increase student 
engagement, and decrease student disruptions during mathematics instruction. In addition, the students were learning mathematics through communication which has been determined to be an integral part of effective mathematics instruction (NCTM, 2000). Increasing communication not only allows students to explain their thinking which is positively related to achievement outcomes (Fuchs, et al., 1997; Nattiv, 1994; \& Webb, 1991), it also gives the teacher an opportunity to formatively assess individual student learning (Franke, et al., 1997). An example of this can be seen in the teacher's comments on the social validity questionnaire. The teacher commented, "I would say to take the opportunity to use the lesson for teachable moments. Don't stick so much to the script. Sometimes one group might lead you in one direction, where another group might take a totally different view on the lesson. That's okay; let students lead the lesson where they need to be taught."

As with all intervention programs for classroom settings, providing efficient, teacher-friendly interventions is necessary for continued implementation. Treatment fidelity scores, as measured by the researcher and data collectors, suggested that the teacher was able to implement the children's literature mathematics lessons with a high level of fidelity $(M=93 \%)$. The teacher indicated on the social validity questionnaire that not only did she find the children's literature mathematics lessons easy to implement, it also increased student engagement and decreased disruptions during mathematics instruction. Furthermore, the teacher stated that she would use this curricular approach in the future and is giving a list of the books and lessons to other teachers so they can implement in their classrooms. 


\section{Implications for Practice}

Although this study suggests that integrating children's literature in mathematics instruction is effective for increasing student engagement and increasing the rate of teacher OTR, there are implications for teachers that need to be further addressed. The researcher of the study was responsible for reviewing the mathematics content and concepts being taught and selecting children's books that related to the concepts being covered. In addition, the researcher developed the lesson plans to introduce new concepts, reinforce concepts already learned, and/or expand on previous concepts learned. The teacher participating in the study was responsible for implementing the researcher-created lessons. For teachers to effectively incorporate interactive read alouds with children's literature during mathematics instruction there will be extensive preparation and planning involved. Children's books will need to be selected and reviewed for content and their relation to mathematical concepts. Furthermore, lesson plans will need to be created that incorporate meaningful and engaging contexts, provide real-world connections, and promote student communication of mathematical practices. Fortunately, there are many books pertaining to teaching mathematics and literature that can be of resource such as Math Through Children's Literature: Making the NCTM Standards Come Alive (Braddon, et al., 1993; How To Use Children's Literature to Teach Mathematics (Welchman-Tischler, 1992); Exploring Mathematics through Literature: Articles and Lessons for Prekindergarten through Grade 8 (National Council of Teachers of Mathematics, 2004); Math and Literature: Grades K-1 (Burns \& Sheffield, 2004); and Math and Literature: Grades 2-3 (Burns \& Sheffield, 2004). 


\section{Conclusion}

This study can be viewed as being both methodologically and pragmatically successful. This study was methodologically successful for the following reasons: (a) it gave a detailed description of the participants, selection criteria, and setting to allow for replication; (b) the dependent variables were operationally defined, continuously measured, and reliability was conducted; (c) the independent variable was described to allow for replication and procedural reliability was conducted; (d) the baseline conditions were described in detail; (e) it systematically introduced the intervention in a time-lagged manner adhering to predetermined criteria; $(f)$ and assessed social validity from both the teacher and student perspective. The study was pragmatically successful in that a clear functional relationship was established between integrating children's literature in mathematics instruction and increasing student engagement and increasing the teacher's rate of OTR.

In summary, this study suggests that integrating children's literature in mathematics instruction is effective for increasing student engagement and increasing the rate of teacher OTR. Although statistically significant results were not obtained from academic achievement data, it does not diminish the study's positive findings since student academic engagement can lead to increased learning opportunities in the long term. This, in turn, can potentially increase mathematics achievement for students with academic difficulties and challenging behaviors. Integrating children's literature in mathematics instruction is a curricular approach that can be used by educators to provide early and appropriate interventions not only to identify and help children with 
disabilities, but to also provide additional supports for students with academic difficulties and challenging behaviors. 


\section{REFERENCES}

Anderson, R. C., (1985). Becoming a nation of readers: The report of the commission on reading. Washington, DC: National Academy of Education. Retrieved from ERIC database.

Armendariz, F., \& Umbreit, J. (1999). Using active responding to reduce disruptive behavior in a general education classroom. Journal of Positive Behavior Interventions, 1(3), 152 - 158. doi: 10.1177/109830079900100303

Baldi, S., Jin, Y., Skemer, M., Green, P.J., and Herget, D. (2007). Highlights from PISA 2006: Performance of U.S. 15-year-old students in science and mathematics literacy in an international context (NCES 2008-016). National Center for Education Statistics, Institute of Education Sciences, U.S. Department of Education. Washington, DC. Retrieved from http://nces.ed.gov/pubs2008 /2008016.pdf

Barrentine, S.J. (1996). Engaging with reading through interactive read-alouds. The Reading Teacher, 50(1), 36-43. Retrieved from ERIC database.

Barry, T.D., Lyman, R.D., \& Klinger, L.G. (2002). Academic underachievement and attention-deficit/hyperactivity disorder: The negative impact of symptom severity on school performance. Journal of School Psychology, 40(3), 259-283. doi: $10.1016 / \mathrm{S} 0022-4405(02) 00100-0$ 
Bos, C., \& Vaughn, S. (2005). Strategies for teaching students with learning and behavior problems. Boston, MA: Pearson Education.

Braddon, K.L., Hall, N.J., \& Taylor, D. (1993). Math through children's literature: Making the NCTM standards come alive. Englewood, CA: Teacher Ideas Press.

Burns, M., \& Sheffield, S. (2004). Math and literature: Grades $K-1$. Sausalito, CA: Math Solutions.

Burns, M., \& Sheffield, S. (2004). Math and literature: Grades 2-3. Sausalito, CA: Math Solutions.

Cambourne, B.L. (1988). The whole story: Natural learning and the acquisition of literacy. Auckland, New Zealand: Ashton-Scholastic.

Cambourne, B.L. (1995). Toward an educationally relevant theory of literacy learning: Twenty years of inquiry. The Reading Teacher, 49(3), 182-190. Retrieved from ERIC database.

Capraro, R.M., \& Capraro, M.M. (2006). Are you really going to read us a story? Learning geometry through children's mathematics literature. Reading Psychology, 27(1), 21-36. doi: 10.1080/02702710500468716

Carnine, D.W. (1976). Effects of two teacher-presentation rates on off-task behavior, answering correctly, and participation. Journal of Applied Behavior Analysis, 9(2), 199-206. doi: 10.1901/jaba.1976.9-199.

Casey, B., Erkut, S., Ceder, I., \& Young, J.M. (2008). Use of a storytelling context to improve girls' and boys' geometry skills in kindergarten. Journal of Applied Developmental Psychology, 29, 29-48. doi: 10.1016/j.ecresq.2004.01.001 
Cazden, C.B. (2001). Classroom discourse ( $2^{\text {nd }}$ ed.). Portsmouth, NJ: Heinemann.

Christle, C.A., \& Schuster, C.A. (2003). The effects of using response cards on student participation, academic achievement, and on-task behavior during whole-class, math instruction. Journal of Behavioral Education, 12(3), 147-165. doi: $10.1023 / A: 1025577410113$

Cohen, J. (1988). Statistical power analysis for the behavioral sciences $\left(2^{\text {nd }}\right.$ ed.). New Jersey: Lawrence Erlbaum.

Columba, L., Kim, Y., \& Moe, A.J. (2009). The power of picture books in teaching math, science, and social studies (2nd ed.). Scottsdale, AZ: Holcomb Hathaway.

Connolly, A.J. (2007). KeyMath-3 DA publication summary form. San Antonio, TX: Pearson. Retrieved from http://psychcorp.pearsonassessments.com /hai/images/pa/products/ keymath3_da/km3-da-pub-summary.pdf

Conroy, M.A., Sutherland, K.S., Snyder, A.L., \& Marsh, S. (2008). Classwide interventions: Effective instruction makes a difference. Teaching Exceptional Children, 40(6), 24-30. Retrieved from ERIC database.

Czerniak, C.M., Weber, W.B, Jr., Sandmann, A., \& Ahern, J. (1999). A literature review of science and mathematics integration. School Science and Mathematics, 99(8), 421-430. doi: 10.1111/j.1949-8594.1999.tb17504.x

Data Accountability Center. (2010). Table 2.2.: Number and percentage of students ages 6 through 21 served under IDEA, Part $B$, by educational environment and state: Fall 2008. Retrieved from https://www.ideadata.org/arc_toc10.asp\#partbLRE 
Davis, L.L., \& O'Neil, R.E. (2004). Use of response cards with a group of students with learning disabilities including those for whom English is a second language. Journal of Applied Behavior Analysis, 37(2), 219-222. doi: 10.1901 /jaba.2004.37-219

Deno, S.L. (1998). Academic progress as incompatible behavior: Curriculum-based measurement (CBM) as intervention. Beyond Behavior, 9(3), 12-17.

Franke, M.L., Fennema, E., \& Carpenter, T.P. (1997). Teachers creating change: Examining evolving beliefs and classroom practices. In Fennema \& Nelson (Eds.), Mathematics teachers in transition (pp.-255-282). Mahwah, NJ: Lawrence Erlbaum Associates.

Fraser, B.J., Anderson, G.J., \& Walberg, H.J. (1991). Assessment of learning environments: Manual for Learning Environment Inventory (LEI) and My Class Inventory $(\mathrm{MCl})\left(3^{\text {rd }}\right.$ Ed.). Perth, Western Australia: Curtin University of Technology, Science and Mathematics Education Center. Retrieved from ERIC database.

Fuchs, L.S., Fuchs, D., Hamlitt, C.L., Phillips, N.B., Karns, K., \& Dutka, S. (1997). Enhancing students' helping behavior during peer-mediated instruction with conceptual mathematical explanations. Elementary School Journal, 97(3), 223-249. Retrieved from http://www.jstor.org/stable/1002198 
Fuchs, L.S., Fuchs, D., \& Hollenbeck, K.N. (2007). Extending responsiveness to intervention to mathematics at first and third grades. Learning Disabilities Research \& Practice, 22(1), 13-24. doi: 10.1111/j.1540-5826.2007.00227.x

Gast, D.L. (2010). Single subject research methodology in behavioral sciences. New York, NY: Routledge.

Geary, D. C. (2004). Mathematics and learning disabilities. Journal of Learning Disabilities, 37(1), 4-15. doi: 10.1177/00222194040370010201

Gersten, R., Beckmann, S., Clarke, B., Foegen, A., Marsh, L., Star, J. R., \& Witzel, B. (2009). Assisting students struggling with mathematics: Response to Intervention (RtI) for elementary and middle schools (NCEE 2009-4060). Washington, DC: National Center for Education Evaluation and Regional Assistance, Institute of Education Sciences, U.S. Department of Education. Retrieved from http://ies.ed.gov/ncee/wwc/publications/practiceguides/.

Gonzales, P., Williams, T., Jocelyn, L., Roey, S., Kastberg, D., and Brenwald, S. (2008). Highlights from TIMSS 2007: Mathematics and science achievement of U.S. fourth-and eighth-grade students in an international context (NCES 2009-001 Revised). National Center for Education Statistics, Institute of Education Sciences, U.S. Department of Education. Washington, DC. Retrieved from http://nces.ed.gov/pubs2009/2009001.pdf Graesser, A.C., \& Person, N.K. (1994). Question asking during tutoring. American Educational Research Journal, 31(1), 104-137. Retrieved from http://www.jstor.org/stable/1163269 
Greenwood, C.R., Delquadri, J.C., \& Hall, R.V. (1984). Opportunity to respond and student academic performance. In W.L. Heward, T.E Heron, D.S. Hill, \& J. Trap-Porter (eds.). Focus on behavior analysis in education (pp. 58-88), Columbus, $\mathrm{OH}$ : Merrill.

Griffin, S. (2007). SRA number worlds: A prevention/intervention math program. Columbus, OH: SRA/McGraw Hill.

Hamre, B.K., \& Pianta, R.C. (2001). Early teacher-child relationships and the trajectory of children's school outcomes through eighth grade. Child Development, 72(2), 625-638. doi: $10.1111 / 1467-8624.00301$

Haydon, T., Conroy, M.A., Scott, T.M., Sindelar, P.T., Barber, B.R., \& Orlando, A. (2010). A comparison of three types of opportunities to respond on student academic and social behaviors. Journal of Emotional and Behavioral Disorders, 18(1), 27-40. doi: 10.1177/1063426609333448

Haydon, T., Mancil, G.R., \& Van Loan, C. (2009). Using opportunities to respond in a general education classroom: A case study. Education and Treatment of Children, 32(2), $267-278$. doi: 10.1353/etc.0.0052

Henson, R.K. (2001). Understanding internal consistency reliability estimates: A conceptual primer on coefficient alpha. Measurement and Evaluation in Counseling and Development, 34(3), 177-189.

Hong, H. (1996). Effects of mathematics learning through children's literature on math achievement and dispositional outcomes. Early Childhood Research Quarterly, 11(4), 477-494. doi:10.1016/S0885-2006(96)90018-6 
Individuals with Disabilities Education Improvement Act of 2004, Pub. L. No. 108-446, §612, 118 Stat. 2676 (2004).

Jennings, C.M., Jennings, J.E., Richey, J., \& Dixon-Krauss, L. (1992). Increasing interest and achievement in mathematics through children's literature. Early Childhood Research Quarterly, 7(2), 263-276. doi: 10.1016/0885-2006(92)90008-M

Kaufman, A.S., \& Kaufman, N.L. (1983). K-ABC Kaufman Assessment Battery for Children. Circle Pines, MN: American Guidance Service.

Keat, J.B., \& Wilburne, J.M. (2009). The impact of storybooks on kindergarten children's mathematical achievement and approaches to learning. US-China Education Review, 6(7), 61-67. Retrieved from ERIC database.

Kennedy, C.H. (2005). Single-case designs for educational research. Boston, MA: Allyn and Bacon.

Kennedy, M. M. (2004). Reform ideals and teachers' practical intentions. Education Policy Analysis Archives, 12(13). Retrieved from http://epaa.asu.edu /epaa/v12n13/.

Keppel, G., \& Wickens, T.D. (2004). Design and analysis: A researcher's handbook (4 ${ }^{\text {th }}$ ed.). Upper Saddle River, NJ: Pearson - Prentice Hall.

Lambert, M.C., Cartledge, G, Heward, W.L., \& Lo, Y. (2006). Effects of response cards on disruptive behavior and academic responding during math lessons by fourthgrade urban students. Journal of Positive Behavior Interventions, 8(2), 88-99. doi: $10.1177 / 10983007060080020701$ 
Landerl, K., \& Moll, K. (2010). Comorbidity of learning disorders: Prevalence and familial transmission. Journal of Child Psychology and Psychiatry, 51(3), 287-294. doi: 10.1111/j.1469-7610.2009.02164.x

Lane, H.B., \& Wright, T.L. (2007). Maximizing the effectiveness of reading aloud. The Reading Teacher, 60(7), 668-675. doi: 10.1598/RT.60.7.7

Louie, J., Brodesky, A., Brett, J., Yang, L.M., \& Tan, Y. (2008). Math education practices for students with disabilities and other struggling learners: Case studies of six schools in two northeast and islands region states (Issues and Answers Report, REL 2008-No. 053). Washington, DC: U.S. Department of Education, Institute of Education Sciences, National Center for Education Evaluation and Regional Assistance, Regional Educational Laboratory Northeast and Islands. Retrieved from http://ies.ed.gov/ncee/edlabs.

McKenzie, G.R., \& Henry, M. (1979). Effects of testlike events on on-task behavior, testanxiety, and achievement in a classroom rule-learning task. Journal of Educational Psychology, 71(3), 370-374. doi: 10.1037/0022-0663.71.3.370

Mink, D.V., \& Fraser, B. (2002, April). Evaluation of a k-5 mathematics program which integrates children's literature: Classroom environment, achievement and attitudes. Paper presented at the Annual Meeting of the American Educational Research Association, New Orleans, LA. Retrieved from ERIC database.

Morse, J.M. (2003). Principles of mixed methods and multimethod research design. In A. Tashakkori \& C. Teddlie (Eds.), Handbook of mixed methods in social \& behavioral research (pp. 51-89). Thousand Oaks, CA: Sage. 
Moyer, P.S. (2000). Communicating mathematically: Children's literature as a natural connection. The Reading Teacher, 54(3), 246-255. Retreived from ERIC database.

Multi-Option Observation System for Experimental Studies [Computer software].

Nashville, TN: Vanderbilt University - Office of Technology Transfer and Enterprise Development.

National Center for Education Statistics (2009). The nation's report card: Mathematics 2009 (NCES 2010-451). Institute of Education Sciences, U.S. Department of Education, Washington, DC. Retrieved from http://nces.ed.gov /nationsreportcard/pdf/main2009/2010451.pdf

National Council of Teachers of English (1996). Standards for the english language arts. Urbana, IL: Author; Newark, DE: International Reading Association.

National Council of Teachers of Mathematics (1989). Curriculum and evaluation standards for school mathematics. Reston, VA: Author.

National Council of Teachers of Mathematics (1991). Professional standards for teaching mathematics. Reston, VA: Author.

National Council of Teachers of Mathematics (2000). Principles and NCTM standards for school mathematics. Reston, VA: Author.

National Mathematics Advisory Panel (2008). Foundations for success: The final report of themathematics advisory panel, U.S. Department of Education: Washington, DC. 
Nattiv, A. (1994). Helping behaviors and math achievement gain of students using cooperative learning. Elementary School Journal, 94(3), 285-297. Retrieved from http://www.jstor.org/stable/1001900

Nelson, J.R., Benner, G.J., Lane, K., Smith, B.W. (2004). Academic achievement of k-12 students with emotional and behavioral disorders. Exceptional Children, 71(1), 59-73. Retrieved from ERIC database.

No Child Left Behind Act of 2001, Pub. L. No. 107-110.

Scott, T.M., Nelson, C.M., \& Liaupsin, C.J. (2001). Effective instruction: The forgotten component in preventing school violence. Education and Treatment of Children, 24(3), 309-322. Retrieved from ERIC database.

Shadish, W.R., Cook, T.D., \& Campbell, D.T. (2002). Experimental and quasi-experimental designs for generalized causal inference. Boston, MA: Houghton Mifflin.

Shavelson, R.J. (1996). Statistical reasoning for the behavioral sciences ( ${ }^{\text {rd }}$ ed.). Needham Heights, MA: Allyn \& Bacon

Skinner, C.H., Belfiore, P.J., Mace, H.W., Williams-Wilson, S., \& Johns, G.A. (1997). Altering response topography to increase response efficiency and learning rates. School Psychology Quarterly, 12(1), 54-64. doi: 10.1037/h0088947

Skinner,C.H., Ford, J.M., \& Yunker, B.D. (1991). A comparison of instructional response requirements on the multiplication performance of behaviorally disordered students. Behavioral Disorders, 17(1), 56-65. 
Simonsen, B., Fairbanks, S., Briesch, A., Myers, D., Sugai, G. (2008). Evidence-based practices in classroom management: Considerations for research to practice. Education and Treatment of Children, 31(3), 351-380. doi: 10.1353/etc.0.0007

Stevens, J.P. (2009). Applied multivariate statistics for the social sciences $\left(4^{\text {th }}\right.$ ed.). New York, NY: Routledge.

Sutherland, K.S., Alder, N., Gunter, P.L. (2003). The effect of varying rates of opportunities to respond to academic requests on the classroom behavior of students with EBD. Journal of Emotional and Behavioral Disorders, 11(4), 239-248. doi: 10.1177/10634266030110040501

Sutherland, K.S., \& Wehby, J.H. (2001). Exploring the relationship between increased opportunities to respond to academic requests and the academic and behavioral outcomes of students with EBD: A review. Remedial and Special Education, 22(2), 113-121. doi: 10.1177/074193250102200205

Sutherland, K.S., Wehby, J.H., \& Yoder, P.J. (2002). Examination of the relationship between teacher praise and opportunities for students with EBD to respond to academic requests. Journal of Emotional and Behavioral Disorders, 10(1), 5-13. doi: $10.1177 / 106342660201000102$

Thiessen, D. (Ed.). (2004). Exploring mathematics through literature: Articles and lessons for prekindergarten through grade 8. Reston, VA: National Council of Teachers of Mathematics. 
U.S. Department of Education, Office of Special Education and Rehabilitative Services, Office of Special Education Programs, 28th Annual Report to Congress on the Implementation of the Individuals with Disabilities Education Act, 2006, vol. 1, Washington, D.C., 2009. Retrieved from http://www2.ed.gov/about/reports /annual/osep/2006/parts-b-c/28th-vol-1.pdf

Van Acker, R., Grant, S.H., \& Henry, D. (1996). Teacher and student behavior as a function of risk for aggression. Education and Treatment of Children, 19(3), 316-334. Retrieved from ERIC database.

Wallace, F.H., \& Clark, K.K. (2005). Reading stances in mathematics: Positioning students and texts. Action in Teacher Education, 27(2), 68-79. Retrieved from Education Full Text database.

Webb, N.M. (1991). Task-related verbal interaction and mathematics learning in small learning groups. Journal for Research in Mathematics Education, 22(5), 366-389. Retrieved from http://www.jstor.org/stable/749186

Wehby, J.H., Symons, F.J., Canale, J.A., \& Go, F.J. (1998). Teaching practices in classrooms for students with emotional and behavioral disorders: Discrepancies between recommendations and observations. Behavioral Disorders, 24(1), 51-56. Retrieved from ERIC database.

Welchman-Tischler, R. (2000). How to use children's literature to teach mathematics ( $7^{\text {th }}$ ed.) Reston, VA: National Council of Teachers of Mathematics 
West, R.P., \& Sloan, H.N. (1986). Teacher presentation rate and point delivery rate: Effects on classroom disruption, performance accuracy, and response rate. Behavior Modification, 10(3), 267-286. doi: 10.1177/01454455860103001 Young-Loveridge, J.M. (2004). Effects on early numeracy of a program using number books and games. Early Childhood Research Quarterly, 19, 82-98. doi: 10.1016/j.ecresq.2004.01.001

Zentall, S.S., (2007). Math performance of students with ADHD: Cognitive and behavioral contributors and interventions. In D.B. Berch, M.M. Mazzacco (Eds.), Why is math so hard for some children? The nature and origins of mathematical learning difficulties and disabilities (pp. 219-243). Baltimore, MD: Brookes Publishing. 
Appendix A: Teacher Consent Form

\section{Subject Informed Consent Document}

\section{Using Literature to Teach Mathematics Concepts}

Investigator(s) name \& address: Amy S. Lingo, Ed.D

University of Louisville, College of Education \& Human Development, Department of Teaching \& Learning, Louisville, KY 40292

Site(s) where study is to be conducted: Atkinson Elementary

Phone number for subjects to call for questions: $502-852-3603$

\section{Introduction and Background Information}

You are invited to participate in a research study. The study is being conducted by Amy S. Lingo, Ed.D and Todd Whitney, M.Ed.. The study is being conducted through the University of Louisville, College of Education and Human Development. The study will take place at Newburg Middle School. Approximately six subjects will be invited to participate.

\section{Purpose}

The purpose of this study is to examine the effects of integrating children's literature in mathematics instruction. The goal is to see if using children's literature in mathematics instruction will increase student academic achievement and student engagement.

\section{Procedures}

In this study, you will be asked to follow lesson plans that integrate children's literature in mathematics instruction. The lesson plans will use the content in the children's books to introduce new concepts, reinforce concepts already learned, and/or expand on previous concepts learned. The read aloud will occur at the beginning of a session that introduces a new mathematics concept. The read aloud will last approximately ten to fifteen minutes and include teacher prompts/questions during the reading and a short discussion following the reading. Data will be collected on your frequency of giving students opportunities to respond, positive feedback, negative feedback, and correction. The study length will be approximately seven weeks and the co-investigator will be collecting data daily during mathematics instruction.

\section{Potential Risks}

There are no foreseeable risks, although there may be unforeseen risks. 


\section{Benefits}

The possible benefits of this study include providing research-based strategies for teachers to improve student engagement and academic achievement during mathematics instruction. The information collected may not benefit you directly. The information learned in this study may be helpful to others.

\section{Compensation}

You will not be compensated for your time, inconvenience, or expenses for your participation in this study.

\section{Confidentiality}

Total privacy cannot be guaranteed. Your privacy will be protected to the extent permitted by law. If the results from this study are published, your name will not be made public. While unlikely, the following may look at the study records:

The University of Louisville Institutional Review Board and Human Subjects Protection Program Office. Office for Human Research Protections (OHRP), Office of Civil Rights, and

Staff from the University of Louisville directly involved with the study

All methods will be used to ensure that the data collected is secured (e.g., locked in a file cabinet, kept in a secured area, or kept in a password protected computer).

\section{Voluntary Participation}

Taking part in this study is voluntary. You may choose not to take part at all. If you decide to be in this study you may stop taking part at any time. If you decide not to be in this study or if you stop taking part at any time, you will not lose any benefits for which you may qualify.

You will be told about any changes that may affect your decision to continue in the study.

\section{Research Subject's Rights, Questions, Concerns, and Complaints}

If you have any concerns or complaints about the study or the study staff, you have three options.

You may contact the principal investigator at 502-852-2183. 
If you have any questions about your rights as a study subject, questions, concerns or complaints, you may call the Human Subjects Protection Program Office (HSPPO) (502) 852-5188. You may discuss any questions about your rights as a subject, in secret, with a member of the Institutional Review Board (IRB) or the HSPPO staff. The IRB is an independent committee composed of members of the University community, staff of the institutions, as well as lay members of the community not connected with these institutions. The IRB has reviewed this study.

If you want to speak to a person outside the University, you may call 1$877-852-1167$. You will be given the chance to talk about any questions, concerns or complaints in secret. This is a 24 hour hot line answered by people who do not work at the University of Louisville.

This paper tells you what will happen during the study if you choose to take part. Your signature means that this study has been discussed with you, that your questions have been answered, and that you will take part in the study. This informed consent document is not a contract. You are not giving up any legal rights by signing this informed consent document. You will be given a signed copy of this paper to keep for your records.

Signature of Subject/Legal Representative Date Signed

Signature of Person Explaining the Consent Form (if other than the Investigator)

Date Signed

Signature of Investigator

Date Signed

LIST OF INVESTIGATORS

PHONE NUMBERS

Amy S. Lingo, Ed.D.

502-852-0563

Todd Whitney, M.Ed.

$502-852-3603$ 
Appendix B: Student Consent Form

\section{Subject Informed Consent Document}

\section{Using Literature to Teach Mathematics Concepts}

Investigator(s) name \& address: Amy S. Lingo, Ed.D.

University of Louisville, College of Education \& Human Development, Department of Teaching \& Learning, Louisville, KY 40292

Site(s) where study is to be conducted: Newburg Middle School

Phone number for subjects to call for questions: $502-852-3603$

\section{Introduction and Background Information}

Your child is invited to participate in a research study. The study is being conducted by Amy S. Lingo, Ed.D. and Todd Whitney, M.Ed.. The study is being conducted through the University of Louisville, College of Education and Human Development. The study will take place at Newburg Middle School. Approximately six subjects will be invited to participate.

\section{Purpose}

The purpose of this study is to examine the effects of integrating children's literature in mathematics instruction. The goal is to see if using children's literature in mathematics instruction will increase student academic achievement and student engagement.

\section{Procedures}

In this study, your child will receive mathematics instruction that includes children's books. Your child's on-task behavior will be observed during mathematics instruction and will be given a mathematics assessment prior to and following the study. The study length will be approximately seven weeks and the co-investigator will be collecting data daily during mathematics instruction.

\section{Potential Risks}

There are no foreseeable risks, although there may be unforeseen risks.

\section{Benefits}

The possible benefits of this study include providing research-based strategies for teachers to improve student engagement and academic achievement during mathematics instruction. The information collected may not benefit your child directly. The information learned in this study may be helpful to others. 


\section{Compensation}

You will not be compensated for your time, inconvenience, or expenses for your child's participation in this study.

\section{Confidentiality}

Total privacy cannot be guaranteed. Your child's privacy will be protected to the extent permitted by law. If the results from this study are published, your child's name will not be made public. While unlikely, the following may look at the study records:

The University of Louisville Institutional Review Board and Human Subjects Protection Program Office.

Office for Human Research Protections (OHRP), Office of Civil Rights, and

Staff from the University of Louisville directly involved with the study

All methods will be used to ensure that the data collected is secured (e.g., locked in a file cabinet, kept in a secured area, or kept in a password protected computer).

\section{Voluntary Participation}

Taking part in this study is voluntary. You or your child may choose not to take part at all. If you decide for your child to be in this study you may stop taking part at any time. If you decide for your child to not to be in this study or if you stop taking part at any time, you will not lose any benefits for which you may qualify.

You will be told about any changes that may affect your decision to continue in the study.

\section{Research Subject's Rights, Questions, Concerns, and Complaints}

If you have any concerns or complaints about the study or the study staff, you have three options.

You may contact the principal investigator at 502-852-0576.

If you have any questions about your rights as a study subject, questions, concerns or complaints, you may call the Human Subjects Protection Program Office (HSPPO) (502) 852-5188. You may discuss any questions about your rights as a subject, in secret, with a member of the Institutional Review Board (IRB) or the HSPPO staff. The IRB is an independent committee composed of members of the University community, staff of the institutions, as well as lay members of the 
community not connected with these institutions. The IRB has reviewed this study.

If you want to speak to a person outside the University, you may call 1$877-852-1167$. You will be given the chance to talk about any questions, concerns or complaints in secret. This is a 24 hour hot line answered by people who do not work at the University of Louisville.

This paper tells you what will happen during the study if you choose to take part. Your signature means that this study has been discussed with you, that your questions have been answered, and that you will take part in the study. This informed consent document is not a contract. You are not giving up any legal rights by signing this informed consent document. You will be given a signed copy of this paper to keep for your records.

Signature of Subject/Legal Representative

Date Signed

Signature of Person Explaining the Consent Form (if other than the Investigator)

Date Signed

Signature of Investigator

Date Signed

LIST OF INVESTIGATORS

PHONE NUMBERS

Amy S. Lingo, Ed.D.

$502-852-0563$

Todd Whitney, M.Ed.

$502-852-3603$ 
Appendix C: Student Assent Form

\section{SUBJECT ASSENT}

\section{Using Literature to Teach Mathematics Concepts}

I am invited to be in a research study being done by Amy S. Lingo, Ed.D. at the University of Louisville. When a person is in a research study, they are called a "subject". I am invited because I am a student in middle school and my mathematics teacher is participating in the study.

This means that someone will be in my classroom watching me and my teacher. There may be some risks with this study. These risks are that my teacher may ask me to participate more in mathematics which may make me feel uncomfortable.

This study will last about seven weeks. The benefit to me for participating in this study is that I could improve my on-task behavior and learn more in mathematics class.

My family, the professor, a few people that work with the professor, and my mathematics teacher will know that I'm in the study. If anyone else is given information about me, they will not know my name. A number or initials will be used instead of my name.

I have been told about this study and know why it is being done and what I have to do. My parent(s) have agreed to let me be in the study. If I have any questions I can ask Nicole Fenty. She will answer my questions. If I do not want to be in this study or I want to quit after I am already in this study, I can tell the researcher and he will discuss this with my parents.

Printed Name of Subject

Signed

Signature of Subject

Date

Printed Name of Parent/Guardian

Printed Name of Investigator

Signature of Investigator

Date

Signed 
Appendix D: Lesson Plans

\author{
Lemonade For Sale \\ By Stuart J. Murphy \\ Illustrated by Tricia Tusa
}

\title{
Before Read Aloud
}

- Read title, author, and illustrator.

- Find out "how old the book is"

- Teacher will say: We are now going to find out how old this book is. (pointing at the date of publication) I know it was published in 1998 and it is now 2011. What would be the best way to do this? To find the age, I could just start with 1998 and add ten. That is 2008. And I know that 2008 is only 3 away from 2011. Then I would just add $10+3$. The book is $\mathbf{1 3}$ years old. Is there another way we could do this?

- Give students an opportunity to predict what the story will be about.

- Teacher will say: What do you think this story will be about? Will there be any math? Why do you think this? Let's start reading to see if our predictions are correct.

During Read Aloud (Day 1)

- Stop after page 6. Teacher will ask: If their goal is $\mathbf{4 0}$ cups a day for one week, how many cups of lemonade will they need to make in all for the week? If student gives an answer, teacher will say: Give a thumbs up if you agree and thumbs down if you don't. If no student answer, teacher will model the steps to find out how many cups in all.

- Stop after page 7. Teacher will hand out the Lemonade for Sale Bar Graph and say: As we read the story, we are going to fill in the bar graph. But before we do this, let's talk about some things about a bar graph. A bar graph has a title and labels. Does this graph have these things? Teacher will discuss with students what the Title should be called and have students write it on their worksheets as well as giving the $x$ and $y$-axis a label. Teacher will ask: If I fill in one bar, how many cups would that be? 
- Teacher will say: Next time we meet, we will continue reading this story. We will see how the kids the story used their graph to keep track of their lemonade sales.

\section{During Read Aloud (Day 2)}

- Teacher will give quick review of what they did on the last session, hand out the Lemonade for Sale Bar Graph, and start with page 8.

- Stop after page 11. Teacher will point to the graph on page 10 and say: I want you to color in the correct number of cups on your graph for Monday. If their goal is $\mathbf{4 0}$ cups each day, give me a thumbs up if they made their goal and a thumbs down if they didn't.

- How far away are they from their goal of 40 ?

- Stop after page 15. Teacher will point to the graph on page 14 and say: I want you to color in the correct number of cups on your graph for Tuesday. If their goal is $\mathbf{4 0}$ cups each day, give me a thumbs up if they made their goal and a thumbs down if they didn't.

- How far away are they from their goal of 40 ?

\section{During Read Aloud (Day 3)}

- Teacher will give quick review of what they did on the last session, hand out the Lemonade for Sale Bar Graph, and start with page 16.

- Stop after page 19. Teacher will point to the graph on page 18 and say: I want you to color in the correct number of cups on your graph for Wednesday. If their goal is $\mathbf{4 0}$ cups each day, give me a thumbs up if they made their goal and a thumbs down if they didn't.

o How much over were they?

- Stop after page 23. Teacher will point to the graph on page 12 and say: I want you to color in the correct number of cups on your graph for Thursday. If their goal is $\mathbf{4 0}$ cups each day, give me a thumbs up if they made their goal and a thumbs down if they didn't.

- How far away are they from their goal of 40 ?

- If their goal was to make $\mathbf{2 0 0}$ cups for the week, how many cups do they need to make on Friday to make their goal?

o Do you think they will make it? 


\section{During Read Aloud (Day 4)}

- Teacher will give quick review of what they did on the last session, hand out the Lemonade for Sale Bar Graph, and start with page 16.

- Stop after page 23. Teacher will say: I want you to color in the correct number of cups on your graph for Friday.

How many cups did they make in all for the week?

$\circ$ How much were they over their goal of 200 cups?

- Teacher will conclude lesson by asking students questions regarding their graphs as well as discussing with students the importance of using graphs. 


\title{
Fair is Fair
}

\author{
By Jennifer Dussling \\ Illustrated by Diane Palmisciano
}

\section{Before Read Aloud}

- Read title, author, and illustrator.

- Find out "how old the book is"

- Teacher will say: We are now going to find out how old this book is. I know it was published in 2003 and it is now 2011. What would be the best way to do this? To find the age, I could just start with 2003 and count on to 2005......That is 2 . I know that 2005 is $\mathbf{5}$ away from 2010 and I know that 2010 is only 1 away from 2011. Then I would just add $2+5$ +1 . The book is 8 years old. Is there another way we could do this?

2003200520102011

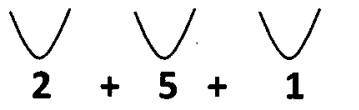

- Give students an opportunity to predict what the story will be about.

- Teacher will say: What do you think this story will be about? Will there be any math? Why do you think this? Let's start reading to see if our predictions are correct.

\section{During Read Aloud (Day 1)}

- Stop after page 13. Teacher will ask students questions regarding the graphs on page 13. Possible questions include:

o How are these graphs alike? How are they different?

o What question is the first graph answering? What question is the second graph answering?

- What was the favorite sport of the class?

- What was the favorite pet of the class?

- Stop after page 16. Teacher will ask questions regarding the graph. Possible questions include:

- Why does Marco say the Ann had a skyscraper?

- Why does he say the he barely had a house? 
- Teacher will conclude with asking students what they learned from the story.

\section{During Read Aloud (Day 2)}

- Teacher will give quick review of what they did on the last session.

- Stop after page 20. Teacher will ask questions regarding the graph.

- Stop after page 25. Teacher will ask questions regarding the two graphs.

- Teacher will conclude with asking students what they learned from the story.

\section{Activity Following Read Aloud (Day 3)}

- Teacher will give quick review of what they did on the last session.

- Teacher will say: Today we are going to practice with bar graphs by finding our "Lucky Color". Teacher will hand out the bar graph and bag of crayons to each student.

- In this activity,

- Have the student pick a crayon out of the bag without looking and fill in the box of the color they picked.

- Return the crayon to the bag and shake up.

o The student will pick another crayon out of the bag without looking and fill in the box of the color they picked.

- Repeat this sequence for 3 to 4 minutes.

- After activity is finished, have each student present their graph to the class.

- Teacher will conclude with a review of what was learned. 


\title{
Alexander, Who Used to Be Rich Last Sunday
}

\author{
By Judith Viorst \\ Illustrated by Ray Cruz
}

\section{Before Read Aloud}

- Read title, author, and illustrator.

- Find out "how old the book is"

- Teacher will say: We are now going to find out how old this book is. (pointing at the date of publication) I know it was published in 1978 and it is now 2011. What would be the best way to do this? To find the age, I could just start with 1978 and count up to 1980...1979, 1980. That is 2 . Starting at 1980, I can skip count by 10 's. $1990,2000,2010$. That is $10+$ $10+10=30$. And I know that 2010 is only 1 away from 2011. Then I would just add $2+30+1$. The book is 33 years old. Is there another way we could do this?

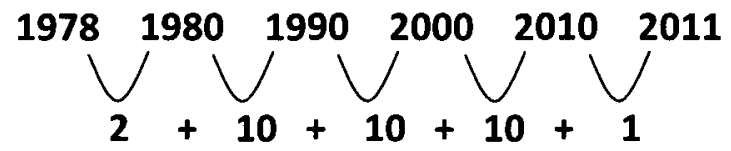

- Give students an opportunity to predict what the story will be about.

- Teacher will say: What do you think this story will be about? Will there be any math? Why do you think this? Let's start reading to see if our predictions are correct.

\section{During Read Aloud (Day 1)}

- Stop after page 7. Teacher will say: We are going to keep track of how Alexander had a dollar last week and has no money now. Place the pre-marked cash register tape on the table and give a pencil or marker to each student.

- Stop after page 12 , pick one of the students to count the tick marks to 15 and make a line. To the left of the line, have student write $15 \mathrm{C}$ and "gum".

- Stop after page 14. Starting at the line made by the previous student, pick another student to count the tick marks to 15 and make a line. To the left of the line, have student write $15 \%$ and "betting". 
- Stop after page 15. Starting at the line made by the previous student, pick another student to count the tick marks to 12 and make a line. To the left of the line, have student write $12 \mathrm{C}$ and "rented snake".

- Stop after page 16. Starting at the line made by the previous student, pick another student to count the tick marks to 10 and make a line. To the left of the line, have student write $10 c$ and "cursing".

- Stop after page 17. Starting at the line made by the previous student, pick another student to count the tick marks to 8 and make a line. To the left of the line, have student write $8 c$ and "lost".

- Teacher will say: Next time we meet, we will continue reading this story and find out other ways that Alexander lost his money.

- Teacher will conclude with a review of what was learned.

\section{During Read Aloud (Day 2)}

- Teacher will give quick review of what they did on the last session and hand out the register tape.

- Stop after page 18. Starting at the line made by the previous student, pick another student to count the tick marks to 11 and make a line. To the left of the line, have student write $11 c$ and "candy bar".

- Stop after page 19. Starting at the line made by the previous student, pick another student to count the tick marks to 4 and make a line. To the left of the line, have student write $4 \zeta$ and "magic trick".

- Stop after page 20. Starting at the line made by the previous student, pick another student to count the tick marks to 5 and make a line. To the left of the line, have student write $5 \mathrm{C}$ and "kicking".

- Stop after page 21. Starting at the line made by the previous student, pick another student to count the tick marks to 20 and make a line. To the left of the line, have student write $20 \mathrm{C}$ and "garage sale".

- Teacher will say: Next time we meet, we are going to make graphs of the items that Alexander spent his money on.

- Teacher will conclude with a review of what was learned. 


\section{Activity Following Read Aloud (Day 3)}

- Teacher will give quick review of what they did on the last session.

- Teacher will say: I want to ask you some questions about the different ways Alexander spent his money but first we have to make graphs to make it easier.

- Teacher will say: We are going to make a pie or circle graph. Can anyone tell me what this graph is? Why do you think some people call it a pie graph?

- Teacher will tape together the register tape so that it makes a circle with the writing on the outside.

- Then, the teacher will put a piece of chart paper on the floor and place the register tape on the chart paper in a circle.

- Teacher and students will draw a circle inside the register tape and put a dot in the center of the circle.

- Teacher and students will draw lines from the register tape to the dot in the center.

- Students will then label the pie pieces (e.g., cursing 10c).

- Teacher will say: Next time we meet, we are going to make another graph of the items that Alexander spent his money on. Can anyone guess what type of graph we will make?

- Teacher will conclude with a review of what was learned.

\section{Activity Following Read Aloud (Day 4)}

- Teacher will give quick review of what they did on the last session.

- Teacher will say: Today we are going to make a bar graph out of the items that Alexander spent his money on.

- Teacher will have the students use scissors to cut the register tape to separate each item that Alexander spent his money on.

- Teacher will lay out chart paper with outline of bar graph and say: What will we have to do first to make our bar graph? Teacher should lead the discussion on elements needed in bar graph with questioning. 
- Teacher and student should construct the bar graph. After completion, teacher will say: Now we have created two types of graphs: a circle graph and a bar graph. Tomorrow, I will ask you some questions and want you to answer them using the bar graphs we created.

\section{Activity Following Read Aloud (Day 5)}

- Teacher will give quick review of what they did on the last session and put up both graphs in view of the students.

- Teacher will say: Now I am going to ask you some questions. (For each question, pick a student to answer, have them explain their thinking, and ask the other students if they agree or disagree.)

- What did Alexander spend the most on?

-What did Alexander spend the least on?

o How much did Alexander spend on candy?

- How much did Alexander have to give to his dad for bad behavior?

- Alexander spent $\mathbf{2 0}$ cents at the garage sale. Can you tell me other things that Alexander spent that equal 20 cents? Combinations include:

- Gum/kicking

- Betting/kicking

- Candy bar/magic trick/kicking

- Rented snake/lost

- Teacher will say: Could you have answered these questions without the graphs? In what ways did the graphs make it easier for you?

- Teacher will conclude lesson by discussing the importance of using graphs. 


\author{
Earth Day - Hooray! \\ By Stuart J. Murphy \\ Illustrated by Renee Andriani
}

\title{
Before Read Aloud
}

- Read title, author, and illustrator.

- Find out "how old the book is"

- Teacher will say: We are now going to find out how old this book is. I know it was published in 2004 and it is now 2011. What would be the best way to do this? To find the age, I could just start with 2004 and count on to 2005...... That is 1 . I know that 2005 is 5 away from 2010 and I know that 2010 is only 1 away from 2011. Then I would just add $1+5$ +1 . The book is 7 years old. Is there another way we could do this?

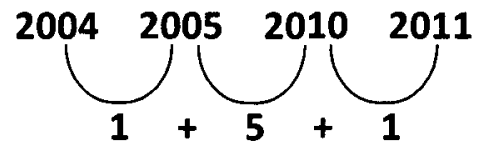

- Give students an opportunity to predict what the story will be about.

o Teacher will say: What do you think this story will be about? Will there be any math? Why do you think this? Let's start reading to see if our predictions are correct.

\section{During Read Aloud (Day 1)}

- Stop after page 8. Teacher will say: What would be the best way to keep track of how many cans they collect?

- Stop after page 10. Teacher will use the pictures on the page to discuss how 10 ones equal 10 and 10 tens equal 100.

- Stop after page 21. Teacher will say: Their teacher says they are going to use bigger bags. What do you think they will label these bags? Why do you think this? Give me a thumbs up if you agree and and thumbs down if you disagree.

- Teacher will say: We will continue this story tomorrow. What have we learned from this story so far? Why is knowing place value so important? 


\section{Read Aloud (Day 2)}

- Teacher will give quick review of what they did on the last session as well as discussing student predictions.

- $\quad$ Start at page 22 .

- Stop after page 22. Teacher will give each student a bag of manipulatives (single cans, bags of 10,100, and 1000) an place value mats and say: Using your cans and bags, show me the number 1,483 . Teacher will pick one student to explain their thinking and say: Give me a thumbs up if you agree and and thumbs down if you disagree.

- Stop after page 23: Teacher will say: Using your cans and bags, show me the number 2,174 . Teacher will pick one student to explain their thinking and say: Give me a thumbs up if you agree and and thumbs down if you disagree.

- Stop after page 28: Teacher will say: Using your cans and bags, show me the number $\mathbf{2 , 8 5 2}$. Teacher will pick one student to explain their thinking and say: Give me a thumbs up if you agree and and thumbs down if you disagree.

- Stop after page 29: Teacher will say: Using your cans and bags, show me the number 5,026. Teacher will pick one student to explain their thinking and say: Give me a thumbs up if you agree and and thumbs down if you disagree.

- Teacher will say: Now that we have finished this story, what can you tell me about what you have learned? 


\title{
Band-Aids
}

\author{
By Shel Silverstein \\ Illustrated by Shel Silverstein
}

\section{Before Read Aloud}

- Read title, author, and illustrator.

- Find out "how old the book is"

- Teacher will say: We are now going to find out how old this poem is. I know it was published in 1974 and it is now 2011. What would be the best way to do this? To find the age, I could just start with 1974 and count on to $1980 . . .1975,1976,1977,1978,1979,1980$...That is 6 . Now I can just count by tens...1990, 2000, 2010. That is $10+10+10=30$. And I know that 2010 is only 1 away from 2011. Then I would just add 6 $+30+1$. The book is 37 years old. Is there another way we could do this?

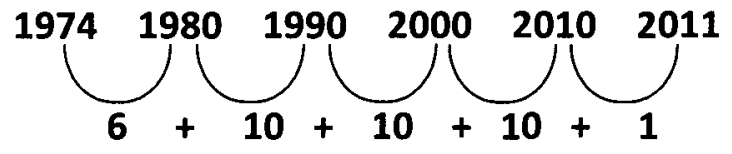

- Give students an opportunity to predict what the story will be about.

o Teacher will say: What do you think this story will be about? Will there be any math? Why do you think this? Let's start reading to see if our predictions are correct.

\section{During Read Aloud (Day 1)}

- Teacher will read the poem straight through.

- After the first reading, the teacher will say: Now I am going to reread the poem and we are going to count how many band-aids he had in all. But first, I want to know how many you think he has. Get a prediction from each student and write on whiteboard.

- Place the pile of Band-Aids on the table. Teacher will say: We are going to use these band-aids to help us count. 
- The teacher will stop after each line and have one student take out the total band-aids and put in a separate pile.

- At the end of the story, teacher will say: Now we have to count the number of band-aids. What would be the best way to do this? Teacher will ask each student the best way. If any student mentions counting each one by one, teacher should say: Is there an easier way?.

- Teacher will conclude with a review of what was learned.

\section{Activity following read aloud (Day 2)}

- Teacher will give quick review of what they did on the last session.

- Teacher will give each student a strip of the poem containing two lines and a blank piece of paper.

- Teacher will say: I have just given you two lines from the poem. I want you to make a number sentence that describes the words and put the number of band-aids under each number.

- Teacher will model the first. Teacher will say: I will do the first one. These two lines say that he has one on his finger, one on his knee, and one on his nose. That would be $1+1+1=3$. Teacher will write down the number sentence and place band-aids under each number. Teacher will say: Now I want you to do one.

- After the students have completed the activity, have each one present to the other students.

- Teacher will conclude with a review of what was learned. 


\section{Ways To Get To 11}

By Eve Merriam

Illustrated by Bernie Karlin

\section{Before Read Aloud}

- Read title, author, and illustrator.

- Find out "how old the book is"

- Teacher will say: We are now going to find out how old this book is. (pointing at the date of publication) I know it was published in 1993 and it is now 2011. What would be the best way to do this? We could just start with 1993 and can count up to 2000. Let's do this together...1994, $1995,1996,1997,1998,1999,2000$. That is seven. I will write that number down. Now I need to count from 2000 to 2011. What would be the easiest way to do this? (If students don't know of another way, count up from 2000). That gives us 11. What do I need to do to the two numbers to find my answer? Correct, add them together. $7+11=18$. The book is 18 years old. Is there another way we could do this?

- Give students an opportunity to predict what the story will be about.

- Teacher will say: What do you think this story will be about? Will there be any math? Why do you think this? Let's start reading to see if our predictions are correct.

\section{During Read Aloud (Day One)}

- Stop after page 1 . Teacher will model $9+2=11$ with counters and say: I have 9 pine cones and have 2 acorns. $9+2=11$. Write down equation on whiteboard and hand out 12 Ways to Get to 11 activity sheet. I want you to write down the equation on your paper under \#1.

- Stop after page 2. Teacher will say: What will this equation be? Write down the equation on the paper under \#2. You can use the counters to help you if you need to. Teacher will ask a student for their equation. Teacher will say: Give me thumbs up if you agree and thumbs down if you disagree?

- Teacher will say: Next time we meet, we will find more ways to get to 11. Can you think of any other ways to make 11 that the author might have used? Write down your prediction on the back of the page. 


\section{During Read Aloud (Day Two)}

- Teacher will give quick review of what they did on the last session, hand out the 12 Ways to Get to 11 activity sheet, and start with page 3 (magician's hat page)

- Stop after page 3. Teacher will model $9+2=11$ with counters and say: I have 4 banners, 5 rabbits, 1 pitcher of water, and 1 bouquet of flowers. $4+5+1+1=$ 11. Write down equation on whiteboard. I want you to write down the equation on your paper under \#3.

- Stop after page 4. Teacher will say: What will this equation be? Write down the equation on the paper under \#4. You can use the counters to help you if you need to. Teacher will ask a student for their equation. Teacher will say: Give me thumbs up if you agree and thumbs down if you disagree?

- Stop after page 5. Teacher will say: What will this equation be? Write down the equation on the paper under \#4. You can use the counters to help you if you need to. Teacher will ask a student for their equation. Teacher will say: Give me thumbs up if you agree and thumbs down if you disagree?

- Stop after page 6. Teacher will say: What will this equation be? Write down the equation on the paper under \#4. You can use the counters to help you if you need to. Teacher will ask a student for their equation. Teacher will say: Give me thumbs up if you agree and thumbs down if you disagree?

- Stop after page 7. Teacher will say: What will this equation be? Write down the equation on the paper under \#4. You can use the counters to help you if you need to. Teacher will ask a student for their equation. Teacher will say: Give me thumbs up if you agree and thumbs down if you disagree?

- Stop after page 8. Teacher will say: What will this equation be? Write down the equation on the paper under \#4. You can use the counters to help you if you need to. Teacher will ask a student for their equation. Teacher will say: Give me thumbs up if you agree and thumbs down if you disagree?

- Stop after page 9. Teacher will say: What will this equation be? Write down the equation on the paper under \#4. You can use the counters to help you if you need to. Teacher will ask a student for their equation. Teacher will say: Give me thumbs up if you agree and thumbs down if you disagree?

- Teacher will conclude with a review of what was learned. 


\section{During Read Aloud (Day Three)}

- Teacher will give quick review of what they did on the last session, hand out the 12 Ways to Get to 11 activity sheet, and start with page 10 (magician's hat page)

- Stop after page 10. Teacher will say: What will this equation be? Write down the equation on the paper under \#4. You can use the counters to help you if you need to. Teacher will ask a student for their equation. Teacher will say: Give me thumbs up if you agree and thumbs down if you disagree?

- Stop after page 11. Teacher will say: What will this equation be? Write down the equation on the paper under \#4. You can use the counters to help you if you need to. Teacher will ask a student for their equation. Teacher will say: Give me thumbs up if you agree and thumbs down if you disagree?

- Stop after page 12. Teacher will say: What will this equation be? Write down the equation on the paper under \#4. You can use the counters to help you if you need to. Teacher will ask a student for their equation. Teacher will say: Give me thumbs up if you agree and thumbs down if you disagree?

- Teacher will conclude with a review of what was learned. 


\section{How Many Feet in the Bed?}

By Diane Johnston Hamm

Illustrated by Kate Salley Palmer

\section{Before Read Aloud}

- Read title, author, and illustrator.

- Find out "how old the book is"

- Teacher will say: We are now going to find out how old this book is. I know it was published in 1991 and it is now 2011. What would be the best way to do this? To find the age, I could just start with 1991 and count on to 2000...1991, 1992, 1993, 1994... 2000...That is 9. Now I can just count by tens... 2010. And I know that 2010 is only 1 away from 2011. Then I would just add $9+10+1$. The book is 20 years old. Is there another way we could do this?

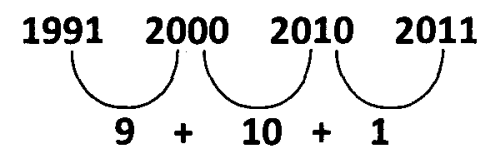

- Give students an opportunity to predict what the story will be about.

- Teacher will say: What do you think this story will be about? Will there be any math? Why do you think this? Let's start reading to see if our predictions are correct.

During Read Aloud (Day 1)

- Stop at marked page (post-it). Teacher will say: They counted by one's to get to 4. Would there be an easier way to count the feet in the bed? Could we count by 2's? Let's do it together. 2,4 ...There are 4 feet in the bed. What would be a number sentence for this? (hand out blank sheet of paper) Write down this number sentence on your paper.

- Stop at next marked page. Teacher will say: Again, it is easier to count by 2's. Let's do it together. 2, 4, 6...There are 6 feet in the bed. What would be a number sentence for this? Write down this number sentence on your paper. 
- Stop at next marked page. Teacher will say: Again, it is easier to count by 2's. Let's do it together. $2,4,6,8$...There are 8 feet in the bed. What would be a number sentence for this? Write down this number sentence on your paper.

- Stop at next marked page. Teacher will say: Again, it is easier to count by 2's. Let's do it together. $2,4,6,8,10$...There are 10 feet in the bed. What would be a number sentence for this? Write down this number sentence on your paper.

- Finish reading the rest of the book.

- Teacher will conclude lesson by saying: What have we learned from this story? Why is counting by 2's important?

\section{Activity Following Read Aloud (Day 2)}

- Teacher will give quick review of what they did on the last session.

- Hand out picture of bed

- Have students draw the feet of the people in their family on the bed

- For example: 5 people in family, 10 feet in the bed

- At the top of the page, give a number sentence to represent this.

- Next, count by 5's the number of toes in bed and give a number sentence to represent this.

- When completed, have students present to class.

- Teacher will conclude with a review of what was learned. 


\author{
Cats Add Up! \\ By Dianne Ochiltree \\ Illustrated by Marcy Dunn-Ramsey
}

Before Read Aloud

- Read title, author, and illustrator.

- Find out "how old the book is"

- Teacher will say: We are now going to find out how old this book is. I know it was published in 1998 and it is now 2011. What would be the best way to do this? To find the age, I could just start with 1998 and count on to 2000 ...1999, 2000...That is 2 . Now I can just add 10 to make 2010. And I know that $\mathbf{2 0 1 0}$ is only 1 away from 2011. Then I would just add $2+10+1$. The book is 13 years old. Is there another way we could do this?

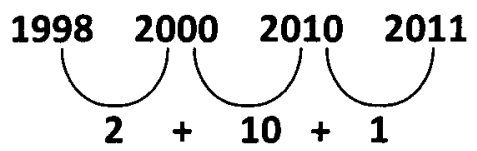

- Give students an opportunity to predict what the story will be about.

- Teacher will say: What do you think this story will be about? Will there be any math? Why do you think this? Let's start reading to see if our predictions are correct.

During Read Aloud (Day 1)

- Read to page 19.

- Teacher will say: Now we are going to go back in the story and see if we can come up with number sentences instead of using words. Hand each student a blank piece of paper.

- Turn to page 5. Teacher will say: It says five kittens and our cat Maxie add up to six. Write down a number sentence to describe this? Call on a student to read number sentence. Teacher will say: Give me thumbs up if you agree and thumbs down if you disagree? 
- Turn to page 8. Teacher will say: It says two old cats and five kittens and our cat Maxie add upt to eight. Write down a number sentence to describe this? Call on a student to read number sentence. Teacher will say: Give me thumbs up if you agree and thumbs down if you disagree?

- Turn to page 11 . Teacher will say: It says one stray cat and two old cats and five kittens and our cat Maxie add up to nine. Write down a number sentence to describe this? Call on a student to read number sentence. Teacher will say: Give me thumbs up if you agree and thumbs down if you disagree?

- Teacher will conclude with a review of what was learned. Teacher will say: Tomorrow, we will finish the rest of the story. What do you think is going to happen?

\section{During Read Aloud (Day 2)}

- Teacher will give quick review of what they did on the last session.

- Read from page 20 to end of book.

- Teacher will say: Now we are going to go back in the story and see if we can come up with number sentences instead of using words. Hand each student a blank piece of paper. Teacher will say: What will we be doing differently from last time?

- Turn to page 22. Teacher will say: It says one cat taken away from ten is nine. Write down a number sentence to describe this? Call on a student to read number sentence. Teacher will say: Give me thumbs up if you agree and thumbs down if you disagree?

- Turn to page 24. : Teacher will say: It says two cats taken away from nine is seven. Write down a number sentence to describe this? Call on a student to read number sentence. Teacher will say: Give me thumbs up if you agree and thumbs down if you disagree?

- Turn to page 27. Teacher will say: It says three cats taken away from seven is four. Write down a number sentence to describe this? Call on a student to read number sentence. Teacher will say: Give me thumbs up if you agree and thumbs down if you disagree?

- Turn to page 29. Teacher will say: It says two cats taken away from four is two? Call on a student to read number sentence. Teacher will say: Give me thumbs up if you agree and thumbs down if you disagree? 
- Turn to page 30. Teacher will say: It says one cat taken away from two is one? Call on a student to read number sentence. Teacher will say: Give me thumbs up if you agree and thumbs down if you disagree?

- Teacher will conclude with a review of what was learned. 


\section{Chickens on the Move}

By Pam Pollack and Meg Belviso

Illustrated by Lynn Adams

\section{Before Read Aloud}

- Read title, author, and illustrator.

- Find out "how old the book is"

- Teacher will say: We are now going to find out how old this book is. I know it was published in 2002 and it is now 2011. What would be the best way to do this? To find the age, I could just start with 2002 and add ten. That would be $\mathbf{2 0 1 2}$. Then I could take one away from 10, which would give me 9 . The book is 9 years old. Is there another way we could do this?

- Give students an opportunity to predict what the story will be about.

o Teacher will say: What do you think this story will be about? Will there be any math? Why do you think this? Let's start reading to see if our predictions are correct.

\section{During Read Aloud (Day 1)}

- Stop after page 9. Hand students a blank sheet of paper. Teacher will model how to find the perimeter of the fence using the following steps on the whiteboard:

- Draw picture of fence

- Label sides

- Write a number sentence below the picture (e.g., $9+3+9+3=24$ feet)

- Have students write down on their paper what the teacher is writing on the whiteboard

- Teacher will conclude the lesson by reviewing concept of perimeter and telling students they will finish the story next time.

\section{Read Aloud (Day 2)}

- Teacher will review concepts introduced in the prior lesson and hand out the students' papers. 
- Stop after page 17. Teacher will say: Now I want you to figure out the perimeter of their new shape. First, you will draw a picture. Then you will label the sides. And finally, you will write the number sentence including the answer.

- Teacher will ask one student to explain his thinking. Teacher will then say: Give me a thumbs up if you agree and a thumbs down if you disagree?

- Stop after page 21. Teacher will say: Now I want you to figure out the perimeter of their new shape. First, you will draw a picture. Then you will label the sides. And finally, you will write the number sentence including the answer.

- Teacher will ask one student to explain his thinking. Teacher will then say: Give me a thumbs up if you agree and a thumbs down if you disagree?

- Teacher will conclude the lesson by reviewing concept of perimeter and telling students they will finish the story next time.

\section{Read Aloud (Day 3)}

- Teacher will review concepts introduced in the prior lesson and hand out the students' papers.

- Stop after page 29. Teacher will say: Now I want you to figure out the perimeter of their new shape. First, you will draw a picture. Then you will label the sides. And finally, you will write the number sentence including the answer.

- Teacher will ask one student to explain his thinking. Teacher will then say: Give me a thumbs up if you agree and a thumbs down if you disagree?

- After finishing book, teacher will ask students questions regarding the concept of perimeter that could include:

Why is knowing the perimeter of something important?

o The children in the story needed to know the perimeter for their chicken coup, can you think of a time where you would need to know the perimeter?

- Can you measure a perimeter of an open shape?

- Can you measure a perimeter of a three sided shape? How about a two sided shape? Why or why not? 


\section{Carrie Measures Up}

By Linda W. Aber

Illustrated by Joy Allen

\section{Before Read Aloud}

- Read title, author, and illustrator.

- Find out "how old the book is"

- Teacher will say: We are now going to find out how old this book is. I know it was published in 2001 and it is now 2011. What would be the best way to do this? To find the age, I could just start with 2001 and add ten. That would be 2011. The book is 10 years old. Is there another way we could do this?

- Give students an opportunity to predict what the story will be about.

- Teacher will say: What do you think this story will be about? Will there be any math? Why do you think this? Let's start reading to see if our predictions are correct.

\section{During Read Aloud (Day 1)}

- Stop after page 9. Teacher will ask students questions that could include:

- How will Carrie measuring things help her grandma with knitting?

- Carrie's grandma gave her measuring tape. Why do you think she gave her this? Could she have given her a regular ruler? Why or why not?

- What type of things do you think Carrie will measure?

- Teacher will conclude the lesson by reviewing the importance of measuring and telling students they will finish the story next time.

\section{Read Aloud (Day 2)}

- Teacher will review concepts introduced in the prior lesson.

- Start at page 10.

- Stop after page 11. Teacher will lay out the tape measure and ask target student to point to $11 \mathrm{y} / 2$ inches. Teacher will say: Give me a thumbs up if you agree and a thumbs down if you disagree. 
- Stop after page 19. Teacher will ask students questions that could include:

- What will Carrie have to do before knitting the scarf?

- How long do you think the scarf will be?

o How wide do you think the scarf will be?

- What are some important things that Carrie will have to do when measuring?

$\circ$ Will she finish?

- Teacher will conclude the lesson by reviewing the importance of measuring and telling students they will finish the story next time.

\section{Read Aloud (Day 3)}

- Teacher will review concepts introduced in the prior lesson and discuss student predictions from previous lessons.

- Stop after page 21. Teacher will lay out the tape measure and ask student to point to 45 inches. Teacher will say: Give me a thumbs up if you agree and a thumbs down if you disagree.

- Teacher will say: Can we figure out about how many feet long this will be?

- Teacher will guide students in finding how many feet will be in 45 inches.

- $\quad$ Stop after page 23.

- Teacher will ask student to point to 2 inches on tape measure. Teacher will say: Give me a thumbs up if you agree and a thumbs down if you disagree.

- Teacher will ask student to point to 4 inches on tape measure. Teacher will say: Give me a thumbs up if you agree and a thumbs down if you disagree.

- Teacher will ask student to point to 7 inches on tape measure. Teacher will say: Give me a thumbs up if you agree and a thumbs down if you disagree.

- Read the rest of story

\section{Activity Following Read Aloud}

- Teacher will give each student a measuring tape and have them work in pairs (teacher will work with one student) to measure items on the activity worksheet.

- When finished, teacher will have each student report their measurements. 
- Teacher will conclude the lesson by reviewing the importance of measuring and telling students they will finish the story next time. 


\title{
The Greedy Triangle
}

\author{
By Marilyn Burns \\ Illustrated by Gordon Silveria
}

\section{Before Read Aloud}

- Read title, author, and illustrator.

- Find out "how old the book is"

- Teacher will say: We are now going to find out how old this book is. I know it was published in 1994 and it is now 2011. What would be the best way to do this? To find the age, I could just start with 1994 and count up to $2000.1995,1996,1997,1998,1999,2000$...That is 6 . And I know that 2000 is 11 away from 2011, so I would add $6+11$. This book is 17 years old. Is there another way we could do this?

- Give students an opportunity to predict what the story will be about.

○ Teacher will say: What do you think this story will be about? Will there be any math? Why do you think this? Let's start reading to see if our predictions are correct.

\section{During Read Aloud (Day 1)}

- Stop at first marked page. Teacher will ask a student to stand up and put their hands on their hips. Teacher will say: Do you see the triangle? Where else do you see triangle on this page? What makes a shape a triangle? Teacher will put the following on the whiteboard:

- Triangle -3

- Stop at next marked page. Teacher will say: What would the triangle look like if its wish was granted? After student makes a prediction, teacher will say: Could it be another shape? (possible answers: square, rectangle, parallelogram, trapezoid) Teacher will say: Let's see what the book says.

- Stop at next marked page. Teacher will write "quadrilateral - 4" on the whiteboard directly under "Triangle - 3". Teacher will say: All of the shapes you mentioned have 4 sides. Four sided shapes are called quadrilaterals.

- Stop at next marked page. Teacher will say: What do you think the new shape will be if the wish is granted? 
- Teacher will conclude the lesson by saying: We will find out what the new shape will be next time. What have we learned so far?

\section{Read Aloud (Day 2)}

- Teacher will review concepts introduced in the prior lesson and write down the following on the whiteboard:

- Triangle -3

- Quadrilateral - 4

- Teacher will discuss with students what their predictions were for the new shape.

- Stop at next marked page. Teacher will write the word "pentagon - 5" on the whiteboard. Teacher will discuss with students the properties of the pentagon.

- Stop at the next marked page. Teacher will ask the students to point out the pentagons they see on the two pages.

- Stop at next marked page. Teacher will say: What do you think the new shape will be if the wish is granted? After students make predictions, teacher will say: Let's see what the book says.

- Stop at next marked page. Teacher will write the word "hexagon - 6" on the whiteboard. Teacher will discuss with students the properties of the hexagon.

- Stop at the next marked page. Teacher will ask the students to point out the hexagons they see on the two pages.

- Teacher will conclude the lesson by reviewing the shapes listed on the whiteboard and having students make predictions about the rest of the story.

\section{Read Aloud (Day 3)}

- Teacher will review concepts introduced in the prior lesson and write down the following on the whiteboard:

- Triangle -3

- Quadrilateral-4

- Pentagon - 5

- Hexagons -6

- Teacher will discuss with students what their predictions were for the new shape. 
- Stop at the next marked page. Teacher will add the following shapes on the whiteboard and discuss with the students the properties of each:

$$
\begin{array}{ll}
\circ \text { Heptagon }-7 \\
\circ \text { Octagon }-8 \\
\circ \text { Nonagon }-9 \\
\circ \text { Decagon }-10
\end{array}
$$

- Teacher will write the word "Polygon" at the top of the whiteboard. Teacher will say: Here is another new word. All of these shapes are called polygons. Even though they have different number of sides, the all have straight sides and all are closed shapes (like the fence in the book Chickens on the Move)

- Teacher will read the rest of the book.

- Teacher will conclude the lesson by reviewing the shapes listed on the whiteboard and telling the students they will be doing an activity with these shapes next session.

\section{Activity Following Read Aloud (Day 4)}

- Teacher will review concepts introduced in the prior lesson.

- Teacher will turn to page in book that displays the various triangles.

- Teacher will say: As you can see, we can see triangles everywhere. Can you see any triangles around the room?

- Teacher will give each student a blank piece of paper and bag of assorted triangles.

- Teacher will say:

- You will each choose one triangle and then turn it around to look at it from different angles.

Think about what your triangle might be a part of. (Use pictures in book to help explain if necessary)

When you have an idea, glue the triangle down and draw a picture around it to show where your triangle is.

- Then write a sentence to describe your picture.

- After completing activity, have students share their pictures with the group. 
The 512 Ants on Sullivan Street

\author{
By Carol A. Losi \\ Illustrated by Patrick Merrell
}

\title{
Before Read Aloud
}

- Read title, author, and illustrator.

- Find out "how old the book is"

- Teacher will say: We are now going to find out how old this book is. I know it was published in 1997 and it is now 2011. What would be the best way to do this? To find the age, I could just start with 1997 and count on to 2000 ...1998, 1999, 2000...That is 3. Now I can just count by tens... 2010. And I know that 2010 is only 1 away from 2011. Then I would just add $3+10+1$. The book is 14 years old. Is there another way we could do this?

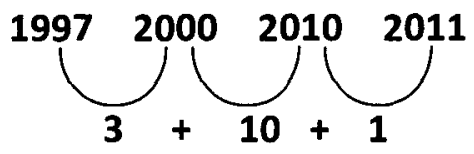

- Give students an opportunity to predict what the story will be about.

- Teacher will say: What do you think this story will be about? Will there be any math? Why do you think this? Let's start reading to see if our predictions are correct.

\section{During Read Aloud (Day 1)}

- Stop after page 2. Put a 1 at the top of the chart paper.

- Stop after page 4. Put a 2 directly below the 1 on the chart paper.

- Stop after page 6. Put a 4 directly below the 2 on the chart paper. Teacher will say: What do you think the next number will be? Why do you think this? (Teacher will not comment on the pattern at this time. Only take predictions.)

- Stop after page 8 . Put a 8 directly below the 4 on the chart paper. Teacher will say: What do you think the next number will be? Why do you think this? (Teacher will not comment on the pattern at this time. Only take predictions.) 
- Stop after page 10. Put a 4 directly below the 2 on the chart paper. Teacher will say: What do you think the next number will be? Why do you think this? (Teacher will not comment on the pattern at this time. Only take predictions.)

- Continue this process until the end of the book.

- If students have not figured out the pattern, teacher will ask questions regarding the numbers. For example, teacher could say "What is happening to the numbers? Are they getting larger or smaller? Do you see anything else happening?

- Teacher will conclude lesson by saying: Next time we will look at these numbers in a different way and see if we can see a pattern.

Activity following read aloud (Day 2)

- Teacher will give quick review of what they did on the last session including looking at the numbers from the chart paper on the previous day.

- Teacher will place a new piece of chart paper up.

- Read the story again and stop after page 2. Put a 1 at the top of the chart paper.

- Stop after page 4. Put $1+1=2$ directly below the 1 on the chart paper.

- Stop after page 6. Put $2+2=4$ directly below $1+1=2$ on the chart paper. Teacher will say: Can anyone tell me what is happening? Yes, we are doubling the number to get the next number? What will we put on the next line?

- Stop after page 8. Put $4+4=8$ directly below $2+2=4$ on the chart paper. Teacher will say: How much is $\mathbf{4}+\mathbf{4}$ ? How did you figure out the sum? What will we put on the next line?

- Teacher will say: How much is $\mathbf{1 6}+\mathbf{1 6}$ ? Talk with the others at the table about the answer. You can use paper and pencil or manipulative if you need them. After discussion, teacher will ask for a volunteer to explain how they figured out the sum and write the number sentence on chart paper.

- Teacher will say: So now what will be the next line? Yes, $32+32$. How much is $32+32$ ? Talk with the others at the table about the answer. You can use paper and pencil or manipulative if you need them. After discussion, teacher will ask for a volunteer to explain how they figured out the sum and write the number sentence on chart paper. 
- Teacher will conclude with a review of what was learned. 


\author{
Guinea Pigs Add Up \\ By Margery Curyler \\ Illustrated by Tracey Campbell Pearson
}

\title{
Before Read Aloud
}

- Read title, author, and illustrator.

- Find out "how old the book is"

- Teacher will say: We are now going to find out how old this book is. I know it was published in 2010 and it is now 2011. Who can tell me how old this book is?

- Give students an opportunity to predict what the story will be about.

o Teacher will say: What do you think this story will be about? Will there be any math? Why do you think this? Let's start reading to see if our predictions are correct.

\section{During Read Aloud (Day 1)}

- Stop after page 3. Teacher will pull out guinea pig cage and put one guinea pig on the page. Teacher will say: We now have one guinea pig in our cage.

- Stop after page 7. Teacher will say: Mr. Gilbert brings in another guinea pig and that makes two. Teacher places another guinea pig on the cage. And then there are three more. Teacher puts 3 more guinea pigs on the cage. How many do we have now?

- Stop after page 14. Teacher will say: So now we have $\mathbf{1 5}$ more guinea pigs. Teacher places 15 guinea pigs on the cage. Teacher will say: It says they counted them one by one. Is there an easier way to count to 20 ?

- Teacher will hand out baggies of guinea pigs to each student and the Guinea Pigs worksheet. Teacher will say: I am going to ask you a few questions and I want you to use your guinea pigs to find the answer.

- (call on one student) If we started with 2 guinea pigs and then added 8 more, how many guinea pigs would we have in all? After student gives answer, Teacher will say: Give me thumbs up if you agree and thumbs down if you disagree? 
- (call on one student) If we started with 10 guinea pigs and then added 4 more, how many guinea pigs would we have in all? After student gives answer, Teacher will say: Give me thumbs up if you agree and thumbs down if you disagree?

- (call on one student) If we started with 14 guinea pigs and then added 5 more, how many guinea pigs would we have in all? After student gives answer, Teacher will say: Give me thumbs up if you agree and thumbs down if you disagree?

- Teacher will say: Next time we meet, we will finish the story.

- Teacher will conclude with a review of what was learned.

\section{During Read Aloud (Day 2)}

- Teacher will give quick review of what they did on the last session, place the picture of the guinea pig cage on the table with 20 guinea pigs on top, and start with page 15.

- Stop after page 22. Teacher will say: These two pages show the $\mathbf{2 0}$ guinea pigs that found homes. Hand out guinea pig subtraction chart.

- Teacher will say: This student took 3 guinea pigs home. Teacher will take out 3 guinea pigs from cage. Teacher will say, we started out with 20, and 3 found a home. That leaves us with 17 (count guinea pigs still in cage). What operation will we be doing when we are taking away? A number sentence for this would be $20-3=17$.

- Teacher will point to the second student in the picture and say: This student took 1 guinea pig home. Teacher will call on a student to take out one guinea pig from the cage. Teacher will say to student: if we had 17 pigs in the cage and 1 found a home. How many will we have left? What would be the number sentence for this? After student gives answer, Teacher will say: Give me thumbs up if you agree and thumbs down if you disagree? When the correct answer is agreed upon, have students write down on subtraction chart.

- Continue this process for all 12 students on pages 21 and 22.

- Teacher will read the rest of the story aloud

- Teacher will conclude with a review of what was learned. 
Appendix E: Observation Coding Variables

CLM Codes

\begin{tabular}{|c|c|c|}
\hline Two Digit Code & Description & Definition \\
\hline OG & OTR Grp & $\begin{array}{c}\text { Teacher provides opportunity to respond that is } \\
\text { directed at whole class or small group that includes the } \\
\text { target student. The opportunity must be instruction } \\
\text { related and not social or a question within the context } \\
\text { of negative feedback. }\end{array}$ \\
\hline OI & OTR Ind & $\begin{array}{l}\text { Teacher provides an opportunity to respond that is } \\
\text { directed to individual student. The opportunity must be } \\
\text { instruction related and not social or a question within } \\
\text { the context of negative feedback. }\end{array}$ \\
\hline TD & Not-Teach & $\begin{array}{l}\text { Teacher is not engaging students and is involved in } \\
\text { independent task with no interactions with student. }\end{array}$ \\
\hline $\mathrm{TI}$ & Teach & $\begin{array}{l}\text { Teacher is engaged in instruction by explaining a } \\
\text { concept, demonstrating a principle, or modeling a skill } \\
\text { or activity to group that includes target student. The } \\
\text { teaching must be academic. }\end{array}$ \\
\hline DR & Disrupt & $\begin{array}{l}\text { Student is neither actively nor passively engaged and } \\
\text { displays behavior that disrupts the lesson. }\end{array}$ \\
\hline DI & Down-time & $\begin{array}{c}\text { There are no academic expectations of the target } \\
\text { student or group target student is a part of. }\end{array}$ \\
\hline OT & S Off-task & $\begin{array}{l}\text { Student is neither actively engaged nor looking at } \\
\text { teacher but is not disrupting the class. }\end{array}$ \\
\hline OF & S Pass Eng & $\begin{array}{l}\text { Student is passively attending to instruction by eyes } \\
\text { oriented on teacher or peer (if appropriate). }\end{array}$ \\
\hline $\mathrm{AE}$ & S Act Eng & $\begin{array}{c}\text { Student is actively engaged with instructional content } \\
\text { including responding to teacher instruction/directive } \\
\text { (oral response, writing, reading), raising hand, or } \\
\text { otherwise completing task. }\end{array}$ \\
\hline TN & TchrN-Min & Teacher Non Minority \\
\hline $\mathrm{TM}$ & Tchr Min & Teacher Minority \\
\hline GM & Tchr GM & Teacher Gender Male \\
\hline GF & Tchr GF & Teacher Gender Female \\
\hline SN & Stud NMin & Student Non Minority \\
\hline SM & Stud Min & Student Minority \\
\hline SC & Science & Subject being taught: Science \\
\hline SS & Soc Stud & Subject being taught: Social Studies \\
\hline RE & Reading & Subject being taught: Reading \\
\hline MA & Math & Subject being taught: Male \\
\hline SE & Stud Male & Student Gender: Male \\
\hline SF & Stud Female & Student Gender: Female \\
\hline RG & Reg Class & Regular Class \\
\hline RS & Resrc Class & Resource Class \\
\hline$S L$ & Self Cont & Self Contained \\
\hline
\end{tabular}


Appendix F: Teacher Fidelity Checklist

TEACHER FIDELITY CHECKLIST

Observer:

Observation Date: __ $/{ }_{-} / 20$ Month Day Year

Name of Book:

Beginning of Read Aloud? $\square$ Yes $\square$ No $\quad$ Reliability Observation? $\square$ Yes $\square$ No

\begin{tabular}{|c|c|c|}
\hline The teacher will: & $+/-$ & Notes: \\
\hline $\begin{array}{l}\text { 1. If beginning read aloud, read } \\
\text { the title of book and have } \\
\text { students predict what it is } \\
\text { about. } \\
\text { If continuing read aloud from } \\
\text { previous day, give review of } \\
\text { previous session. }\end{array}$ & & \\
\hline $\begin{array}{l}\text { 2. If beginning read aloud, find out } \\
\text { "how old the book is" with the } \\
\text { help of the students. }\end{array}$ & & \\
\hline $\begin{array}{l}\text { 3. Ask students questions related } \\
\text { to mathematical concepts in the } \\
\text { book during lesson. }\end{array}$ & & \\
\hline $\begin{array}{l}\text { 4. Model a strategy for answering } \\
\text { a question related to the book } \\
\text { during lesson. }\end{array}$ & & \\
\hline $\begin{array}{l}\text { 5. Give students manipulatives to } \\
\text { work out problems associated } \\
\text { with the book, if applicable. }\end{array}$ & & \\
\hline $\begin{array}{l}\text { 6. Conclude the lesson by } \\
\text { reviewing concepts discussed in } \\
\text { the book. }\end{array}$ & & \\
\hline
\end{tabular}

$+=$ completed step

- = did not complete step

$\mathrm{N} / \mathrm{A}=$ not applicable 
Appendix G: Social Validity Questionnaire - Student

Directions: Circle a response for each question.

1. Did you like reading books during Mathematics?

Yes No Don't know

2. Do you think that reading the books helped you learn mathematics better, worse or the same?

Better Worse The Same

3. Would you like your teacher to continue reading books during Mathematics?
Yes
No
Don't care

Directions: Write an answer for each question.

4. What did you like best about reading books in Mathematics?

5. What, if anything, did you dislike about reading books in Mathematics?

6. What else would you like me to know about reading books in Mathematics? 
Appendix H: Social Validity Questionnaire - Teacher

Integrating Children's Literature in Mathematics Instruction Teacher Survey

Directions: Circle a response for each question. Please write comments to further explain your response.

1. Did you like using children's literature to teach mathematics?
Yes
No
Maybe

Comments (please be specific):

2. Do you think that this helped your students learn mathematics concepts better, the same, or worse?

Better Same Worse

Comments (please be specific):

3. How would you describe the overall student engagement when implementing the children's literature mathematics lessons compared to your regular instruction?

Increased Engagement Decreased Engagement No Difference

Comments (please be specific):

4. How would you describe the level of student disruptions when implementing the children's literature mathematics lessons compared to your regular instruction?

Increased Disruptions $\quad$ Decreased Disruptions No Difference

Comments (please be specific): 
5. How would you describe the amount of opportunities students had to respond through either questions or verbal prompts when implementing the children's literature mathematics lessons compared to your regular instruction?

More Opportunities $\quad$ Less Opportunities $\quad$ No Difference

Comments (please be specific):

6. Please rate the ease of implementing the children's literature mathematics lessons.

Easy Moderately Easy Somewhat Difficult Very Difficult

Comments (please be specific):

7. Will you use children's literature to teach mathematics concepts in the future?

$\begin{array}{lll}\text { Yes No Nure } & \text { Not Sul }\end{array}$

Comments (please be specific):

8. What would you tell other teachers about using children's literature to teach mathematics?

Try It

Don't Try It

I wouldn't say anything

Comments: 
9. What did you like best about using children's literature to teach mathematics?

10. What, if applicable, did you dislike about using children's literature to teach mathematics?

11. Please include any comments, suggestions, or ideas you may have for integrating children's literature in mathematics instruction. 
CURRICULUM VITAE

Jeremy Todd Whitney

\section{Murray Avenue Apt. \#2 \\ Louisville, Kentucky 40205 \\ 502-649-5431 (home) \\ 502-852-3603 (work) \\ whitney.todd@gmail.com \\ jtwhit01@louisville.edu}

\section{ACADEMIC BACKGROUND}

2009-present Enrolled in the PhD program, Curriculum and Instruction with concentration in Special Education, University of Louisville Doctoral Candidate Status: October, 2010

Expected Graduation: August, 2011

2007

Master of Education, Special Education with concentration in Learning \& Behavior Disorders (K - 12), University of Louisville

2005

Bachelor of Arts, History with concentration in Social Sciences, University of Louisville

\section{PROFESSIONAL EXPERIENCE}

2009 - Present Graduate Assistant, College of Education and Human Development, Department of Teaching and Learning, University of Louisville Provided assistance for ABRI (Academic and Behavioral Response to Intervention) and SPLASH (Strategies for Programming Longitudinally for All Students with Severe Handicaps). Responsibilities included assisting in providing training and support for teachers and school districts in Kentucky.

2009-2011

Data Collector, First Step to Success: Home/School Intervention for Preschoolers with Disruptive Behaviors Assisted in training of data collectors and conducted reliability observations. 
2010, Summer

2009, Fall

$2006-2009$
Teaching Assistant, Instructors: Karen Karp, Ed.D. and Amy Lingo, Ed.D., University of Louisville EDAP 620, Teaching Math to Students with Disabilities

Practicum Student Observer, Instructor: Amy Lingo, Ed.D., University of Louisville EDSP 442, LBD Practicum

Special Education Teacher, Emmett Field Elementary School, Jefferson County Public Schools

Developed and delivered specially designed instruction through service delivery models including collaboration in the regular education classroom and resource instruction.

\section{CERTIFICATION}

Professional Certificate for Teaching Exceptional Children - Learning and Behavior Disorders, Grades Primary through 12

\section{PRESENTATIONS}

Cooper, J., Lingo, A.S., \& Whitney, T. (2011, February). Effective Strategies for Teaching Reading to Students with Challenging Behaviors. Midwest Symposium for Leadership in Behavior Disorders, Kansas City, Missouri.

Lingo, A.S., \& Whitney, T. (2011, February). Mathematics for Students Exhibiting Challenging Behavior: Characteristics of Learners and Strategies for Intervention. Midwest Symposium for Leadership in Behavior Disorders, Kansas City, Missouri.

Hirn, R.G., \& Whitney, T. (2010, February). A Targeted Intervention for Children with Challenging Behaviors: Positive Results with a Mathematics Fluency Building Strategy. Midwest Symposium for Leadership in Behavior Disorders, Kansas City, Missouri.

\section{PUBLICATIONS}

Cooper, J.T., Lingo, A.S., Whitney, T., \& Slaton, D.B., (2011). The effects of instruction in a paired associates learning strategy as an intervention for college students with learning disabilities. Journal of Postsecondary Education and Disability, 24(2), 133-145. 